\title{
Improving Ventilation and Saving Energy: Final Report on Indoor Environmental Quality and Energy Monitoring in Sixteen Relocatable Classrooms
}

\author{
Michael G. Apte, Bourassa Norman*, David Faulkner, Alfred T. Hodgson, \\ Toshfumi Hotchi, Michael Spears, Douglas P. Sullivan, and Duo Wang
}

4 April 2008

Indoor Environment Department

Environmental Energy Technologies Division

Lawrence Berkeley National Laboratory

*Now with the California Energy Commission

PIER Program,

Sacramento CA.

This research was sponsored by the California Energy Commission through the Public Interest Energy Research program as the Lawrence Berkeley National Laboratory Classroom HVAC: Improving Ventilation and Saving Energy research project, CEC Contract Number 500-03-041. The study was additionally supported by the Assistant Secretary for Energy Efficiency and Renewable Energy, Building Technology Program of the U.S. Department of Energy under contract DE-AC02-05CH11231. 


\section{Abstract}

An improved HVAC system for portable classrooms was specified to address key problems in existing units. These included low energy efficiency, poor control of and provision for adequate ventilation, and excessive acoustic noise. Working with industry, a prototype improved heat pump air conditioner was developed to meet the specification. A one-year measurementintensive field-test of ten of these IHPAC systems was conducted in occupied classrooms in two distinct California climates. These measurements are compared to those made in parallel in side by side portable classrooms equipped with standard 10 SEER heat pump air conditioner equipment. The IHPAC units were found to work as designed, providing predicted annual energy efficiency improvements of about $36 \%$ to $42 \%$ across California's climate zones, relative to 10 SEER units. Classroom ventilation was vastly improved as evidenced by far lower indoor minus outdoor $\mathrm{CO}_{2}$ concentrations. The IHPAC units were found to provide ventilation that meets both California State energy and occupational codes and the ASHRAE minimum ventilation requirements; the classrooms equipped with the 10 SEER equipment universally did not meet these targets. The IHPAC system provided a major improvement in indoor acoustic conditions. HVAC system generated background noise was reduced in fan-only and fan and compressor modes, reducing the nose levels to better than the design objective of $45 \mathrm{~dB}(\mathrm{~A})$, and acceptable for additional design points by the Collaborative on High Performance Schools. The IHPAC provided superior ventilation, with indoor minus outdoor $\mathrm{CO}_{2}$ concentrations that showed that the Title 24 minimum ventilation requirement of 15 CFM per occupant was nearly always being met. The opposite was found in the classrooms utilizing the 10 SEER system, where the indoor minus outdoor $\mathrm{CO}_{2}$ concentrations frequently exceeded levels that reflect inadequate ventilation. Improved ventilation conditions in the IHPAC lead to effective removal of volatile organic compounds and aldehydes, on average lowering the concentrations by $57 \%$ relative to the levels in the 10 SEER classrooms. The average IHPAC to 10 SEER formaldehyde ratio was about $67 \%$, indicating only a $33 \%$ reduction of this compound in indoor air. The IHPAC thermal control system provided less variability in occupied classroom temperature than the 10 SEER thermostats. The average room temperatures in all seasons tended to be slightly lower in the IHPAC classrooms, often below the lower limit of the ASHRAE 55 thermal comfort band. State-wide and national energy modeling provided conservative estimates of potential energy savings by use of the IHPAC system that would provide payback a the range of time far lower than the lifetime of the equipment. Assuming electricity costs of $\$ 0.15 / \mathrm{kWh}$, the perclassroom range of savings is from about $\$ 85$ to $\$ 195$ per year in California, and about $\$ 89$ to $\$ 250$ per year in the U.S., depending upon the city. These models did not include the non-energy benefits to the classrooms including better air quality and acoustic conditions that could lead to improved health and learning in school. Market connection efforts that were part of the study give all indication that this has been a very successful project. The successes include the specification of the IHPAC equipment in the CHPS portable classroom standards, the release of a commercial product based on the standards that is now being installed in schools around the U.S., and the fact that a public utility company is currently considering the addition of the technology to its customer incentive program. These successes indicate that the IHPAC may reach its potential to improve ventilation and save energy in classrooms. 


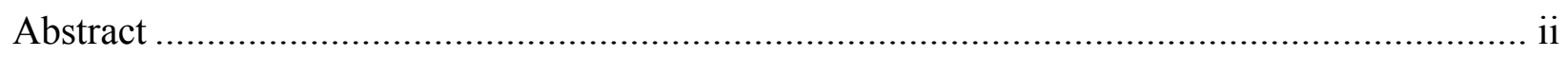

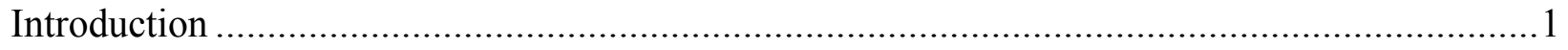

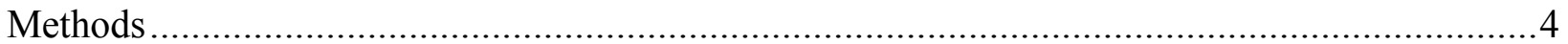

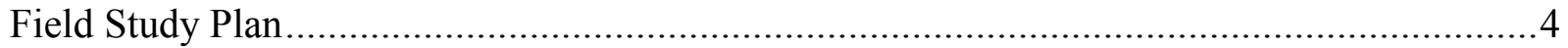

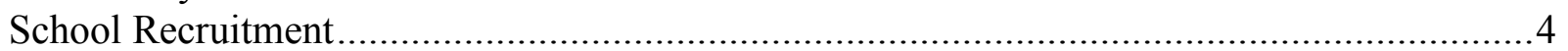

Improved HPAC system installation and RC HVAC commissioning ...................................... HVAC Control Systems ..........................................................................................

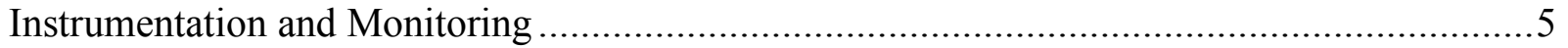

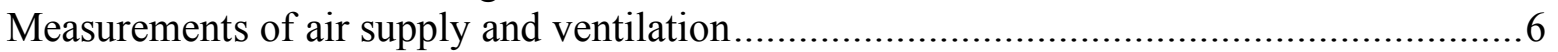

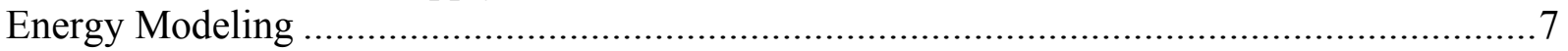

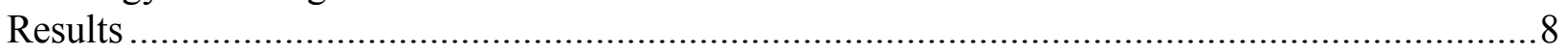

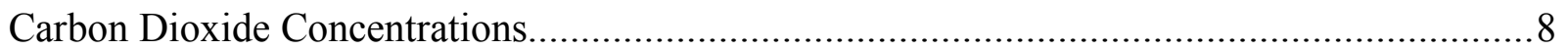

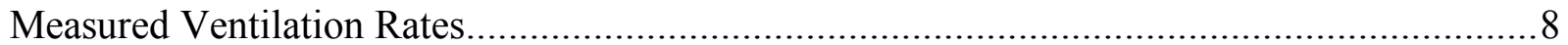

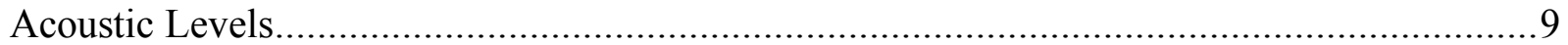

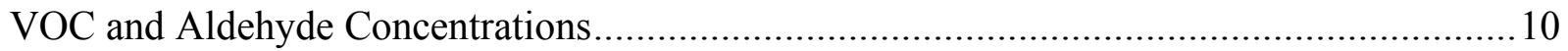

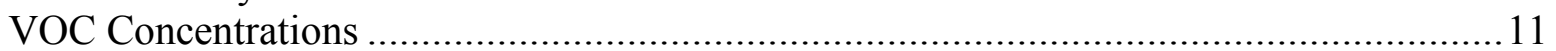

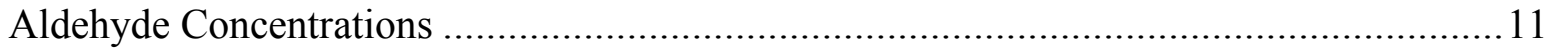

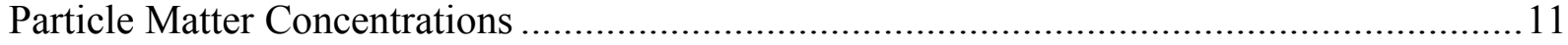

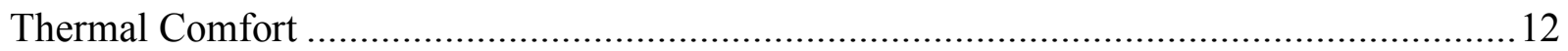

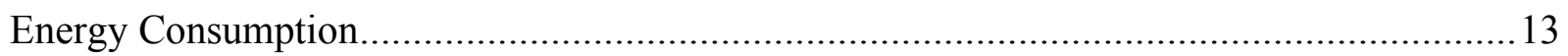

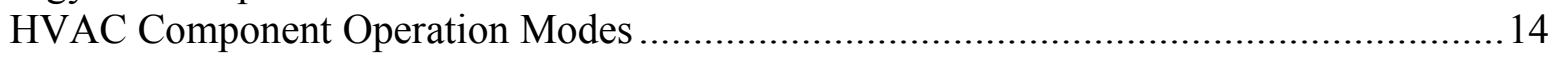

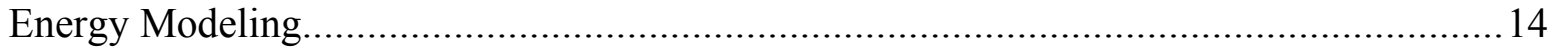

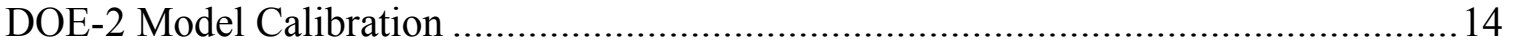

DOE-2 model results - California Climate Zones ....................................................15

DOE-2 model results - U.S. Cities .....................................................................15

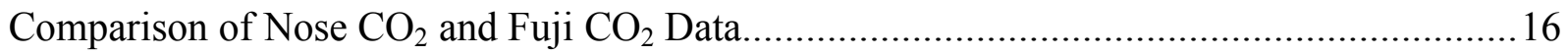

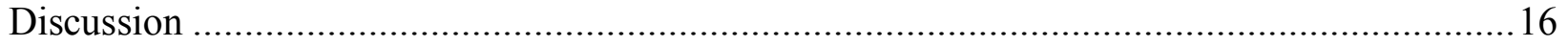

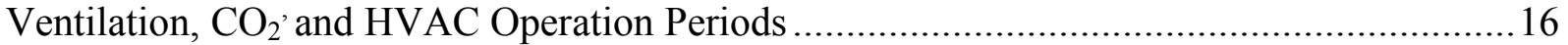

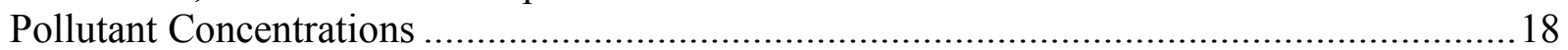

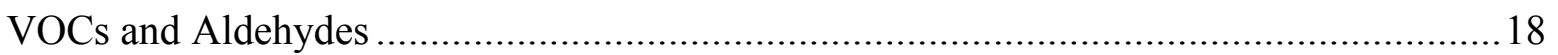

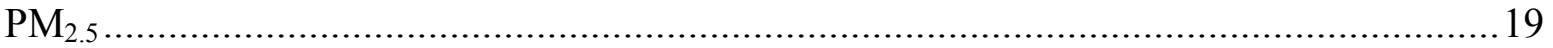

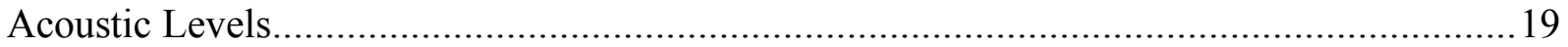

Thermal Comfort, Indoor Temperature and Relative Humidity ...........................................2.

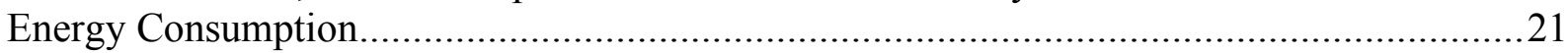

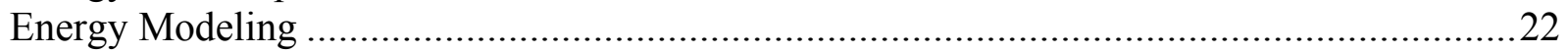

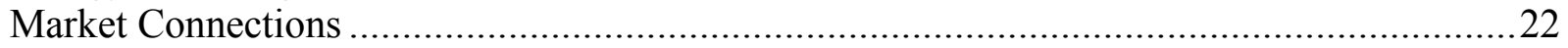

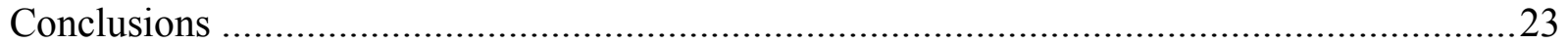

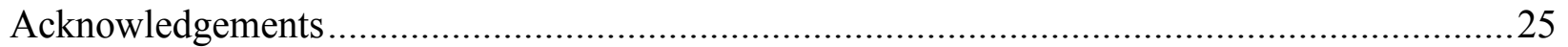

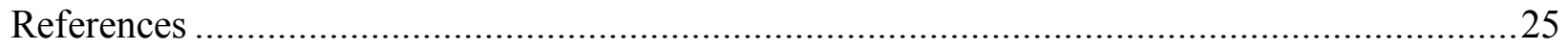

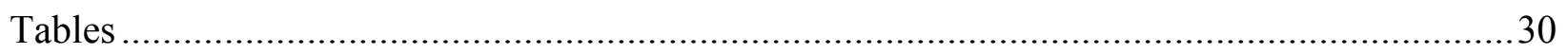

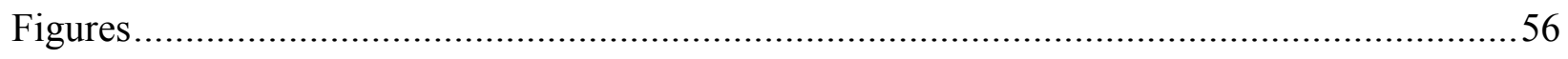




\section{Introduction}

This is the final report on the California Energy Commission's (CEC) Public Interest Energy Research (PIER) Program funded project "Improving Ventilation and Saving Energy," Contract Number 500-03-041. It is an update of the interim report submitted to CEC in Fall 2005 (Apte et al., 2005). The primary goals of the "Improving Ventilation and Saving Energy" (IVSE) project were to develop, evaluate, and demonstrate a very practical HVAC system for portable or relocatable classrooms ( $\mathrm{RCs}$ ) that consistently provides them with the current minimum ventilation standards, while saving energy, and reducing HVAC-related noise levels. The ultimate goal was to provide the specification of this system to the public domain, and stimulate increased use of advanced classroom HVAC in the market through interaction with key school facility stakeholders.

A number of studies (e.g., Seppanen et al. 1999, Wargocki et al. 2002; Erdmann et al. 2002) have investigated the relationship of ventilation rates to health outcomes (sick building syndrome symptoms, respiratory illnesses), absence rates, and perceived air quality; however, most studies have been performed in office buildings. Some studies have used indoor $\mathrm{CO}_{2}$ concentrations as a surrogate for ventilation rate per occupant. A large majority of these studies have found a worsening of some health, absence, or perceived air quality outcomes at lower ventilation rates or higher $\mathrm{CO}_{2}$ concentrations. Detrimental effects have been particularly clear when ventilation rates are reduced below $20 \mathrm{CFM}$ per occupant and several studies have found benefits of increasing ventilation rates above $20 \mathrm{CFM}$ per occupant. These studies indicate that ventilation rates have important effects on the health of occupants.

Although continuous ventilation is required in California classrooms under both state energy and occupational laws (CEC. 2001, CCR 1995,) and is a required component of ASHRAE Standard 62.1 (ASHRAE 2004), there is a need for an improved classroom ventilation system. This need is based, in part, on the considerable evidence, summarized in Daisey et al. (1998, 2003), indicating that ventilation rates in classrooms often do not meet the current ASHRAE minimum rate of 15 CFM per occupant (ASHRAE, 2004). While relatively few measurements of actual classroom ventilation rates are available, concentrations of $\mathrm{CO}_{2}$ in classrooms often substantially exceeded 1000 ppm; implying ventilation rates less than 15 CFM per occupant, with several studies reporting peak concentrations exceeding $1500 \mathrm{ppm}$, and some concentrations exceeding 3000 ppm (Daisey et al 2003, Daisey and Angell 1998). In a recent statewide random survey of California $\mathrm{RCs} \mathrm{CO}_{2}$ concentrations exceeded $1000 \mathrm{ppm}$ in about $40 \%$ of classrooms and concentrations exceeded 2000 ppm in approximately 10\% of classrooms (CARB-DHS 2003). In a survey of 400 classrooms in Washington state and Idaho (Shendell et al. 2004), $\mathrm{CO}_{2}$ concentrations measured in $45 \%$ of classrooms exceeded 1000 ppm, thus, a considerably larger fraction of steady state or peak $\mathrm{CO}_{2}$ concentrations would have exceeded $1000 \mathrm{ppm}$.

Additional evidence of low classroom ventilation rates was obtained in a study in 14 California schools (Lagus Applied Technologies 1995). The measured mean minimum air exchange rate was $2.4 \mathrm{~h}^{-1}$, with a range of 1.2 to $2.9 \mathrm{~h}^{-1}$, while the air exchange rate corresponding to the current standard was estimated to be $3 \mathrm{~h}^{-1}$. 
Several statutes and standards address the provision of adequate ventilation in California classrooms. Continuous ventilation is required in California Classrooms under both state energy and occupational laws (CEC. 2001, CCR 1995) and is a required component of ASHRAE Standard 62.1 (ASHRAE 2004).

Anecdotally, we are aware that ventilation rates in classrooms are often low because teachers frequently operate classroom HVAC systems in the mode where the supply fan shuts off except when heating or cooling is required. Thus, outside air is supplied mechanically only during periods of heating or cooling and the time average rate of supply is often below standards. We also observe that teachers use this mode of HVAC system operation to avoid HVAC systemrelated noise. These anecdotal reports are supported by the findings from a recently completed survey of California RCs. Teachers in $60 \%$ of RCs reported that they sometimes turned off HVAC systems to reduce noise levels (CARB-CDHS 2003). Consequently, the available evidence indicates the importance of reducing HVAC noise in the development of improved classroom HVAC systems.

The RC HVAC industry has been incrementally addressing the classroom noise levels generated by the wall mount heat pump air conditioner (HPAC) that they produce. For example, in the late 1990s Bard Manufacturing Company developed a 12 SEER (Seasonal Energy Efficiency Ratio) "Quiet Climate" model to meet specifications from the Los Angeles Unified School District (LAUSD, 1998). This unit was designed to operate at indoor sound levels $\leq 50 \mathrm{~dB}(\mathrm{~A})$ measured at a point $3 \mathrm{~m}\left(10^{\prime}\right)$ from the return grille and $1.5 \mathrm{~m}$ high. This model is the current state of the art, but has a relatively small market penetration in California. Unfortunately, $50 \mathrm{~dB}(\mathrm{~A})$ is not currently considered an adequate target for classroom sound levels. The Collaborative on High Performance Schools (CHPS) recommends unoccupied classroom levels to be at or below 45 $\mathrm{dB}(\mathrm{A})$ (CHPS 2002). Additionally, the Acoustical Society of America (ASA) provide a guideline for classrooms of $35 \mathrm{~dB}(\mathrm{~A})$ (ASA 2002).

A great deal of energy is used to condition ventilation air in high occupancy spaces such as classrooms. Mudarri et al. (1996) used an energy simulation model and estimated that increasing school building ventilation rates by $10 \mathrm{CFM}$, from 5 to 15 CFM per occupant, would increase annual HVAC energy use by $15 \%, 31 \%$, and $32 \%$ in Miami, Washington, DC, and Seattle, respectively. From these predictions, we can estimate that the energy to provide $15 \mathrm{CFM}$ per student of ventilation is approximately $22 \%, 45 \%$, and $45 \%$ of total classroom HVAC energy in these three climates, respectively. This finding indicates a clear energy and financial penalty from increasing ventilation to meet existing standards. Therefore, improved energy efficiency must be applied to offset the increased demand.

When we consider these factors together - the important effects of ventilation on people, the evidence of ventilation deficiencies in classrooms, and the energy used for ventilation, it is very clear that we need to develop and promote the use of highly energy efficient systems for providing classroom ventilation. To this end, an improved heat pump air conditioner (IHPAC) HVAC system was designed and fabricated. The prototype IHPAC was the product of improvement specifications to address indoor environmental quality (IEQ) and energy efficiency needs by LBNL, and design, in-house testing and refinement, and fabrication of a prototype design by Bard Manufacturing. The IHPAC was extensively tested in an RC test-bed facility at 
LBNL for energy efficiency, control of ventilation, and acoustic noise output, and suitability as a retrofit or new construction replacement for RCs. The results of these extensive tests have been presented in detail in a previous report (Apte et al. 2005).

- The laboratory testing procedure involved installation and verification of the performance of an IHPAC system, and its comparison with a standard HVAC system having an efficiency of 10 SEER. Points of verification included checking that the physical characteristics of the IHPAC system are suitable for direct replacement of existing 10 SEER systems;

- quantitative demonstration of improved energy efficiency;

- reduced acoustic noise levels;

- quantitative demonstration of improved ventilation control; and

- verification that the system would meet temperature control demands necessary for the thermal comfort of the occupants.

Results indicated showed that the IHPAC met these goals. The IHPAC was found to be a direct bolt-on replacement for the 10 SEER system. Calculated energy efficiency improvements based on many days of classroom cooling or heating showed that the IHPAC system was about $44 \%$ more efficient during cooling and 38\% more efficient during heating than the 10 SEER system. Noise reduction was dramatic, with measured A-weighed sound level for fan only operation conditions of $34.3 \mathrm{~dB}(\mathrm{~A})$, a reduction of $19 \mathrm{~dB}(\mathrm{~A})$ compared to the 10 SEER system. Similarly, the IHPAC stage- 1 and stage- 2 compressor plus fan sound levels were $40.8 \mathrm{~dB}(\mathrm{~A})$ and 42.7 $\mathrm{dB}(\mathrm{A})$, reductions of 14 and $13 \mathrm{~dB}(\mathrm{~A})$, respectively. Thus, in these tests the IHPAC was 20 to 35 times quieter than the 10 SEER systems depending upon the operation mode. The IHPAC system met the ventilation requirements and was able to provide consistent outside air supply throughout the study. Indoor $\mathrm{CO}_{2}$ levels with simulated occupancy were maintained below 1000 ppm. Finally temperature settings were met and controlled accurately. The goals of the laboratory testing phase were met and the system was found to be acceptable and ready for further study in a field test of occupied RCs.

This report summarizes and evaluates the data from the field test of the IHPAC system. The objectives of the field study were to evaluate the energy, ventilation, and IEQ performance of the advanced HVAC system when deployed in occupied classrooms and to perform a highly visible demonstration of the system. Although highlights of study methods are presented here, a detailed field study design and methods description has been reported (Apte et al. 2004) and should be referred to for complete information on how the field study was conducted.

During this field study some parameters ware measured in real-time (continuously or every 1 to 30 minutes) and periodic measurements (once per season) are made for other parameters. Parameters measured in real time include indoor and outdoor temperature and humidity, HVAC power, and indoor and outdoor carbon dioxide concentrations. Parameters measured periodically include: concentrations of formaldehyde and other volatile organic compounds, particle concentrations, noise levels, and ozone concentrations.

The objectives of the data evaluation include quantifying how the advanced HVAC system influences: a) ventilation rates; b) pollutant concentrations; c) noise levels; d) HVAC operation periods; e) HVAC energy use; and f) thermal comfort. 


\section{Methods}

\section{Field Study Plan}

The IHPAC system was installed in six relocatable classrooms, called intervention classrooms. Six matched control classrooms were also selected. The control classrooms were matched with intervention classrooms by location (school), grade level, manufacturer, and classroom age. Each intervention RC was located exactly next door to a control RC. In addition to the six RC pairs, an additional four RCs were equipped with an IHPAC at the same school sites, but were studied less intensively. Instrumentation systems were installed in each intervention and control classroom and HVAC energy performance and IEQ were monitored over an entire school year. The benefits of the advanced HVAC system have been quantified by comparing the measured data from the intervention and control classrooms. The field study monitored the RCs for over 12 months, and site visits for detailed IEQ monitoring were completed in four seasons.

\section{School Recruitment}

Criteria for school selection were based upon climate, and geography. Northern and Southern California locations were selected for broader representation of the state. The San Joaquin Valley was selected for cold winter and hot summers, and the San Bernardino Valley was selected for the high cooling demand and long cooling season. Schools were selected and recruited for this study in early 2004. Recruitment of participant schools was accomplished through two mechanisms. In the case of the Modesto City Schools in Northern California, we contacted the Facilities Manager directly, as LBNL had previously conducted research in the district and had a working relationship with them. In the case of San Bernardino, Geary Pacific Corp., the California Distributor of Bard HVAC equipment provided a list of potential school districts in the Southern CA region to LBNL. Contact letters were sent to a number of school district facilities managers in the region and site visits were conducted at those districts that expressed interest in participating. The Fontana Unified School District was found to meet the needs of the study and was therefore selected. Principals from two schools in each district were contacted with the assistance of their facilities managers, and were found to be willing to host the research in their schools.

RCs in each school were assessed for their potential to be studied as a set where some would be used as controls and others would receive the HVAC system upgrade with the advanced systems. Each school had to have a group of RCs, preferably sited in a row, equipped with 10 SEER Bard HVAC systems, and in at least pairs with the same year of manufacture. It was preferred that the RCs were at most 10 years old. Additionally if they had a known or suspected IAQ problem they would not be acceptable.

\section{Improved HPAC system installation and RC HVAC commissioning}

Ten IHPAC systems were shipped from Bard Corporation's factory to Northern and Southern CA branches of Geary Pacific Corp. Geary Pacific installed, with the assistance of local HVAC contractors, the HVAC systems and associated ducting, registers, and controls in all ten study RCs. Geary Pacific also commissioned the advanced systems and re-commissioned the existing HVAC systems in the matched control RCs. Commissioning included setting of the outdoor air 
supply rates at 465 CFM (equivalent to 15 CFM per occupant), replaced air filters, balanced supply registers, and verified proper functioning of controls.

The IHPAC systems were equipped with standard 2 inch pleated panel filters (MERV rating 7, ASHRAE 52.1 efficiency 25-30\%, see ASHRAE 1992). The 10 SEER systems were equipped with the standard 1 inch filter typically supplied with these units (ASHRAE 52.1 arrestance 70$75 \%$, MERV rating $1-4$, efficiency $<20 \%$ ). New filters were installed at the beginning of the study and replaced every 30 days.

\section{HVAC Control Systems}

The HVAC systems in the Control RCs were left for the teachers to operate using the existing standard thermostat coupled with an existing standard twist-type four-hour shutoff timer. The operation of this thermostat is entirely under the control of the teachers, and sometimes the school custodians at the beginning or end of the day. The thermostat has an automatic mode where it heats or cools according to setpoint, providing ventilation and air circulation only when thermal conditioning is required. An additional manual setting on the thermostat allows the teacher to turn on the fan independently if desired, allowing for continuous ventilation. However, as discussed above, this option is seldom used consistently due to the additional noise produced when the air supply fan is operating. The expectation in leaving them "as-is" is that the thermostats in the Control RCs would be used in the typical fashion during the study, and that they would follow their school district policy for HVAC operation.

In the RCs equipped with the IHPAC systems, an automatic "smart controller" was provided. Bard Manufacturing developed this controller for the IHPAC system as part of this project. It was designed to relieve the responsibility of the teachers of the majority of HVAC operation tasks. Additionally, it decouples the ventilation and thermal aspects of control through the use of an internal infrared motion-detector-type occupancy sensor that triggers ventilation whenever occupants are detected. The teacher's control interface is limited to a simple temperature setting adjustment, using up-arrow and down-arrow buttons to provide a locked indoor temperature range (field settable by a technician, and set to $\pm 4.0^{\circ} \mathrm{F}\left(2.5^{\circ} \mathrm{C}\right)$ in this study) in order to accommodate individual comfort differences. The occupancy sensor logic is set to wait 30 minutes after the last observed motion in the RC before setting back the temperature and shutting down the ventilation. It is also desensitized to very short (i.e., one-minute) detection of motion to avoid unneeded operation, but triggers HVAC operation as soon as a valid occupancy is detected. Finally, the system is designed to learn the classroom occupancy schedule over a moving two-week period, and then start anticipating occupancy by pre-conditioning the $\mathrm{RC}$ to the settings learned from the teacher's temperature control use patterns. Pre-conditioning also includes a pre-occupancy ventilation purge of three air changes (roughly one hour) as required by California Title 24. An additional benefit of this control system is that it has a digital electronic interface configured to operate on a LonWorks (www.echelon.com) network, allowing remote access for monitoring and control of all of the thermostat and HVAC functions.

\section{Instrumentation and Monitoring}

The instrumentation used in this field study is shown in Table 1. Real-time data were stored as 6-minute averages or totals. Real-time data included total RMS power consumption and indoor and outdoor temperature, $\mathrm{RH}$, and $\mathrm{CO} 2$ concentrations. Total RMS power consumption was 
measured on each HVAC system using WattNode ${ }^{\mathrm{TM}}$ (Continental Control Systems, Boulder CO, www.wattnode.com) power meters. Indoor and outdoor temperature, $\mathrm{RH}$, and $\mathrm{CO}_{2}$ concentrations were measured for each RC continuously. Indoor and outdoor particle, aldehydes, VOCs, and ozone concentrations in the RCs were monitored once a season during site visits. Classroom acoustic noise was measured during occupied and unoccupied periods with the HVAC operating during the seasonal site visits in each RC.

Indoor and outdoor temperature and $\mathrm{RH}$ were monitored primarily using the sensors in the PureChoice Nose ${ }^{\mathrm{TM}}$ (PureChoice Inc., Lakeview, MN). This device is connected to an i.Lon 100 network, and was accessible on the Internet by the researchers 24 hours a day.

$\mathrm{CO}_{2}$ was measured using two different systems: the Fuji ZPF-9 and the PureChoice Nose ${ }^{\mathrm{TM}} \mathrm{CO}_{2}$ sensor. The Fuji ZPF-9 has been used by LBNL for many years as a standard method in buildings. In this study a PureChoice Nose ${ }^{\mathrm{TM}} \mathrm{CO}_{2}$ sensor was also installed in each RC. The sensors differ in stated accuracy, and the Fuji unit samples with a pump, while the PureChoice sensor samples using gas diffusion. The PureChoice sensor was factory-calibrated and expected to maintain accuracy specifications for five years. The Fuji units was calibrated at least once a season during site visits and an automatic calibration check system was run in situ once a week. Both systems were connected to the i.Lon 100 network and were accessible on the Internet by the researchers 24 hours a day.

Site visits to the schools occurred once per season (May 2005, early September 2005, late November 2005; and February 2006) in order to check and calibrate instrumentation, to characterize indoor and outdoor concentrations of particles, VOCs, aldehydes, and ozone, and to conduct acoustical measurements. Classroom ventilation rates were measured during unoccupied periods using $\mathrm{CO}_{2}$ decays. Real-time data from the particle, sound level meter, and thermal comfort (TC) carts were downloaded onto a laptop computer for subsequent analysis. $\mathrm{CO}_{2}$ decay data was monitored using the existing monitors installed in each RC. Similarly, the VOC, aldehyde, and ozone sampling media were transported to LBNL for subsequent laboratory analysis.

\section{Measurements of air supply and ventilation}

Outside air supply flowrates and supply register flowrates were measured using an active flow hood method (Walker et al. 2001) developed at LBNL. The same process was applied to measure the outside air intake flow and the return flow. Outside air supply rates (outside air is about $30 \%$ of the total supply air in this recirculating system) was set to 15 CFM per occupant, or 465 CFM for a class of 30 students and one teacher. The three supply registers were balanced to split the total supply flow equally (about 500 CFM per register).

$\mathrm{RC}$ air exchange rates have been measured using a tracer decay method. $\mathrm{CO}_{2}$ decays were be measured with the installed $\mathrm{CO}_{2}$ monitors, and the air exchange rate was calculated after subtracting the outdoor $\mathrm{CO}_{2}$ concentration. During seasonal site visits, additional $\mathrm{CO}_{2}$ decays with the HVAC system ventilation fans on were conducted. This was achieved by injecting $\mathrm{CO}_{2}$ from a cylinder into the unoccupied rooms until a concentration of approximately $2000 \mathrm{ppm}$ was reached. After allowing the $\mathrm{CO}_{2}$ to decay to background levels, the air exchange rate was 
calculated as the negative slope of the natural logarithm of the indoor minus outdoor tracer concentration during the tracer decay (ASHRAE 2005).

\section{Energy Modeling}

Classroom energy modeling was conducted in order to assess the energy savings potential of the IHPAC system. Monitored HVAC energy consumption in the sixteen classrooms, as well as indoor and outdoor temperature and humidity measurements provide the basis for calibration of the portable classroom energy model. The model was fashioned after the previous work of Rainer et al (2003) using DOE-2 version 2.1E (Buhl et al 1993). The fine details of this model are beyond the scope of this report, however a DOE-2 input file is available upon request. All RCs and their operating schedules modeled were identical with the exception of the HVAC system - either the 10 SEER or IHPAC. Classrooms of the two system types were always located side by side in the same row of classrooms, so energy loads from environmental conditions were very well matched.

The 1-minute averaged data collected in the field from all of the classrooms were averaged up to 1-hour for modeling purposes since DOE-2 operates at this time step. For the 10 SEER classrooms the average hourly indoor temperatures collected from the indoor Nose sensors during occupied school hours were used as setpoint values. In the case of the IHPAC classrooms the Viconics thermostat temperatures available via the LonWorks network were used for the setpoint value as these were exactly the temperatures that the thermostat used for control. These setpoints were scheduled into the DOE-2 run deck to simulate loads as close as possible.

Weather files for DOE-2 input were developed for both climate zones. Measured hourly average outdoor temperature and RH were used. Solar data in RAW form (unpacked DOE-2 weather data file format) for monitoring network sites closest to the Modesto and Fontana schools were purchased from Western Regional Climate Center of the Desert Research Institute and converted to the DOE-2 input format and merged into the data files.

Energy performance data for the 10 SEER and IHPAC units used in the DOE-2 models were provided by Bard Manufacturing. These data are published in Bard's specification sheets and include energy cooling and heating capacities, energy efficiency ratios, and part load curves (Bard Mfg 2006, 2007).

Once assembled, the DOE-2 model was run for each of the ten IHVAC and six 10 SEER units in the field. Due to DOE-2 schedule capacity constraints, the models were run four times; once per season for about 6 weeks of each period. Hourly energy consumption predictions for each 6week period of each season for each classroom were inspected. As discussed below, the results of the modeling were varied. Some periods of model-to-measured comparisons show very close correspondence, while other periods have poor correlation.

Two parameters appeared to have the greatest influence on whether the model and measured data would agree - solar data and occupancy schedule. Visual model output inspection was ultimately used as confirmation that the model's simulation accuracy was adequate in order to consider it sufficiently calibrated for California climate zone and national energy savings estimates. 


\section{Results}

\section{Carbon Dioxide Concentrations}

Indoor $\mathrm{CO}_{2}$ concentrations in the intervention and control RCs during the study, are presented in Tables 2 and 3, for Northern and Southern California, respectively. Plots of indoor $\mathrm{CO}_{2}$ concentration distributions by season for all intervention and control RCs are provided in the Appendix (Figs A-1 to A-4). The annual average schoolday indoor-outdoor $\mathrm{CO}_{2}$ concentrations, across all intervention and control classrooms, were $250 \pm 100 \mathrm{ppm}$ and $660 \pm 330 \mathrm{ppm}$, respectively. Likewise, the average outdoor $\mathrm{CO}_{2}$ concentration was $370 \pm 20 \mathrm{ppm}$. Indoor annual averages in the Northern California classrooms were $220 \pm 90 \mathrm{ppm}$ and $520 \pm 450 \mathrm{ppm}$ for intervention and controls, respectively. In Southern California RCs the annual average concentrations were $280 \pm 110 \mathrm{ppm}$ and $630 \pm 370 \mathrm{ppm}$ for intervention and controls, respectively

In Northern California the intervention classrooms' schoolday average indoor-outdoor $\mathrm{CO}_{2}$ concentrations ranged from a low of about $120 \pm 120 \mathrm{ppm}$ to a high of $340 \pm 240 \mathrm{ppm}$. The lowest averages were observed during the Winter 2005 without exception while the highest classroom averages mostly occurred during Fall 2005. The control classroom indoor-outdoor $\mathrm{CO}_{2}$ concentrations ranged from a low of about $240 \pm 320 \mathrm{ppm}$ to a high of $1400 \pm 680 \mathrm{ppm}$. Again, the lowest seasonal concentrations occurred during Winter 2005.

In Southern California the intervention classrooms' schoolday average indoor-outdoor $\mathrm{CO}_{2}$ concentrations ranged from a low of about $120 \pm 110 \mathrm{ppm}$ to a high of $560 \pm 570 \mathrm{ppm}$. No observable seasonal trend was identified in intervention classroom $\mathrm{CO}_{2}$ classrooms. The control classroom indoor-outdoor $\mathrm{CO}_{2}$ concentrations ranged from a low of about $140 \pm 230 \mathrm{ppm}$ to a high of $1400 \pm 110 \mathrm{ppm}$. The lowest seasonal concentrations occurred during Summer 2005.

The maximum $99^{\text {th }}$ percentile seasonal indoor-outdoor $\mathrm{CO}_{2}$ concentrations in intervention classrooms were 950 ppm (classroom 24) and 3000 ppm (classroom 13) in Northern and

Southern California, respectively. Similarly, the $99^{\text {th }}$ percentile concentration differences for control classrooms were 3700 ppm and 4300 ppm for Northern and Southern California classrooms.

\section{Measured Ventilation Rates}

Tables 4 - 6 present measured outside airflows, supply airflows, and ventilation rates for the classrooms for spring, summer, and fall visits. Flow rates as found, and after adjustment where needed, are provided. Table 4 shows the 10 SEER HVAC system data. Unadjusted outside air supply rates as found in the spring visit to Northern CA RCs 21, 23, and 26 ranged from 128 to 260 CFM. These were adjusted to the highest setting achievable for the units, with rates of 230 and 275 CFM. This was below the target of 480 CFM. The Southern CA classrooms 14, 16, and 36 had outside air supply rates initially ranging from 256 to 377 CFM during the spring visit. These were adjusted to achieve the target. Only classroom 36 had the ability to achieve the setting, while rooms 14 and 16 rates were low.

With the exception of classrooms 21 and 14, the outdoor air supply rates between seasonal visits was reasonably stable. The rates in room 21 dropped significantly from 242 CFM in the spring 
to about 100 CFM in the fall and about 150 CFM in the winter. Similarly the spring rate of 428 CFM in classroom 14 degraded to below 100 CFM in the following summer and fall.

Total supply flows measured during the spring visit for the 10 SEER classrooms (Table 4) as measured as the sum of supply register flows (S1+S2) ranged from below 700 to almost 1200 CFM, with Room 16 having the lowest fan output. This can be compared with the rated total supply flow for the 4 ton 10 SEER unit of 1550 CFM (with wet coil at $0.2 " \mathrm{H}_{2} \mathrm{O}$ static pressure, Bard 2006). The supply register flows in the 10 SEER rooms were reasonably well balanced, with room 26 having the greatest imbalance, a relative flow difference of about $20 \%$ between the two registers.

Measured air exchange rates in the classrooms were conducted with outside air fan on during a $\mathrm{CO}_{2}$ decay during an unoccupied period with door and windows closed. For purposes of comparison, a room with volume of $9120 \mathrm{ft}^{3}$ (24' by $40^{\prime}$ by $9.5^{\prime}$ high) and an outside air supply rate of 480 CFM would have an air exchange rate of about $3.2 \mathrm{~h}^{-1}$. As seen in Table 4, measured air exchange rates in the 10 SEER classrooms ranged from a low or $1.2 \mathrm{~h}^{-1}$ to a high of $4.0 \mathrm{~h}^{-1}$. Across seasons the average air exchange rates $1.6 \pm 0.6 \mathrm{~h}^{-1}$ to $3.7 \pm 0.4 \mathrm{~h}^{-1}$. The northern CA classrooms had lower air exchange rates than those in the south, but the difference was only marginally significant $(\mathrm{p}=0.06$, Students $\mathrm{t}$ test).

The IHPAC classroom ventilation rate measurement data are shown in Tables 5 (Northern CA) and 6 (Southern CA). As can be seen from the data, after initial adjustment to close to 480 CFM during the spring visits the outside air settings varied little across the seasons, with only a few exceptions. The flow rate drift between seasons observed in northern CA units that did need adjustment was nearly always downward, with a maximum drift of about 90 CFM between spring and summer measurements. Similar drift patterns were seen in a few southern CA units across seasons (Table 6), about equally split between downward and upward changes. The greatest upward change was seen in Room 13 where the rates had dropped and were adjusted in the summer, and then increased and had to be lowered in the fall, with the stage 2 setting having increased by $128 \mathrm{CFM}$. This was atypical of the units, whose rate changes ranged from about -80 CFM to +80 CFM.

Register balance among the three supply diffusers were reasonably stable and consistent across season. The Tables clearly show the increasing total supply rate from fan only, to Stage 1 to Stage 2 compressor operation, while the outside air remained relatively constant. The measured return rates also indicate this ramped supply rate.

Again, the target air exchange rate was $3.2 \mathrm{~h}^{-1}$. The classroom air exchange rate for Northern CA averaged across seasons ranged from $2.5 \pm 0.1 \mathrm{~h}^{-1}$ to $3.6 \pm 0.4 \mathrm{~h}^{-1}$ (average $=3.0 \pm 0.4$ ), and for Southern CA ranged from $2.4 \pm 1.0 \mathrm{~h}^{-1}$ to $4.0 \pm 0.1 \mathrm{~h}^{-1}$ (average $=3.3 \pm 0.6$ ). The northern and southern classrooms air exchange rates were not different statistically $(\mathrm{p}>0.05)$.

\section{Acoustic Levels}

Sound pressure (noise) levels were measured in each classroom, unoccupied, in at least two seasons. Tables 7 and 8 present noise levels at the standard distance of 10 feet normal to the center of the return plenum grille and 5 feet above the floor with classroom lights on. Tables 9 and 10 contain the same data background adjusted to a $25 \mathrm{~dB}(\mathrm{~A})$ for better comparisons between 
HVAC units. As shown in Table 7, average of the three season measured unadjusted noise levels in 10 SEER classrooms ranged from $40.2 \pm 2.3$ to $52.4 \pm 3.2 \mathrm{~dB}(\mathrm{~A})$ in fan only mode, while the range was $51.3 \pm 1.6$ to $55.3 \mathrm{~dB}(\mathrm{~A})$ when both fan and compressor was running. As seen in Table 8 , the similar ranges for the IHPAC were $38.2 \pm 0.6$ to $40.7 \pm 1.1 \mathrm{~dB}(\mathrm{~A}), 41.1 \pm 3.2$ to $46.8 \pm 2.1$ $\mathrm{dB}(\mathrm{A})$, and 44.0 to $48.2 \pm 1.8 \mathrm{~dB}(\mathrm{~A})$ for fan only, fan and stage 1 compressor, and fan and stage 2 compressor operation, respectively. In the both 10 SEER and IHPAC classrooms no systematic trend of changing sound pressure output of the systems appeared across the seasonal measurements. Variability in measured sound levels across the seasons was small, indicating that the noise output was stable within the school year of the study.

After normalization of the sound pressure levels in the classrooms to a $25 \mathrm{~dB}(\mathrm{~A})$ background the levels dropped somewhat in all cases. As seen in Table 9, the highest average of season levels were $52.3 \pm 3.1 \mathrm{~dB}(\mathrm{~A})$ and $55.2 \pm 0.7 \mathrm{~dB}(\mathrm{~A})$ for 10 SEER fan only and fan and compressor, respectively. Likewise, as shown in Table 10, the highest levels for the IHPAC were 39.6 \pm 0.7 $\mathrm{dB}(\mathrm{A}), 46.8 \pm 2.1 \mathrm{~dB}(\mathrm{~A})$, and $48.2 \mathrm{~dB}(\mathrm{~A})$ for fan only, fan and stage 1 compressor, and fan and stage 2 compressor operation, respectively. Again, no systematic trend is observed in the noise output of the HVAC systems.

Figures A-5-to A-7 (see Appendix) provide additional information on the acoustics of the HVAC systems, showing octave band sound pressure level spectra from $63 \mathrm{~Hz}$ to $8 \mathrm{kHz}$ during the spring, summer, and fall season field visits measured at the standard position. These plots also provide noise criteria (NC) level curves for direct interpretation of the $\mathrm{NC}$ in the classrooms (ASHRAE 2005). Figures A-8 to A-10 (see Appendix) show the noise levels in different classroom locations starting from the standard position normal to and 10 feet from the return plenum, at a 45-degree angle and 10 feet from the return, and at 20 feet and 30 feet from the return. Figures A-8 to A-10 show the HVAC system noise levels under the different operating conditions, fan only and fan and compressor modes.

\section{VOC and Aldehyde Concentrations}

VOC and aldehydes samples were collected in the classrooms during each site visit (see Methods report, Apte et al. 2004). The GC-MS was calibrated for a wide range of compounds typical of indoor environments. Concentration data for IHAPC and 10 SEER classrooms, averaged across the two school districts, both by season and across the three seasons' measurements are presented in the sections below. A subset of compounds of particular interest due to their odorous or toxic nature has been extracted from the entire VOC dataset for the purpose of comparison of indoor conditions in the two classroom types.

Table 11 lists a set of compounds that have low odor thresholds (Devos et al. 1989, and AIHA 1989) and/or are listed as chronic reproductive toxin or carcinogens by the State of California's Proposition 65 (State of California 1986), and/or are listed by the California Environmental Protection Agency for their chronic toxicity (OEHHA 2005), or are listed by the U.S. Environmental Protection Agency as Hazardous Air Pollutants (USEPA 2005). These chemicals are representative of portable classrooms. Due to their relevance to classroom occupants, these compounds were focused on in this study. 


\section{VOC Concentrations}

Tables 12 - 14 present results of measured indoor and outdoor VOC concentrations in the spring, summer, fall monitoring visits, respectively, aggregated separately across the IHPAC and 10 SEER classrooms. Table 15 presents the three measurement period average of these data, again for the IHPAC and 10 SEER rooms. Figure 1 shows the relative average concentrations of the selected list of compounds in the IHPAC and 10 SEER classrooms, and outdoors. Note that the GC-MS analysis of a few of the compounds yielded slightly negative concentrations, as shown in the tables and figures. These should be interpreted as zero values. Figure 2 shows the ratio of average indoor IHPAC to 10 SEER VOC concentrations. The ratios range from zero to 0.86 with an average of 0.43 , suggesting that on average, concentrations of odorous and toxic VOCs in the IHPAC classrooms were less than half of those in the 10 SEER classrooms.

\section{Aldehyde Concentrations}

Tables 12 - 14 present results of measured indoor and outdoor formaldehyde and acetaldehyde concentrations in the spring, summer, fall monitoring visits, respectively, aggregated separately across the IHPAC and 10 SEER classrooms. Table 15 presents the average of these data, again for the IHPAC and 10 SEER rooms. Across all rooms and all year, average concentrations of formaldehyde were $16 \pm 7.9$ and $24 \pm 6.5 \mu \mathrm{g} \mathrm{m}^{-3}$ for the IHPAC and 10 SEER classrooms, respectively. Similarly, average concentrations of acetaldehyde were $7.8 \pm 4.3$ and $12 \pm 5.2 \mu \mathrm{g} \mathrm{m}^{-3}$ The maximum concentrations of these compounds were $38 \mu \mathrm{g} \mathrm{m}^{-3}$ and $35 \mu \mathrm{g} \mathrm{m}^{-3}$, and $16 \mu \mathrm{g} \mathrm{m}^{-3}$ and $21 \mu \mathrm{g} \mathrm{m}^{-3}$ for the IHPAC and 10 SEER rooms, for formaldehyde and acetaldehyde, respectively. From Figure 2, the average concentrations of both acetaldehyde and formaldehyde in the IHAPC classrooms were about $65 \%$ of those in the 10 SEER classrooms.

\section{Particle Matter Concentrations}

Particle concentrations are presented as schoolday averages of the real-time data collected by the optical particle counters (see Table 1). Tables 16 - 19 present the schoolday average, standard deviation, first percentile, and $99^{\text {th }}$ percentile size-resolved and bin total PM mass concentrations for each classroom and outdoors and each season's field sampling campaign. A few classroomsampling periods were missed over the study duration due to instrument failure. Particle mass was calculated assuming a density of $1 \mathrm{~g} \mathrm{~cm}^{-3}$. $\mathrm{PM}_{2.5}$ concentrations are approximate, being the sum of the lower five particle size bins. Figure 3 summarizes the average approximate $\mathrm{PM}_{2.5}$ concentrations and their range for each classroom and outdoors.

A comparison of the 10 SEER and IHPAC average $\mathrm{PM}_{2.5}$ data for paired side-by side classrooms indicates no evidence that concentrations of particle matter were influenced by the type of HVAC system present, the concentrations in the two types of classrooms not being statistically different (Student's paired two sample for means t-test, $\mathrm{p}=0.81$ ). The schoolday average ( \pm standard deviation) $\mathrm{PM}_{2.5}$ concentrations across all 10 SEER and IHPAC classrooms and seasons were $13.7 \pm 6.3 \mu \mathrm{g} \mathrm{m}^{-3}$ and $15 \pm 9.1 \mu \mathrm{g} \mathrm{m}^{-3}$, respectively. Likewise, the outdoor average concentration was $22 \pm 18 \mu \mathrm{g} \mathrm{m}^{-3}$, slightly higher than those indoors. Particle concentration data may be reviewed in greater detail in Tables 16=19.

Particle mass concentrations were highest in the $2.0 \mu \mathrm{m}$ and $5.0 \mu \mathrm{m}$ size bins as expected. The ratio of the sum particle mass in the $0.3 \mu \mathrm{m}$ to $2.0 \mu \mathrm{m}$ bins (approximate $\mathrm{PM}_{2.5}$ ) to the sum mass concentration of all six bins is an indicator of the relative fine and course fractions of particle matter in the classrooms, or in the outdoor air. The ratios across seasons by HVAC groupings 
for the 10 SEER and IHPAC classrooms were $0.32 \pm 0.06$ and $0.32 \pm 0.09$, respectively. Similarly, the ratio for outdoor air averaged across all sites was $0.46 \pm 0.07$. The size ratios by classroom types were virtually identical, whereas that of the outdoor air was different (statistically significant, Student's t-test, $\mathrm{p}=0.01$ ).

\section{Thermal Comfort}

Thermal comfort (TC) measurements in occupied classrooms according to ASHRAE Standard 55 (ASHRAE, 1992, 1995) were accomplished during each field measurement visit using the LBNL thermal comfort carts. Although only two TC carts were available, an attempt was made to collect data in as many classrooms as possible during a morning and afternoon period. This involved moving the carts between classrooms at recess and lunch breaks, often moving the carts from one school in a study district to the other. Logistics notwithstanding, much TC data were collected. Figures 4 - 6 report AM and PM measurement periods in the classrooms, including averaged temperature and relative humidity and the percent of time that, according to ASHRAE Standard 55, that TC would be acceptable. This latter variable is reported in the case where measured air velocity was included in the model, and that where it was excluded. Further details of these measurements may be found in the Appendix, Table A-1.

As shown in Figure 4, TC cart data show that springtime indoor average AM temperatures ranged from about $21.1^{\circ} \mathrm{C}$ to $24.7{ }^{\circ} \mathrm{C}$ and $21.0^{\circ} \mathrm{C}$ to $22.1{ }^{\circ} \mathrm{C}$ for the 10 SEER and IHPAC classrooms, respectively. Similarly, afternoon average temperatures ranged from $22.8^{\circ} \mathrm{C}$ to $23.4^{\circ} \mathrm{C}(10 \mathrm{SEER})$ and $20.8^{\circ} \mathrm{C}$ to $22.5^{\circ} \mathrm{C}$ (IHPAC). Relative humidity ranged from about $50.5 \%$ $\mathrm{RH}$ to $58 \%$ across both 10 SEER and IHPAC classrooms. Given the measured springtime thermal conditions in the classrooms acceptable thermal comfort by the ASHRAE definition was often unmet in either 10 SEER or IHPAC. The 10 SEER classrooms in Southern California, 14, 16 , and 36 , and IHPAC classroom 35 , had acceptability 67 to $100 \%$ of the afternoon time period (model excluding air velocity). Classroom 36 also met the TC acceptability criterion in the AM period.

Summer TC cart data (Figure 5) show that average AM temperatures ranged from $21.5^{\circ} \mathrm{C}$ to $25.3^{\circ} \mathrm{C}$ and $20.2{ }^{\circ} \mathrm{C}$ to $21.4^{\circ} \mathrm{C}$ in the 10 SEER and IHPAC classrooms, respectively. Afternoon average temperatures ranged from $23.2^{\circ} \mathrm{C}$ to $26.7^{\circ} \mathrm{C}$ and $20.0^{\circ}$ to $24.9^{\circ} \mathrm{C}$ in these respective classroom types. Average indoor relative humidity levels ranged from about $39 \%$ up to $67 \%$. ASHRAE Standard 55 TC was much more often acceptable in the 10 SEER classrooms, however the large portion of schoolday TC conditions did not meet the standard's criteria.

Fall TC cart data (Figure 6) show that average AM temperatures ranged from $16.2{ }^{\circ} \mathrm{C}$ to $22.3{ }^{\circ} \mathrm{C}$ and $17.8^{\circ} \mathrm{C}$ to $20.1{ }^{\circ} \mathrm{C}$ in the 10 SEER and IHPAC classrooms, respectively. Afternoon average temperatures ranged from $22.0^{\circ} \mathrm{C}$ to $23.6^{\circ} \mathrm{C}$ and $20.7^{\circ}$ to $23.0^{\circ} \mathrm{C}$ in these respective classroom types. Average indoor relative humidity levels ranged from about $34 \%$ up to $62 \%$. ASHRAE Standard 55 TC was almost never acceptable in any of the classrooms.

In addition to TC cart measurements, temperature and relative humidity data were collected in real time during the entire study period from January 2005 on. Indoor and outdoor schoolday hour statistics from these data are provided in Tables 20 and 21. Average temperature and RH data are graphed for easy interpretation in Figures 7-10. 
As seen in Figure 7, average northern California classroom indoor temperatures in the 10 SEER and IHPAC were quite different. Spring and Summer 10 SEER temperatures were about $2.5^{\circ} \mathrm{F}$ warmer than in the IHPAC, on average. Winter and fall average temperatures were $1-2^{\circ} \mathrm{F}$ lower in the 10 SEER classrooms. In all seasons, the variability in average indoor temperatures was much greater in the 10 SEER classrooms.

As shown in Figure 8, Southern California 10 SEER classrooms were about 2 to $4{ }^{\circ} \mathrm{F}$ warmer on average in the spring, summer, and fall and just slightly cooler in the winter. As in the North, the 10 SEER average classroom temperatures were more variable.

Northern California indoor RH (Figure 9) in the winter and spring were higher by 3 to 6 percent in the 10 SEER classrooms, and lower by about 5 percent in the summer. Average RH in the fall was approximately the same in classrooms of both HVAC types. In southern California average indoor RH (Figure 10) was always lower in the 10 SEER classrooms with a difference of as much as about 8 percent in the summer. As with temperatures, the variability in average $\mathrm{RH}$ levels was greater in the 10 SEER classrooms.

\section{Energy Consumption}

Daily HVAC energy consumption statistics for Northern and Southern California classrooms are presented in Table 22. Figures 11-15 are box and whisker plots that show the distributions of daily HVAC energy consumption for IHPAC and 10 SEER systems during the winter 2004, and spring, summer, fall, and winter 2005, respectively. These plots show the median, first and third quartile, and minimum and maximum measured daily energy consumption.

In Northern California, measured daily average electric energy consumption was about $2.7 \pm 1.1$ $\mathrm{kWh}$ and $3.4 \pm 0.6 \mathrm{kWh}$ for the 10 SEER and IHPAC systems, respectively. Similarly, average daily Southern California energy consumption across all seasons was about $3.0 \mathrm{kWh}$ and 3.4 $\mathrm{kWh}$ for the 10 SEER and IHPAC systems, respectively.

Northern California Fall, spring, summer, and Winter 10 SEER daily energy consumption were about $2.3 \pm 0.7,2.5 \pm 1.2,4.8 \pm 3.3$, and $1.8 \pm 0.2 \mathrm{kWh}$, respectively. Southern California Fall, spring, summer, and Winter 10 SEER daily energy consumption were about $2.7 \pm 1.1,2.7 \pm 1.0,6.6 \pm 3.2$, and $1.2 \pm 0.5 \mathrm{kWh}$, respectively. Similarly, Northern California Fall, spring, summer, and Winter IHPAC daily energy consumption were about $2.7 \pm 0.7,3.2 \pm 0.7,5.6 \pm 2.2$, and $2.7 \pm 0.3 \mathrm{kWh}$, respectively. Southern California Fall, spring, summer, and Winter IHPAC daily energy consumption were about $3.2 \pm 0.9,3.2 \pm 0.8,6.2 \pm 1.8$, and $1.8 \pm 0.3 \mathrm{kWh}$, respectively.

Finally, across both climate zones the year average daily average energy consumption was $2.9 \pm 0.9 \mathrm{kWh}$ and $3.4 \pm 0.7 \mathrm{kWh}$ for the 10 SEER and IHPAC systems, respectively. The fall, spring, summer, and Winter 10 SEER daily energy consumption averages were about $2.9 \pm 0.9$, $2.6 \pm 1.0,5.7 \pm 3.0$, and $1.5 \pm 0.4 \mathrm{kWh}$, respectively. Lastly. Fall, spring, summer, and Winter IHPAC daily energy consumption averages were about $2.9 \pm 0.7,3.2 \pm 0.7,5.9 \pm 1.9$, and $2.2 \pm 0.5$ $\mathrm{kWh}$, respectively. 


\section{HVAC Component Operation Modes}

Tables 23 and 24 present, for each classroom, data on the average percent of time that HVAC systems operated in various component modes: off, supply fan only, and compressor plus fan operation. "School hours" in the Tables refer to standard schedule hours of Monday-Friday from 7:30 AM to 3:00 PM. Operation of the 10 SEER systems was triggered by thermostat setting and a 4-hour twist timer; if the system was not activated, HVAC operation would not occur. The IHPAC was operated by a more complicated system that automatically provided a one-hour preoccupancy ventilation purge, and pre-occupancy conditioning that anticipated the classroom schedule, and had an occupancy override that turned on the system supply fan on sensing arrival of occupants. The occupancy sensor guaranteed ventilation as long as occupants were detected and provided a 15-minute time-to-shut-off when the classroom was vacated. Monitored energy use patterns showed distinct IHPAC system off-times during recess and lunch hour periods.

The 10 SEER systems have only one compressor mode while the IHPAC compressor has two stages. These detailed data are summarized in Tables 25 and 26. On average, across the entire school year, the 10 SEER systems were turned off during school day hours $77 \%$ and $53 \%$ of the time in Northern and Southern California, respectively. In comparison, the IHPAC system was turned off $25 \%$ and $24 \%$ of the time, respectively, during the same time periods. 10 SEER system fans were turned off most frequently during the winter and least frequently in the summer in both climate zones. Interestingly, the opposite was observed for the IHPAC systems, where the fan was turned off most frequently in the summer and least in the winter.

As seen from Table 25, 10 SEER compressor use frequency was greatest during the summer in both Northern (34\%) and Southern (41\%), and the least in the winter (north: 9\%; south 4\%). IHPAC stage 1 compressor use varied little in either climate zone, with an average of $30 \% \pm 22$ in the north and $19 \% \pm 3 \%$ in the south. Compressor stage 2 varied more with greatest use in the summer (north: $22 \%$; south $31 \%$ ) and winter (north: $4 \%$; south $2 \%$ ).

\section{Energy Modeling}

\section{DOE-2 Model Calibration}

Figures 16 and 17 show selected weekly sequences of measured hourly average indoor temperature and hourly HVAC energy use. DOE-2 predicted indoor temperatures and energy use for the same time periods for 10 SEER classrooms (Figure 16) and IHPAC classrooms (Figure 17 ) is plotted for comparison. The data shown are typical weeks of HVAC operation chosen from each season during the study, although not all predicted days agree as well as those shown. The degree to which measured data and modeled results depend upon the accuracy of correspondence between the true and modeled occupancy and operation schedules, and upon the degree to which the solar radiation data used for the DOE-2 models agree with the true hourly total and horizontal solar radiation incident on the classrooms.

As can be seen in both Figures16 and 17, the basic shape, and trend, and magnitude of modeled 10 SEER and IHPAC energy load in each season is relatively good correspondence with the measured data. The thermostat setting estimate that is derived from measured data drives predicted indoor temperature during occupied hours. During unoccupied hours the temperature 
is allowed to swing based on thermal balance driven by external loads. The predicted indoor temperature does not track the measured values consistently during unoccupied hours.

As discussed in the Methods Section, the purpose of the DOE-2 - measured data comparisons is to assess the calibration of the model; i.e., degree to which the DOE-2 building model and HVAC parameters correctly predict energy use. With the models calibrated, it is possible to run them for different climate zones.

\section{DOE-2 model results - California Climate Zones}

Table 27 presents the predicted annual energy use of the 10 SEER and IHPAC equipped classrooms across all sixteen California climate zones (CEC 2004). The table has the results broken out by heating, cooling, and fan consumption components. It provides model results for continuous ventilation during classroom occupancy and for both systems as well as intermittent ventilation on compressor cycling for the 10 SEER systems. Annual predicted heating energy demand ranged from $126(\mathrm{CZ} 7)$ to $1727(\mathrm{CZ} \mathrm{16)} \mathrm{kWh}$ for the 10 SEER classrooms and between 60 (CZ 7) to 1127 (CZ 16) $\mathrm{kWh}$ for the IHPAC classrooms. Annual cooling energy ranged from 17 (CZ 1) to 1258 (CZ 15) kWh in 10 SEER classrooms vs. 23 (CZ 1) to 787 (CZ 15) kWh in IHPAC rooms. Predicted fan energy ranged from 973 (CZ 7) to 1593 (CZ 15) kWh for the 10 SEER classrooms and 748 (CZ 1) to 1005 (CZ 14) kWh for the IHPAC classrooms. Figure 18 compares energy consumption for the 10 SEER and IHPAC classrooms for Oakland (CZ 3), Burbank (CZ 9), and Sacramento (CZ 12) using continuous ventilation.

Using the 10 SEER unit with continuous operation during occupancy as the reference, total annual energy savings per classroom using the IHPAC system in the 16 climates zones range from about 570 to $1300 \mathrm{kWh}$, average $880 \pm 220 \mathrm{kWh}$. On average this is a $39 \% \pm 2 \%$ energy saving, ranging from $36 \%$ to $42 \%$. Assuming electricity costs of $\$ 0.15 / \mathrm{kWh}$, the range of savings is from about $\$ 85$ to $\$ 195$ per year per IHPAC system (Figure 19).

An estimated net incremental cost of $\$ 1150$ per IHPAC unit relative to the 10 SEER product was provided by Bard (Tiernan 2006) based on the relative unit list prices minus the incremental cost of the R410A refrigerant used in the IHPAC. Simple payback estimates for the California climate zones were calculated by dividing annual energy savings into the net incremental cost. Figure 20 shows the sixteen climate zones, energy cost savings and simple payback. At the $\$ 0.15 / \mathrm{kWh}$ cost of electricity, simple payback times (shown in parentheses in Figure 20) range from six years in CZ 16 to 13 years in CZ 7.

The 10 SEER classrooms operated with intermittent ventilation (Table 27) show lower fan energy use, as expected. For the classroom models used, the heating and cooling component energy benefits of intermittent fan use based on load were not large, and in some cases, due most likely to "economizer" effects, were negative.

\section{DOE-2 model results - U.S. Cities}

Table 28 compares component and total annual energy consumption for classrooms using the 10 SEER and IHPAC systems for 37 major cities in the United States. Again, the table has the results broken out by heating, cooling, and fan consumption components. It provides model 
results for continuous ventilation during classroom occupancy and for both systems. Annual predicted heating energy demand ranged from 28 (Miami) to 7272 (Anchorage) $\mathrm{kWh}$ and 13 (Miami) to 6481 (Anchorage) $\mathrm{kWh}$ for the 10 SEER and IHPAC classrooms, respectively. Likewise, annual cooling energy ranged from 18 (Anchorage) to 1467 (Miami) kWh in 10 SEER classrooms vs. 11 (Anchorage) to 871 (Miami) kWh in IHPAC rooms. Predicted fan energy ranged from 1006 (San Diego) to 1868 (Anchorage) kWh and 629 (San Diego) to 1163 (Anchorage) $\mathrm{kWh}$ for these different HVAC systems.

Total annual energy savings per classroom using the IHPAC system in the 37 Cities range from about 593 to $1667 \mathrm{kWh}$, average $1100 \pm 220 \mathrm{kWh}$. On average this is a $34 \% \pm 6 \%$ energy saving, ranging from $16 \%$ to $44 \%$. Assuming electricity costs of $\$ 0.15 / \mathrm{kWh}$, the range of savings is from about $\$ 89$ to $\$ 250$ per year per classroom, depending upon the city.

\section{Comparison of Nose $\mathrm{CO}_{2}$ and Fuji $\mathrm{CO}_{2}$ Data}

Carbon dioxide measurements were made contemporaneously using both PureChoice ${ }^{\mathrm{TM}}$ Nose and the Fuji ZPF-9 sensors in thirteen of the sixteen classrooms in the study. Table 29 presents the results of least-squares linear regression of Nose and Fuji measurements collected from three one-week periods following Fuji calibrations conducted during Spring, Summer, and Fall field visits. The regression model is Nose $(\mathrm{ppm})=$ Slope $*$ Fuji $(\mathrm{ppm})+$ Intercept. Figure 21 shows the paired data for all thirteen-sensor pairs. The "Shared" column in the table refers to whether the sampling line for a particular Fuji paired with that room's Nose was multiplexed with another room or outdoors site. Multiplexed sampling lines switched between up to 3 sites on a sixminute sample cycle - the first three minutes of each locations data were dropped to accommodate instrument stabilization.

With the exception of one sensor pair (Room 25, using a shared Fuji sensor) the correlation coefficient $\left(\mathrm{R}^{2}\right)$ was greater than 0.95 . The regression slope $(\mathrm{m})$ was greater than unity in 8 of the pairs with three having $\mathrm{m} \leq 1.10$; five of these had $\mathrm{m} \leq 1.05$. Five sensor pairs had slopes less than unity, and all but one of these had $\mathrm{m} \geq 0.95$. Intercepts were all positive, ranging from $13 \mathrm{ppm}$ to $119 \mathrm{ppm}$.

\section{Discussion}

As discussed earlier, the objectives of the data evaluation were to quantify how the advanced HVAC system influences:

- Ventilation rates;

- Pollutant concentrations;

- Noise levels;

- HVAC operation periods;

- HVAC energy use; and

- Thermal comfort.

\section{Ventilation, $\mathrm{CO}_{2}$ and HVAC Operation Periods}

Development of a system that would reliably provide adequate ventilation was a key goal of this project. As discussed above, only one of the six 10 SEER systems under test could not be adjusted to provide the 465 CFM (15 CFM per occupant * 31 occupants) of outside ventilation 
air required by state code and recommended in ASHRAE Standard 62.1. The IHPAC was found to be fully field-adjustable in the required ventilation supply range. However, the flow rate settings were observed to drift from their intentional setting over a period of months. Typically the drift was in the upward direction, which is the fail-safe direction in terms of meeting minimum ventilation requirements.

Air exchange rates measured by $\mathrm{CO}_{2}$ decay during ventilation periods corroborate the relatively low ventilation provided by the classrooms using the 10 SEER system relative to the IHPAC. This is not particularly surprising since the HVAC fan provides the only significant ventilation in the classrooms; the windows were kept closed and infiltration through the portable classroom shell is relatively low.

Indoor minus outdoor (delta) $\mathrm{CO}_{2}$ concentrations during occupied hours are a good indicator of how well occupant bioeffluents are being removed through ventilation. At 15 CFM per occupant, delta $\mathrm{CO}_{2}$ reaches a steady-state concentration of about $700 \mathrm{ppm}$ (ASHRAE, 2004). If observed concentrations are at or in excess of this level, and the concentration has not yet reached steady state, the ventilation rate must be less than 15 CFM per occupant. For example, if the school day average delta $\mathrm{CO}_{2}$ concentration is $>700 \mathrm{ppm}$, steady state values, if they were ever achieved would be higher since the average includes sub-steady-state concentrations.

Elevated $\mathrm{CO}_{2}$ concentrations are a function of both inadequate supply of outside air and inadequate use of the outside air supply fan. As discussed previously, a number of reasons exist for low use of the outside air supply fan; of these, system noise and thermostat/control design are key. Teachers may decide to forgo space conditioning in order to avoid the mechanical noise levels created by the HVAC system. The thermostatic link to ventilation in the standard operating design of the 10 SEER system ensures lower than continuous ventilation except when conditioning demands are so great that the compressor remains on continuously.

In the case of the 10 SEER classrooms in this study, four of the six classrooms studied had delta $\mathrm{CO}_{2}$ averages close to or in excess of $700 \mathrm{ppm}$ for entirety of the study. In contrast, none of the IHPAC units had all-study average delta $\mathrm{CO}_{2}$ concentrations near $700 \mathrm{ppm}$ - the highest average was $410 \mathrm{ppm}$. Half of the yearlong $99^{\text {th }}$ percentile delta $\mathrm{CO}_{2}$ concentrations in the 10 SEER classrooms were well above $3000 \mathrm{ppm}$, and all of them were greater than double the 700-ppm target. In the IHPAC classrooms, $30 \%$ of the $99^{\text {th }}$ percentile whole year values never exceeded $700 \mathrm{ppm}$, and $80 \%$ were below $850 \mathrm{ppm}$ all but $1 \%$ of the time. Two of the IHPAC units, classrooms 13 and 35, in the Southern California SD reached $1600 \mathrm{ppm} \mathrm{1 \%}$ of the time. In the case of room 13 this is due to $99^{\text {th }}$ percentile levels of $3000 \mathrm{ppm}$ and $1500 \mathrm{ppm}$, during the spring '05 and summer '05, respectively. In classroom 35 the spring and summer top $1 \%$ delta $\mathrm{CO}_{2}$ concentrations were both $1700 \mathrm{ppm}$. Since both of these classrooms were capable of providing adequate ventilation for 31 occupants and the controller was designed to turn provide the ventilation during occupancy, and since both had very low average delta $\mathrm{CO}_{2}$ concentrations, it is likely that the problem occurred due to a system malfunction that was corrected. In all IHPAC cases the peak $\mathrm{CO}_{2}$ problems stopped occurring after summer '05, probably due to correction of a brownout condition due to poor power distribution at the school.

The very high $99^{\text {th }}$ percentile delta $\mathrm{CO}_{2}$ values across seasons in the 10 SEER classrooms indicate that chronic peak levels in the thousands of ppb were occurring. The highest $99^{\text {th }}$ 
percentile delta $\mathrm{CO}_{2}$ levels, 4300 ppm, were observed in the Southern California SD in the winter season. Excluding summer, these peak values were regularly above 2000 to $3000 \mathrm{ppm}$.

The 10 SEER and IHPAC operation mode data show clearly why the IHPAC provided lower delta $\mathrm{CO}_{2}$ concentrations throughout the year. The percentage of time that the fan or fan + compressor modes were activated were substantially lower with the 10 SEER than with the IHPAC. This was because the occupancy sensor triggered the ventilation fan in the IHPAC smart control system whenever the occupants were present. In the 10 SEER classrooms the teacher had to make a conscious decision to turn on the ventilation fan, or had to rely on the thermal cycling of the HVAC system to provide ventilation.

The above discussion provides evidence that the IHPAC systems in use provided the ventilation to the classrooms, as designed. It also corroborates earlier studies in portable classrooms where inappropriate ventilation control scheme coupled with the noise-related disincentive to use the system leads to excessive $\mathrm{CO}_{2}$ buildup and poor overall ventilation. The fact that some excessive $\mathrm{CO}_{2}$ peaks were still evident in some of the IHPAC classrooms is evidence that the system was not infallible, but the problems that came up were remedied by system adjustments.

\section{Pollutant Concentrations}

\section{VOCs and Aldehydes}

The gas phase compounds identified in the classrooms are typical of those seen in modular classroom construction (Hodgson et al, 2004). The measured results follow the logic that increased ventilation provides improved indoor air quality; the measured compounds were all substantially lower in the IHPAC classrooms. Formaldehyde is likely the compound that has received greatest concern in portable classrooms; as a registered Toxic Air Contaminant, an irritant and carcinogen, low concentrations are of importance. The formaldehyde Chronic Reference Exposure Level (REL) set by the California EPA is $3 \mu \mathrm{g} \mathrm{m}^{-3}$ (Cal/EPA 2003). Given the repeated daily schedule of students and teachers over many years, the chronic REL is an appropriate comparison to measured concentrations. However the value of $3 \mu \mathrm{g} \mathrm{m}^{-3}$ is very difficult to achieve and ambient levels may often be at this level. The acute REL for formaldehyde (Cal/EPA 1999) is $94 \mu \mathrm{g} \mathrm{m}^{-3}$ averaged over and 1-hour period. An intermediate 8hour Acute REL level of $33 \mu \mathrm{g} \mathrm{m}^{-3}$, based on the acute REL 1-hr value has been published in a guideline by Cal EPA (Broadwin 2000, CalEPA/ARB 2004, Lam 2004).

If the intermediate acute 1-hour REL of $33 \mu \mathrm{g} \mathrm{m}^{-3}$ is used as a comparative value, average formaldehyde concentrations in the both the 10 SEER and IHPAC classrooms would be considered acceptable. However, this level was exceeded in at least one classroom with each type of HVAC system at least once.

It is interesting that the ratio of IHPAC to 10 SEER average formaldehyde concentrations was about 0.67 compared to the average across all of the VOCs discussed where the average was 0.43. Using ventilation for removal of formaldehyde from indoor emissions is not as effective as it is for many VOCs. This is due to the mechanism of natural diffusion of formaldehyde from materials. The rate of diffusion out of the materials is governed by Fick's Law, which states that it is proportional to the concentration gradient at the surface of the material. With higher 
amounts of ventilation, the formaldehyde in the materials diffuses at a greater mass transfer rate, increasing the amount of the gas that is released into the air. This factor reduces the effectiveness of ventilation at formaldehyde removal. Source control and reduction as well as ventilation are needed to ensure that formaldehyde levels are as low as possible in classrooms. This can best be accomplished through careful material selection.

Acetaldehyde levels follow a similar pattern to formaldehyde in the classrooms studied. On average across the year of study the IHPAC classroom acetaldehyde concentrations were lower than the chronic REL (Cal/EPA 2003) of $9 \mu \mathrm{g} \mathrm{m}^{-3}$, while the 10 SEER average concentrations exceeded that value. In the fall the IHPAC average also exceeded the chronic REL. Again, the chronic REL is rather restrictive for this compound and may be virtually impossible to meet on a consistent basis. Overall, the increased amount of ventilation provided by the IHPAC did lead to lower levels than those in the 10 SEER classrooms.

Octanal and pentanal, two carbonyl compounds with low odor thresholds $\left(7 \mu \mathrm{g} \mathrm{m}^{-3}\right.$ and $2 \mu \mathrm{g} \mathrm{m} \mathrm{m}^{3}$, respectively) were observed in the classrooms sometimes above the odor threshold. The yearlong average 10 SEER classroom average pentanal concentrations were at the odor threshold, whereas the IHPAC average was many time lower $\left(0.16 \mu \mathrm{g} \mathrm{m}^{-3}\right)$. Nonetheless, classroom types had some measurements of these concentrations above the odor threshold.

In general, VOCs are ubiquitous in the portable classroom environment, but were found to be generally lower when the IHPAC ventilation was provided.

\section{$\mathrm{PM}_{2.5}$}

As discussed above, the HVAC system type did not affect PM2.5 concentrations. The IHPAC systems used in the classrooms, despite the upgrade to 2" pleated filters, did not employ particulate filters with sufficient efficiency to improve particle removal rates. Outdoor $\mathrm{PM}_{2.5}$ concentrations were higher than those indoors, so dilution by additional ventilation air would not be expected to reduce the particle matter load in the classrooms. Although the indoor $\mathrm{PM}_{2.5}$ concentrations observed in the classrooms in this study were not of great concern, this is not always the case (Daisey et al. 2003). Development of an improved filtration capability in the IHPAC would be of value in many classroom situations, particularly where the outside particle concentrations are of concern.

Since more outside air volume was provided to the IHPAC classrooms relative to the 10 SEER classrooms, more particle mass from outdoor air was entrained into these HVAC systems. If the two system types had the filters with the same particle removal efficiency it would stand to reason that more PM from outdoors would enter the IHPAC classrooms and they would have higher indoor PM concentrations. Since concentrations were relatively the same in the two classroom types, the higher efficiency of the 2" pleated particle filters in the IHPAC system was likely responsible for removal of the additional PM mass provided due to additional ventilation.

\section{Acoustic Levels}

An evolution of sound level standards for classroom background noise levels has occurred over the past few years. For example: 
1. Collaborative for High Performance Schools (CHPS) - Various CHPS points are granted for 45, 40 and $35 \mathrm{~dB}(\mathrm{~A})$ levels.

2. Los Angeles Unified School District (LAUSD 1998) requited a maximum of $50 \mathrm{~dB}(\mathrm{~A})$ at 10 feet in front of the HVAC unit. LAUSD has since adopted CHPS standards.

3. ANSI/ASA S12.60-2002:- ASA has set a maximum background level in classrooms of 35 $\mathrm{dB}(\mathrm{A})$, a technological challenge to achieve at low cost points, but possible when extremely low background classroom levels are essential, for example when teaching the hearing impaired.

The reduction of acoustic noise emitted from the wall mount classroom HVAC system achieved in the IHPAC is one of the major achievements of this project. Noise plays an important role in the operation of the portable classroom as a learning environment. Teachers must be able to bring noise levels under control in their classrooms in order to be heard and to maximize the attention of the students. When voices must be raised over a high background noise level, an environment is created where the room occupants must compete to be heard, leading to an upward spiral of speech amplitude. Teachers often opt to turn off an offending ventilation system if doing so improves the acoustic environment in the classroom. The consequences of this action are poor ventilation, indoor air quality, and thermal control, with possible outcomes including increased transmission of respiratory infections, increased exposure to toxic air contaminants, increased absenteeism, etc.

The fan-only sound pressure level range of 36 to $40 \mathrm{~dB}(\mathrm{~A})$ in the IHPAC classrooms is a substantial improvement compared to the 38 to $52 \mathrm{~dB}(\mathrm{~A})$ range in the 10 SEER classrooms. Across all of the IHPAC units and three measurement sessions, the average background sound pressure level was $38 \pm 1.4 \mathrm{~dB}(\mathrm{~A})$. Since under the Title 24 requirement for continuous ventilation implies that the fan must be on always during occupied hours, the fan only operation can make up a large part if total daily noise exposure. With the exclusion of classroom 24 the fans were operated about $38 \% \pm 14 \%$ of the time without the HVAC compressor activated.

During Stage 1 operation of the IHPAC compressor the noise levels ranged from 41 to $47 \mathrm{~dB}$ (averaged across the three seasons of measurements. The average measured background noise level for this mode was $44 \pm 2 \mathrm{~dB}(\mathrm{~A})$. Across the seasons and all IHPAC classrooms the HVAC system was in Stage 1 mode for $24 \% \pm 16 \%$ of the schoolday hours.

The IHPAC system was in the Stage 2 mode for only $13 \% \pm 6 \%$ of schoolday hours. The average measured background noise level for this mode of operation across IHPAC classrooms was $46 \pm 1.5 \mathrm{~dB}(\mathrm{~A})$.

Thus, the IHPAC met the background sound pressure level goal of $45 \mathrm{~dB}(\mathrm{~A})$ in both Fan only an Stage 1 modes. In Stage 2 mode, the system was on average slightly higher. However, on average this mode was only in use $13 \%$ of the time. If the noise level is normalized by the amount of HVAC operating time, the average sound pressure level experienced in the classroom is about $41 \mathrm{~dB}(\mathrm{~A})$. 


\section{Thermal Comfort, Indoor Temperature and Relative Humidity}

As discussed above, measurements of thermal environmental parameters seldom showed that the ASHRAE 55-defined thermal comfort level was rarely met in classrooms using either HVAC system. This is similar to the findings in another portable classroom study where TC parameters were measured (Apte et al. 2003). TC, as ASHRAE defines it has a narrow band of acceptable relative humidity and temperature. It is unclear that Standard 55 is relevant to elementary school students; children's metabolism and activity levels, and the frequency of changing of activities differ from those of adults; they also wear different levels and styles of clothing.

The acceptable ranges of operative temperature and relative humidity for the cooling season, based on ASHRAE Standard $55(1992,1995 \mathrm{a})$, are $22.5^{\circ} \mathrm{C}$ to $26.0^{\circ} \mathrm{C}$ and $30 \%$ to $60 \% \mathrm{RH}$, respectively. Likewise, for the heating season the ranges are $20.0^{\circ} \mathrm{C}$ to $23.5^{\circ} \mathrm{C}$ and $30 \%$ to $60 \%$ $\mathrm{RH}$, respectively.

In general, the indoor humidity levels measured in both types of classrooms were within the acceptable ranges during the TC cart measurements across all three seasons where the carts were used. Most often, when the TC criteria were unmet it was due to classroom temperature. It appears that the thermostat setpoint selected by the teachers in the IHPAC rooms tended to be slightly lower than those used in the 10 SEER classrooms. This combined with the much tighter thermal control provided by the IHPAC control system acted to keep the room temperature below ASHRAE 55 temperature bands. The relevance of this to actual student and teacher thermal comfort is uncertain.

\section{Energy Consumption}

As expected, due to the increased use of outside air ventilation by the IHPAC classrooms, measured daily energy consumption was with one exception (discussed below) greater than for the 10 SEER classrooms. Interpretation of this fact must be weighed against the fact that the State of California requires continuous ventilation that is supplied by the IHPAC by law (CEC 2001, CCR 1995). Thus, the appropriate comparison between the energy consumption of the 10 SEER and the IHPAC systems must be based on an equivalency of conditioned outside air delivered to the classroom. Since the 10 SEER classrooms studied were not in compliance with this requirement, for all of the reasons discussed above, it is necessary to use a modeling approach to explore the energy benefits of the IHPAC.

The one exception, where the IHPAC used less daily energy than the 10 SEER system, was during the summer in the Southern California schools. In this case the 10 SEER consumption was $6.6 \pm 3.2 \mathrm{kWh}$ per school day while the IHPAC consumed $6.2 \pm 1.8$ per day. The reason for this is that outdoor temperatures in the Southern climate zone were sufficiently extreme that HVAC was a necessity. Additionally, the cooling demand was sufficient to have high 10 SEER compressor use; consequently, more ventilation and therefore more outside air thermal conditioning was provided. In this case, the cost of that extra outside air conditioning is seen in higher daily energy consumption. This observation is evident from the delta $\mathrm{CO}_{2}$ data for the summer time period in the Southern California school district (Table 3) that typically had the lowest average and $99^{\text {th }}$ percentile values during this period. 


\section{Energy Modeling}

Calibration of the HVAC systems energy performance using DOE-2 proved to be very difficult. In retrospect, more detailed measurements of local weather conditions including wind speed and horizontal and total insolation would have been very useful. As it was, the closest available weather station data was not from locations sufficiently close to provide the temporal detail needed for hourly energy modeling. In addition, although daily attendance records were used in energy modeling, uncertainty in occupancy numbers and activities was problematic when trying to close energy load balances. A third problem was programming the appropriate hourly thermostat set points for the 10 SEER classrooms. Since the setting values were not monitored it was necessary to use hourly indoor temperature measurements to infer the thermostat setting.

Nonetheless, it was possible to identify sufficient numbers of days where modeling agreement with both measured indoor temperature and energy consumption data to show that the compressor and fan performance curves used in the models were correct.

Once the system calibrations were complete, application of the DOE-2 models to the typical meteorological conditions by climate zone in California was straightforward. The results of comparisons between the 10 SEER system with the assumption of continuous ventilation and the IHPAC show favorable energy savings of about $36 \%$ to $42 \%$ across California's climate zones.

Payback periods, even with a conservative modeled electricity cost of $\$ 0.15 / \mathrm{kWh}$, are reasonable but not exceptionally short. As expected, the climate zones with more extreme temperatures provide the fastest payback. Interestingly, the fast growing geographic regions of the State are inland with more extreme seasonal temperatures including the Central Valley (CZ 12, 13), the San Bernardino Valley and Riverside County (CZ 14) have the lowest payback periods of six to seven years. With rising cost of energy the payback period may drop to a few years in some climate zones.

\section{Market Connections}

The content of this report has been largely technical. However, a major goal of the project was to work towards bringing the energy and indoor environmental benefits of the improved HVAC technology to the market. The design of this study that hinged on collaboration with an industrial partner, Bard Manufacturing Co., and a marketing partner, Geary Pacific Supply Corporation, proved to be a successful model. From the beginning, management at these companies saw the benefit of combining a self-funded product development project with a technical specification being developed through CEC-PIER funded research despite the fact that the end product specification would be publicly available. A benefit to them was that their product would be rigorously tested with a degree of measurement and scientific scrutiny not typically applied to HVAC system development. This collaboration led to the manufacture of the ten IHPAC systems that were studied in this project.

The risk to the companies involved was fairly high because technical success would not necessarily translate into a marketing success. The HVAC market and the School Facilities market are both traditionally rather conservative and slow to adopt new technology. Thus, a product must have a compelling advantage to attract market share. In the case of this project, these advantages were increased energy efficiency, improved acoustical characteristics, and 
improved classroom air quality. Potential benefits included lower energy costs, and improved health and learning conditions for the classroom occupants.

The specification for the IHPAC system is not manufacturer specific, but is available through the Collaborative in High Performance Schools (CHPS 2006). This specification was developed and written at LBNL as part of this project and will now presumably used by all HVAC manufacturers with an interest in producing wall mount unitary HVAC systems for RCs.

A stakeholders workshop was held in Sacramento CA on March 9, 2007 to identify a means to promote the benefits of the IHPAC specification and to find support for development of a public utility product incentive to schools who purchase products meeting the specification. The meeting was well attended by stakeholders from the HVAC industry, School Facilities industry, major California school districts, California Energy Commission, California Air Resources Board, California Department of Health Services, Cal EPA, three California public utilities. One follow-up telephone conference was held about a month later. The outcome of this meeting was twofold. First, stakeholder awareness of the potential for saving energy and simultaneously improving the quality of the portable classroom environment was raised. Second, the public utilities went away with interest in developing a product incentive package for the school portable classroom market.

To date, no incentive package has been brought to the market. However, Pacific Gas and Electric has continued to work on the package development, and together with the California Public Utilities Commission is currently assessing the energy and non-energy benefits to the Company and ratepayers (Flood, 2008).

Finally, Bard Manufacturing and Geary Pacific Supply now markets the IHPAC as their premium portable classroom HVAC system under the product name Quiet Climate 2 (Bard 2007), and are now having major production runs of the IHPAC product, supplying their system to large school districts in California and in the Southeastern part of the U.S. (Derks, 2008)

\section{Conclusions}

An improved HVAC system for portable classrooms was specified to address key problems in existing units. These included low energy efficiency, poor control of and provision for adequate ventilation, and excessive acoustic noise. Working with industry, a prototype improved heat pump air conditioner was manufactured to meet the specification developed by this project. In this report we have presented the results of a year of field-testing of ten of these IHPAC systems in occupied classrooms in two distinct California climates that were manufactured in a limited production run. These results are compared to those of parallel measurements in side by side portable classrooms equipped with standard 10 SEER heat pump air conditioner equipment.

The IHPAC units were found to work as designed, providing predicted annual energy efficiency improvements of about $36 \%$ to $42 \%$ across California's climate zones, relative to 10 SEER units. Classroom ventilation was vastly improved as evidenced by far lower indoor minus outdoor $\mathrm{CO}_{2}$ concentrations. The IHPAC units were found to provide ventilation that meets both California State energy and occupational codes and the ASHRAE minimum ventilation requirements; the classrooms equipped with the 10 SEER equipment universally did not meet these targets. 
The IHPAC system provided a major improvement in indoor acoustic conditions. HVAC system generated background noise was reduced in fan only and fan and compressor modes, reducing the nose levels to better than the design objective of $45 \mathrm{~dB}(\mathrm{~A})$, and acceptable for additional design points by the Collaborative on High Performance Schools.

The IHPAC provided superior ventilation, with indoor minus outdoor $\mathrm{CO}_{2}$ concentrations that showed that the Title 24 minimum ventilation requirement of 15 CFM per occupant was nearly always being met. The opposite was found in the classrooms utilizing the 10 SEER system, were the indoor minus outdoor $\mathrm{CO}_{2}$ concentrations frequently exceeded levels that reflect inadequate ventilation.

The improved ventilation conditions in the IHPAC lead to effective removal of volatile organic compounds and aldehydes, on average lowering the concentrations by $57 \%$ relative to the levels in the 10 SEER classrooms. The average IHPAC to 10 SEER formaldehyde ratio was about $67 \%$, indicating only a $33 \%$ reduction of this compound in indoor air. Use of ventilation for formaldehyde removal is not as effective as it is for many VOCs because of the diffusion mechanisms that cause the compound to be emitted from composite wood products. This underscores the importance of choosing low formaldehyde emitting materials for use in classroom environments.

Indoor particulate matter concentrations in the classrooms were not changed by the IHPAC system relative to the 10 SEER systems. This was not surprising since the filtration supplied by both systems were relatively similar. Average ambient PM concentrations were higher than indoor levels during the study, suggesting that filtration and other particle removal mechanisms were at work. The fact that increased volume of outside air supplied to the IHPAC classrooms did not lead to higher particle levels indoors suggests that the 2 " pleated filters used in the IHPAC provided some additional particle removal benefit not afforded by the 1" standard filters typically provided for the relocatable classrooms.

The IHPAC thermal control system provided less variability in occupied classroom temperature than the 10 SEER thermostats. This is not surprising since the conditions were controlled by occupancy sensor rather than manually by a teacher. The average room temperatures tended to be slightly lower in the IHPAC classrooms, often below the lower limit of the ASHRAE 55 thermal comfort band. Calculated thermal comfort values indicate that neither 10 SEER or IHPAC classrooms provided conditions technically considered comfortable, and those in the IHPAC were slightly satisfying. However, the value of this observation is unclear - the control systems in both classroom types provided latitude in temperature control that would have allowed higher or lower temperatures suggesting that the ASHRAE 55 definition may not be appropriate for the classroom situation.

State-wide and national energy modeling provided conservative estimates of potential energy savings by use of the IHPAC system that would provide payback a the range of time far lower than the lifetime of the equipment. These models did not include the non-energy benefits to the classrooms including better air quality and acoustic conditions that could lead to improved health and learning in school. 
The market connection efforts that were part of the study give all indication that this has been a very successful project. The successes include the specification of the IHPAC equipment in the CHPS standards, the release of a commercial product based on the standards that is now being installed in schools around the U.S., and the fact that a public utility company is currently considering the addition of the technology to its customer incentive program. These successes indicate that the IHPAC may reach its potential to improve ventilation and save energy in classrooms.

\section{Acknowledgements}

This research was sponsored by the California Energy Commission through the Public Interest Energy Research program as the Lawrence Berkeley National Laboratory Classroom HVAC: Improving Ventilation and Saving Energy research project, CEC Contract Number 500-03-041. The study was additionally supported by the Assistant Secretary for Energy Efficiency and Renewable Energy, Building Technology Program of the U.S. Department of Energy under contract DE-AC02-05CH11231. We would like to thank Joe Huang and Fengxian Su for their contribution to the development of weather data input files for the DOE-2 models. We would also like to thank Agnes Lobscheid, Randy Maddalena, and William Fisk for their reviews and editorial comments on this report. We would like to thank the teachers and school staff in the four schools studied in this project. We would like to thank Echelon Corp. (San Jose, CA), Pure Choice Inc. (Burnsville, MN), and Continental Control Systems (Boulder CO) for their generous donations of equipment and expertise for the project. Thanks also go to Irv Derks and Jim Austermiller of Bard Manufacturing Company, and Maury Tiernan of Geary Pacific Supply, and others in these companies, provided a tremendous amount of time and effort in coordinating the industry collaboration side of this project. Finally we want to thank the project managers that patiently supported this research; Brad Meister and Martha Brook in the PIER Buildings Program at CEC and Terry Logee in the Building Technology Program at DOE.

\section{References}

AIHA. 1989. Odor Thresholds for Chemicals with Established Occupational Health Standards. Akron, Ohio: American Industrial Hygiene Association; Concentrations listed are detection thresholds

MG. Apte, D. Faulkner, AT. Hodgson, DP Sullivan. 2004. Classroom HVAC: Improving Ventilation and Saving Energy Field Study Plan, LBNL-56527, Lawrence Berkeley Laboratory, University of California, Berkeley, CA 94720.

Apte MG, Faulkner D, Hodgson AT., Fisk WJ., Hotchi T., Spears M., Sullivan DP., and Wang D.. 2005. Improving Ventilation and Saving Energy: Relocatable Classroom Field Study Interim Report, LBNL-58824, Lawrence Berkeley Laboratory, University of California, Berkeley, CA 94720.

Apte M.G., Dibartolomeo D., Hotchi T., Hodgson A.T., Lee S.M., Liff, S.M. Shendell D.G., Sullivan D.P., Fisk W.J., and Rainer LI. (2003) "Simultaneous Improvements In Relocatable Classrooms," ASHRAE IAQ Applications, Fall 2003: 7-10.

ASA 2002. "Acoustical Performance Criteria, Design Requirements, and Guidelines for Schools." 
ANSI S12.60-2002. Acoustical Society of America. Melville, NY 11747

ASHRAE. 2005. 2005 ASHARAE Handbook Fundamentals, Chapter 27 - Ventilation and Infiltration. Atlanta: American Society of Heating, Refrigerating and Air-Conditioning Engineers, Inc.

ASHRAE. 2004. ANSI/ASHRAE Standard 62.1-2004 Ventilation for Acceptable Indoor Air Quality. Atlanta: American Society of Heating, Refrigerating and Air-Conditioning Engineers, Inc.

ASHRAE 1995. ANSI/ASHRAE 55a-1995 ASHRAE standard, Addendum to Thermal Environmental Conditions for Human Occupancy, Atlanta: American Society of Heating, Refrigerating and Air-Conditioning Engineers, Inc.

ASHRAE, 1992. ANSI/ASHRAE 55-1992 ASHRAE standard, Thermal Environmental Conditions for Human Occupancy, Atlanta: American Society of Heating, Refrigerating and AirConditioning Engineers, Inc.

ASHRAE. 1992. Gravimetric and dust-spot procedures for testing air cleaning devices used in general ventilation for removing particulate matter, ANSI/ASHRAE Standard 52.1, American Society of Heating, Refrigerating, and Air Conditioning Engineers. Atlanta.

Bard Mfg (2007) “The Wall-Mount ${ }^{\mathrm{TM}}$ Heat Pumps - CH (60 HZ)," Product Specification S32102006_02, Bard Manufacturing Inc., Bryan, OH. www.bardhvac.com Quiet Climate 2

Bard Mfg (2006) "The Wall-Mount ${ }^{\mathrm{TM}}$ Heat Pumps - WH (60 HZ)," Product Specification S3210-2006_02, Bard Manufacturing Inc., Bryan, OH. www.bardhvac.com

Broadwin R. (2000). Development of and Uses of Health-based Exposure Levels for Indoor Air Contaminants. California Office of Environmental Health Hazard Assessment, Air Toxics and Epidemiology Section, Oakland, CA. Presented at 10th Annual Conference of the International Society of Exposure Analysis, October 24-27, Asilomar, CA.

Buhl, W.F., B. Birdsall, A.E. Erdem, K.L. Ellington, F.C. Winkelmann, and Hirsch \& Associates. 1993. DOE-2 SUPPLEMENT, VERSION 2.1e. LBL34947.

Cal/EPA/ARB. 2004. Formaldehyde in the Home, Indoor Air quality Guideline No. 1, California Environmental Protection Agency and California Air Resources Board, Sacramento, CA. http://www.arb.ca.gov/research/indoor/formaldGL08-04.pdf

Cal/EPA. 2003. Air Toxics “Hot Spots”' Program Risk Assessment Guidelines. Part III. Technical Support Document for the Determination of Chronic Reference Exposures Levels for Airborne Toxicants. Oakland, CA, Office of Environmental Health Hazard Assessment, Air Toxicology and Epidemiology Section, California Environmental Protection Agency, URL: http://www.oehha.org/air/chronic_rels/. 
Cal/EPA (1999) Air Toxics "Hot Spots" Program Risk Assessment Guidelines Part I: Technical Support Document for The Determination of Acute Reference Exposure Levels for Airborne Toxicants. Oakland, CA, Office of Environmental Health Hazard Assessment, Air Toxicology and Epidemiology Section, California Environmental Protection Agency, URL:

http://www.oehha.org/air/acute rels/index.html

CEC. 2001. California Building Standards, Title 24-Energy Efficiency, California Energy Commission, Sacramento CA, Part six.

CEC. 2004. Joint Appendices for the 2005 Building Energy Efficiency Standards For Residential and Nonresidential Buildings, California Energy Commission, Sacramento, CA. P400 -03 $001 J A F$

CCR. 1995. Occupational Safety and Health Codes for non-residential buildings, Title 8. California Code of Regulations, State of California, Sacramento.

CARB/DHS (2003) California portable classrooms study: project executive summary. California Air Resources Board and California Department of Health Services. http://www.arb.ca.gov/research/indoor/pcs/pcs-fr/pcs-fr_v3_pes.pdf

CHPS 2002. "HVAC Best Practices Manual," Collaborative on High Performance Schools, CHPS Inc. http://www.chps.net/manual/documents.htm

CHPS. 2006. CHPS Best Practices Manual VI Relocatable Classrooms. Collaborative on High Performance Schools. San Francisco CA. http://www.chps.net

Daisey J.M., Angell W.J., and Apte M.G.. 2003 "Indoor Air Quality, Ventilation and Health Symptoms in Schools: An Analysis of Existing Information," Indoor Air, 13(1):53-64.

Daisey, J and Angell, WJ. A Survey and Critical Review of the Literature on Indoor Air Quality, Ventilation, and Health Symptoms in Schools. Berkeley, CA: E.O. Lawrence Berkeley National Laboratory, Environmental Energy Technologies Division, Indoor Environment Department, March 1998. LBNL-41517

Derks, I. 2008. Personal telephone communication. Bard Manufacturing Co. Bryan OH. March.

Devos, M.; Patte, F.; Rouault, J.; Laffort P.; and Van Gemert, L.J., Editors. 1990. Standardized Human Olfactory Thresholds. New York, New York: Oxford University Press

Erdmann, C.A., Steiner, K.C,, Apte, M.G., (2002) "Indoor carbon dioxide concentrations and SBS symptoms in office buildings revisited: Analyses of the 100 building BASE Study dataset". Proceedings of Indoor Air 2002 Conference, Monterey, CA, Vol. 3, pp. 443-448. Indoor Air 2002, Santa Cruz, CA.

Flood R. (2008) Personal Communication, Richard Flood, Pacific Gas and Electric, San Francisco CA. February. 
Hodgson A. T., Shendell D. G., Fisk W. J. and Apte M. G. 2004. Comparison of predicted and derived measures of volatile organic compounds inside four new relocatable classrooms. Indoor Air 2004; 14 (Suppl 8): 135-144

Lagus Applied Technologies. 1995. Air Change Rates in Non-Residential Buildings in California. Report P400-91-034BCN, Prepared for the California Energy Commission by Lagus Applied Technology, Inc., San Diego, California.

LAUSD. 1998. "LAUSD Specifications for Air Conditioning Systems (Wall Mount Heat Pump). Specifications data 7/5/98." Los Angeles Unified School District, Los Angeles CA.

Lam R., Blaisdell R. and Marty M. A. 2004. "Interim Indoor Health Guidance Level For Formaldehyde," Abstract from the Proceedings of the Annual Meeting of the Society of Toxicology, March 24-25, Baltimore Maryland, The Toxicologist

Mudarri, D, Hall JD, and Werling E. 1996. Energy cost and IAQ performance of ventilation systems and controls. Proceedings of IAQ'96 Paths to Better Building Environments, pp 151160. ASHRAE, Atlanta, GA.

OEHHA. 2005. "All Chronic Reference Exposure Levels Adopted by OEHHA as of February 2005." Office of Environmental Health Hazard Assessment, Sacramento CA. http://www.oehha.ca.gov/air/chronic_rels/AllChrels.html

Rainer L.I., Hoeschele M.A., Apte M.G., Shendell D.G., and Fisk W.J. (2003) Energy Savings Estimates and Cost Benefit Calculations for High Performance Relocatable Classrooms, LBNL 54230, Lawrence Berkeley National Laboratory, University of California, Berkeley, CA 94720.

Shendell DG, Prill R, Fisk WJ, Apte MG, Blake D, Faulkner D (2004) Associations between classroom $\mathrm{CO}_{2}$ concentrations and student attendance. Indoor Air, 14 (3) 333-41.

Seppanen, O.A., Fisk, W.J., and Mendell, M.J. (1999) Association of ventilation rates and $\mathrm{CO}_{2}$ concentrations with health and other human responses in commercial and institutional buildings. Indoor Air 9: 226-252.

State of California. 1986. "Proposition 65, the Safe Drinking Water and Toxic Enforcement Act of 1986," Sacramento CA.

Tiernan M. (2006) Personal communication with Maury Tiernan, Geary Pacific Supply, Orange CA.

USEPA. 2005. "List of chronic hazardous air pollutants," Technology Transfer Network, Air Toxics Website. Washington DC. http://www.epa.gov/ttn/atw/toxsource/summary.html 
Wargocki P et al. (2002) Ventilation and health in non-industrial indoor environments: report from a European multidisciplinary scientific consensus meeting (EUROVEN). Indoor Air 12: 113-128. 


\section{Tables}

Table 1. The field study instrumentation

\begin{tabular}{|c|c|c|c|}
\hline $\begin{array}{c}\text { Parameters } \\
\text { Measured }\end{array}$ & Instrument & Calibration method & $\begin{array}{l}\text { Data collection rate/ } \\
\text { acquisition method }\end{array}$ \\
\hline $\begin{array}{l}\text { Air } \\
\text { temperature }\end{array}$ & $\begin{array}{l}\text { Onset Instrument, HOBO-Pro Series Temp Ext } \\
\text { C loggers with a resolution of } 0.02{ }^{\circ} \mathrm{C} \text { and rated } \\
\text { accuracy of } \pm 0.2{ }^{\circ} \mathrm{C}\end{array}$ & $\begin{array}{l}\text { NIST-traceable RTD system } \\
\text { with } 0.02{ }^{\circ} \mathrm{C} \text { rated accuracy }\end{array}$ & $\begin{array}{l}\text { Real-time, internal data } \\
\text { logger - download } \\
\text { monthly }\end{array}$ \\
\hline $\begin{array}{l}\text { Relative } \\
\text { humidity }\end{array}$ & $\begin{array}{l}\text { Onset Instrument } \mathrm{HOBO} \AA \text { Temperature, } \mathrm{RH} \subset \\
\text { with rated accuracy of } \pm 3 \% \mathrm{RH}\end{array}$ & $\begin{array}{l}\text { Use of salt solutions to } \\
\text { produce air with various } \\
\text { reference values of humidity }\end{array}$ & $\begin{array}{l}\text { Real-time, internal data } \\
\text { logger - download } \\
\text { monthly }\end{array}$ \\
\hline $\begin{array}{l}\text { Carbon } \\
\text { dioxide } \\
\text { concentration }\end{array}$ & $\begin{array}{l}\text { California Analytical Instruments infrared } \\
\text { analyzer, ZPF-9, 0-3000 ppm range }\end{array}$ & $\begin{array}{l}\text { Cylinders of primary standard } \\
\text { calibration gases }\end{array}$ & $\begin{array}{l}\text { Real-time - data logged } \\
\text { to i.Lon } 100 \text { web server, } \\
\text { acquired continuously }\end{array}$ \\
\hline $\begin{array}{l}\text { Air } \\
\text { Temperature, } \\
\text { Relative } \\
\text { Humidity, } \\
\text { Carbon } \\
\text { Dioxide }\left(\mathrm{CO}_{2}\right) \\
\end{array}$ & $\begin{array}{l}\text { PureChoice Nose } \mathrm{TM} \text {. Temperature (resolution } \\
0.1^{\circ} \mathrm{C} \text {, rated accuracy } \pm 0.5^{\circ} \mathrm{C} \text { ), } \mathrm{RH} \text { (resolution } \\
1 \% \mathrm{RH} \text {, rated accuracy larger of } \pm 10 \% \text { or } \pm 5 \% \\
\mathrm{RH} \text { ), } \mathrm{CO}_{2} \text { range } 0-5000 \mathrm{ppm} \text { (resolution } 10 \\
\text { ppm, accuracy greater of } \pm 5 \% \text { or } 100 \mathrm{ppm} \text { ). }\end{array}$ & NIST-traceable calibrations & $\begin{array}{l}\text { Real-time - data logged } \\
\text { to i.Lon } 100 \text { web server, } \\
\text { acquired continuously }\end{array}$ \\
\hline $\begin{array}{l}\text { Ventilation } \\
\text { rate }\end{array}$ & $\begin{array}{l}\text { Tracer gas decay during unoccupied time using } \\
\text { sulfur hexafluoride }\left(\mathrm{SF}_{6}\right) \text {, or carbon dioxide } \\
\text { tracer gas. Tracers monitored using infrared } \\
\text { analyzers }\end{array}$ & $\begin{array}{l}\text { Cylinders of primary standard } \\
\text { calibration gases }\end{array}$ & $\begin{array}{l}\text { Measured once a season } \\
\text { per RC during site visits. } \\
\text { Real-time data collected } \\
\text { on laptop computer }\end{array}$ \\
\hline $\begin{array}{l}\text { Particle } \\
\text { concentration, } \\
\text { size } \\
\text { distribution }\end{array}$ & $\begin{array}{l}\text { Optical particle counter (OPC) with } 6 \text { channels } \\
\text { for particle number size distribution }(\# \mathrm{~m}-3) \text {, } \\
\text { with size bins } 0.3,0.5,0.7,1,2 \text { and } 5 \mu \mathrm{m} \text { (Met } \\
\text { One, Model 237B) }\end{array}$ & $\begin{array}{l}\text { Factory calibration, and } \\
\text { intercomparison with other } \\
\text { aerosol instrumentation at } \\
\text { LBNL }\end{array}$ & $\begin{array}{l}\text { Measured once a season } \\
\text { per RC during site visits. } \\
\text { Real-time data collected } \\
\text { on laptop computer }\end{array}$ \\
\hline $\begin{array}{l}\text { Aldehyde } \\
\text { concentrations }\end{array}$ & $\begin{array}{l}\text { 7-hour aldehyde samples collected onto treated } \\
\text { silica-gel cartridges (WAT047205, Waters } \\
\text { Corp.) with sample flow rate of } 0.15 \mathrm{~L} / \mathrm{min} \text {. } \\
\text { Analysis by high performance liquid } \\
\text { chromatography with UV detection following } \\
\text { ASTM standard method D-5197-97 (ASTM, } \\
\text { 1997b). }\end{array}$ & $\begin{array}{l}\text { Sorbent tubes spiked with } \\
\text { known quantity of aldehydes }\end{array}$ & $\begin{array}{l}\text { Samples collected once a } \\
\text { season per RC during site } \\
\text { visits. Analyzed at } \\
\text { LBNL post sampling. }\end{array}$ \\
\hline $\begin{array}{l}\text { VOC } \\
\text { concentrations }\end{array}$ & $\begin{array}{l}\text { 7-hour VOC gas samples collected onto Tenax- } \\
\text { TA }^{\text {TM }} \text { sorbent tubes (CP-16251; Varian Inc.) } \\
\text { modified by substituting a } 15-\mathrm{mm} \text { section of } \\
\text { Carbosieve S-III } 60 / 80 \text { mesh }(10184 \text {, Supelco } \\
\text { Inc.) at the outlet end. Sample flow rate will be } \\
0.0051 / \text { min. VOC samples analyzed by thermal } \\
\text { desorption-gas chromatography/mass } \\
\text { spectrometry generally following U.S. EPA } \\
\text { Method TO-1 (U.S. EPA, 1984) }\end{array}$ & $\begin{array}{l}\text { Sorbent tubes spiked with } \\
\text { known quantity of VOCs }\end{array}$ & $\begin{array}{l}\text { Samples collected once a } \\
\text { season per RC during site } \\
\text { visits. Analyzed at } \\
\text { LBNL post sampling. }\end{array}$ \\
\hline $\begin{array}{l}\text { Ozone } \\
\text { concentrations }\end{array}$ & $\begin{array}{l}\text { 7-hour indoor and outdoor ozone passive } \\
\text { samplers (Ogawa 3300) with Ion } \\
\text { Chromatography (IC) analysis by IML Inc., } \\
\text { Sheridan WY. }\end{array}$ & $\begin{array}{l}\text { Nitrite to nitrate chemistry. } \\
\text { Nitrate standards used to } \\
\text { calibrate IC. }\end{array}$ & $\begin{array}{l}\text { Samples collected once a } \\
\text { season per RC during site } \\
\text { visits. Analyzed at IML } \\
\text { post sampling. }\end{array}$ \\
\hline Sound levels & $\begin{array}{l}\text { Sound spectrum meter for } \sim 6 \text { to } 20 \mathrm{~Hz} \text { spectrum } \\
\text { such as the Bruel and Kjaer model } 2260\end{array}$ & Factory calibration & $\begin{array}{l}\text { Measured once a } \\
\text { season/RC during site } \\
\text { visits, collected on laptop } \\
\text { computer }\end{array}$ \\
\hline $\begin{array}{l}\text { Power } \\
\text { Monitoring }\end{array}$ & $\begin{array}{l}\text { WattNode }{ }^{\mathrm{TM}} \text { datalogging line power monitor } \\
\text { measures true RMS power and energy } \\
\text { consumption- logged continuously. Current } \\
\text { measured with inductive current transducers } \\
\text { simultaneously with line voltage. Accuracy of } \\
\text { the WattNode }{ }^{\mathrm{TM}} \text { is } \pm 0.5 \% \text { of reading over } \\
\text { operating range. }\end{array}$ & Factory Calibration & $\begin{array}{l}\text { Real-time - data logged } \\
\text { to i.Lon } 100 \text { web server, } \\
\text { acquired continuously }\end{array}$ \\
\hline $\begin{array}{l}\text { Thermal } \\
\text { Comfort }\end{array}$ & $\begin{array}{l}\text { LBNL Thermal Comfort Cart. ASHRAE } \\
\text { Standard 55-2004. Measures air temperature, } \\
\text { mean radiant temperature, relative humidity, and } \\
\text { air velocity. }\end{array}$ & $\begin{array}{l}\text { Factory Calibration and } \\
\text { Calibration checks using } \\
\text { NIST-traceable methods }\end{array}$ & $\begin{array}{l}\text { Integrated datalogger } \\
\text { downloaded after } \\
\text { collection }\end{array}$ \\
\hline
\end{tabular}


Table 2. $\mathrm{CO}_{2}$ Concentrations in Northern California Classrooms. ${ }^{1}$

\begin{tabular}{|c|c|c|c|c|c|c|c|}
\hline & & Delta CC & )$_{2}(p p r$ & & Outdoor & $\mathrm{O}_{2}(\mathrm{p}$ & \\
\hline Site & Room Season & Avg (Stdev) & 1 st \% & 9th \% & Avg (Stdev) & st $\%$ & th \% \\
\hline N1 & $21 \mathrm{All}$ & $300(440)$ & 0 & 2200 & $360(50)$ & 330 & 440 \\
\hline & Spring '05 & $570(740)$ & 0 & 2700 & $370(90)$ & 340 & 470 \\
\hline & Summer '05 & $280(400)$ & 0 & 2400 & $350(40)$ & 330 & 380 \\
\hline & Fall '05 & $260(330)$ & 0 & 1400 & $370(20)$ & 340 & 450 \\
\hline & Winter '05 & $240(320)$ & 0 & 1300 & $370(40)$ & 350 & 410 \\
\hline & 22 All & $240(210)$ & -10 & 690 & & & \\
\hline & Winter '04 & $230(200)$ & -10 & 650 & & & \\
\hline & Spring '05 & $150(130)$ & -10 & 380 & & & \\
\hline & Summer '05 & $260(200)$ & -10 & 650 & & & \\
\hline & Fall '05 & $340(240)$ & 0 & 760 & & & \\
\hline & Winter '05 & $180(210)$ & 0 & 640 & & & \\
\hline & 23 All & $1000(870)$ & 0 & 3300 & 360 (110) & 310 & 420 \\
\hline & Winter '04 & $1100(800)$ & 0 & 2600 & $350(110)$ & 320 & 390 \\
\hline & Spring '05 & $1000(670)$ & 0 & 2500 & $360(140)$ & 330 & 380 \\
\hline & Summer '05 & $890(670)$ & -10 & 2400 & $340(90)$ & 290 & 350 \\
\hline & Fall '05 & $1300(960)$ & 10 & 3400 & $370(30)$ & 330 & 430 \\
\hline & Winter '05 & 810 (1100) & 0 & 3700 & $390(160)$ & 350 & 410 \\
\hline & 24 All & $290(230)$ & 0 & 830 & $350(30)$ & 320 & 420 \\
\hline & Spring '05 & $300(200)$ & -10 & 670 & $350(40)$ & 330 & 360 \\
\hline & Summer '05 & $280(240)$ & -10 & 950 & $340(30)$ & 320 & 350 \\
\hline & Fall '05 & $330(210)$ & 10 & 710 & $360(40)$ & 340 & 420 \\
\hline & Winter '05 & $250(240)$ & 0 & 700 & $360(30)$ & 340 & 390 \\
\hline N2 & 25 All & $120(130)$ & 0 & 430 & & & \\
\hline & Winter '04 & $210(160)$ & 0 & 550 & & & \\
\hline & Spring '05 & $120(120)$ & 0 & 380 & & & \\
\hline & Summer '05 & $42(78)$ & 0 & 300 & & & \\
\hline & Fall '05 & $150(130)$ & 10 & 470 & & & \\
\hline & Winter '05 & $120(120)$ & 0 & 470 & & & \\
\hline & 26 All & $760(760)$ & 0 & 2400 & $350(70)$ & 320 & 420 \\
\hline & Winter '04 & $1400(680)$ & 10 & 2500 & $390(120)$ & 350 & 420 \\
\hline & Spring '05 & $810(760)$ & 0 & 2500 & $350(10)$ & 330 & 380 \\
\hline & Summer '05 & $190(390)$ & -10 & 1700 & $330(30)$ & 320 & 360 \\
\hline & Fall '05 & $960(670)$ & 30 & 2400 & $340(110)$ & 330 & 360 \\
\hline & Winter '05 & $770(760)$ & 0 & 2300 & $360(10)$ & 340 & 370 \\
\hline
\end{tabular}

${ }^{\mathrm{T}}$ Rooms 22, 24, and 25 were intervention classrooms and Rooms 21, 23, and 26 were control classrooms. 
Table 3. $\mathrm{CO}_{2}$ Concentrations in Southern California Classrooms ${ }^{1}$.

\begin{tabular}{|c|c|c|c|c|c|c|c|}
\hline \multirow{2}{*}{$\frac{\text { Site }}{\text { S1 }}$} & \multirow{2}{*}{$\frac{\text { Room Season }}{35 \text { All }}$} & \multicolumn{3}{|c|}{$\begin{array}{c}\text { Delta } \mathrm{CO}_{2} \text { (ppm) } \\
\text { Avg (Stdev) 1st \% 99th \% }\end{array}$} & \multicolumn{3}{|c|}{$\begin{array}{c}\text { Outdoor } \mathrm{CO}_{2} \quad(\mathrm{ppm}) \\
\text { Avg (Stdev) } 1 \text { st } \% \text { 99th \% }\end{array}$} \\
\hline & & $240(360)$ & -20 & 1600 & & & \\
\hline & Winter '04 & $320(250)$ & -10 & 820 & & & \\
\hline & Spring '05 & $490(530)$ & -10 & 1700 & & & \\
\hline & Summer '05 & $180(350)$ & -20 & 1700 & & & \\
\hline & Fall '05 & $110(130)$ & -10 & 440 & & & \\
\hline & Winter '05 & $90(110)$ & 0 & 380 & & & \\
\hline & 36 All & $240(400)$ & -20 & 1900 & $380(50)$ & 340 & 480 \\
\hline & Winter '04 & $240(350)$ & -10 & 2000 & $380(30)$ & 350 & 440 \\
\hline & Spring '05 & $360(490)$ & -30 & 2000 & $380(70)$ & 350 & 600 \\
\hline & Summer '05 & $190(380)$ & -20 & 1900 & $370(20)$ & 340 & 460 \\
\hline & Fall '05 & $230(440)$ & -20 & 2100 & $380(80)$ & 340 & 450 \\
\hline & Winter '05 & $140(230)$ & -10 & 1100 & $370(20)$ & 340 & 460 \\
\hline & 37 All & $150(170)$ & -30 & 660 & $380(110)$ & 260 & 810 \\
\hline & Winter '04 & $99(140)$ & -30 & 480 & $290(20)$ & 260 & 340 \\
\hline & Spring '05 & $200(180)$ & -10 & 730 & $340(20)$ & 300 & 370 \\
\hline & Summer '05 & $91(140)$ & -50 & 550 & $510(150)$ & 350 & 880 \\
\hline & Fall '05 & $170(180)$ & -10 & 700 & $360(30)$ & 330 & 410 \\
\hline & Winter '05 & $140(160)$ & -10 & 630 & $360(20)$ & 330 & 380 \\
\hline \multirow[t]{24}{*}{ S2 } & 13 All & $410(370)$ & -20 & 1600 & & & \\
\hline & Winter '04 & $560(570)$ & -20 & 3000 & & & \\
\hline & Spring '05 & $480(360)$ & -10 & 1500 & & & \\
\hline & Summer '05 & $340(260)$ & -10 & 820 & & & \\
\hline & Fall '05 & $320(240)$ & -20 & 810 & & & \\
\hline & Winter '05 & $290(300)$ & 0 & 920 & & & \\
\hline & 14 All & $970(890)$ & 0 & 3800 & $430(90)$ & 350 & 670 \\
\hline & Winter '04 & $1400(1100)$ & 30 & 4300 & 480 (180) & 360 & 810 \\
\hline & Spring '05 & $850(710)$ & 10 & 3400 & $420(60)$ & 360 & 570 \\
\hline & Summer '05 & $650(630)$ & 0 & 2600 & $420(50)$ & 350 & 520 \\
\hline & Fall '05 & $1300(840)$ & 10 & 3100 & $440(40)$ & 370 & 550 \\
\hline & Winter '05 & 990 (1100) & 0 & 3900 & $420(70)$ & 340 & 580 \\
\hline & 15 All & $320(250)$ & -10 & 830 & $390(40)$ & 340 & 510 \\
\hline & Winter '04 & $250(270)$ & -10 & 830 & $460(30)$ & 410 & 530 \\
\hline & Spring '05 & $350(250)$ & -10 & 840 & $380(30)$ & 340 & 430 \\
\hline & Summer '05 & $310(220)$ & 0 & 850 & $370(30)$ & 340 & 400 \\
\hline & Fall '05 & $380(230)$ & 0 & 840 & $360(10)$ & 340 & 400 \\
\hline & Winter '05 & $320(260)$ & 0 & 790 & $350(10)$ & 330 & 390 \\
\hline & $16 \mathrm{All}$ & $690(740)$ & 0 & 3500 & $380(70)$ & 340 & 440 \\
\hline & Winter '04 & 1100 (990) & 10 & 4300 & $410(50)$ & 370 & 710 \\
\hline & Spring '05 & 700 (710) & 10 & 3300 & 380 (100) & 350 & 410 \\
\hline & Summer '05 & $460(380)$ & 0 & 1800 & $370(40)$ & 340 & 390 \\
\hline & Fall '05 & $780(830)$ & 0 & 3300 & $360(10)$ & 340 & 410 \\
\hline & Winter '05 & $24(19)$ & 10 & 62 & $370(10)$ & 340 & 400 \\
\hline
\end{tabular}

${ }^{1}$ Rooms 35, 37, 13, and 15 were intervention classrooms and Rooms 36, 14, and 16 were control classrooms. 
Table 4. Outside Air Supply and Air Exchange Rates for Northern and Southern California 10 SEER HVAC systems ${ }^{1}$.

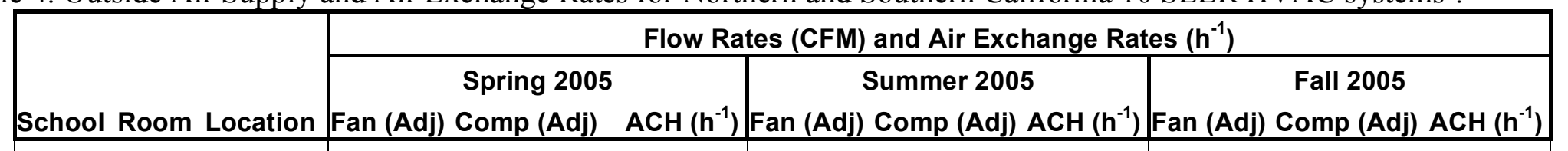

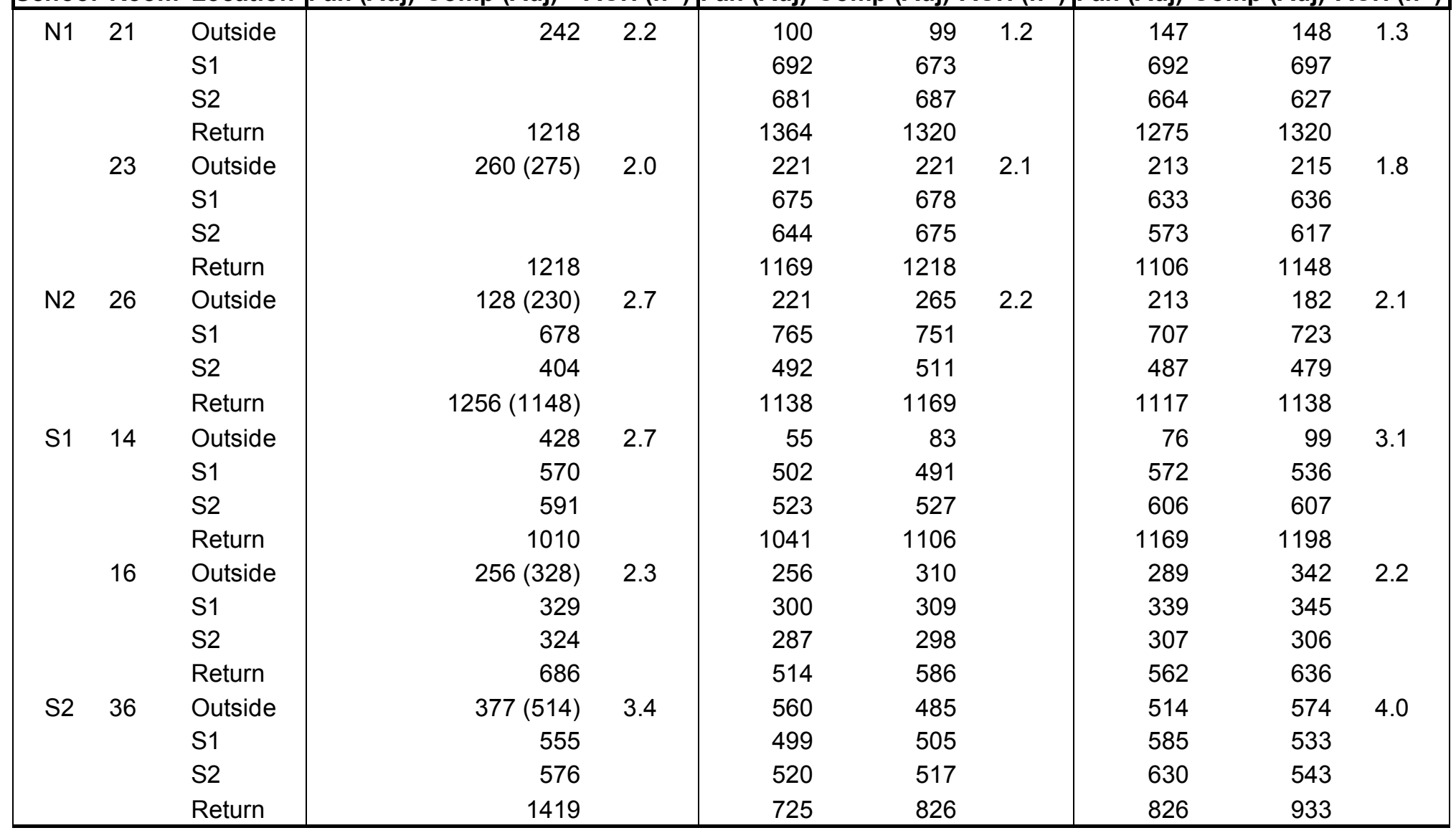

1 "Fan" refers to measured airflow rates with fan only, "Comp" refers to measured airflow rates with fan and compressor on. "Adj" refers to measurement after adjustment of flow rates. "ACH" refers to air exchange rates measured with fan on. 
Table 5. Outside Air Supply and Air Exchange Rates for Northern California IHPAC Systems ${ }^{1}$.

\begin{tabular}{|c|c|c|c|c|c|c|c|c|c|c|c|c|c|c|}
\hline \multirow[b]{3}{*}{ Schoo } & \multirow[b]{3}{*}{ Room } & \multirow[b]{3}{*}{ Location } & \multicolumn{12}{|c|}{ Flow Rates (CFM) and Air Exchange Rates $\left(h^{-1}\right)$} \\
\hline & & & \multicolumn{4}{|c|}{ Spring 2005} & \multicolumn{4}{|c|}{ Summer 2005} & \multicolumn{4}{|c|}{ Fall 2005} \\
\hline & & & Fan (Adj) & Stg1 (Adj) & $\operatorname{Stg} 2$ (Adj) A & $\mathrm{ACH}\left(\mathrm{h}^{-1}\right)$ & Fan (Adj) & Stg1 (Adj) & Stg2 (Adj) & $\mathrm{ACH}\left(\mathrm{h}^{-1}\right)$ & Fan (Adj) & Stg1 (Adj) S & Stg2 (Adj) & $\mathrm{ACH}\left(\mathrm{h}^{-1}\right)$ \\
\hline \multirow[t]{15}{*}{ N1 } & 20 & Outside & & & & & 476 & 448 & 509 & 2.5 & 461 & 450 & 460 & 2.4 \\
\hline & & S1 & & & & & 287 & 334 & 442 & & 297 & 332 & 452 & \\
\hline & & S2 & & & & & 278 & 339 & 462 & & 302 & 336 & 463 & \\
\hline & & S3 & & & & & 256 & 296 & 403 & & 259 & 302 & 409 & \\
\hline & & Return & & & & & 483 & 1041 & 1320 & & 446 & 883 & 1218 & \\
\hline & 22 & Outside & 483 & 497 & 487 & 3.3 & 456 & 428 & $384(452)$ & 2.3 & 406 (497) & $336(497)$ & 390 & 2.6 \\
\hline & & S1 & & & & & 288 & 340 & 400 & & 300 & 318 & 427 & \\
\hline & & $\mathrm{S} 2$ & & & & & 295 & 331 & 442 & & 310 & 318 & 427 & \\
\hline & & S3 & & & & & 295 & 328 & 419 & & 287 & 311 & 421 & \\
\hline & & Return & 530 & 262 & 1148 & & 534 & 1074 & 1218 & & 511 & 879 & 1198 & \\
\hline & 24 & Outside & 476 & 476 & 504 & 2.7 & 517 (465) & 450 & 474 & 3.9 & 450 & $426(481)$ & $440(463)$ & 3.0 \\
\hline & & S1 & & & & & 304 & 330 & 433 & & 304 & 344 & 441 & \\
\hline & & S2 & & & & & 260 & 281 & 381 & & 275 & 300 & 383 & \\
\hline & & S3 & & & & & 262 & 304 & 364 & & 253 & 279 & 374 & \\
\hline & & Return & 476 & 970 & 1237 & & 465 & 983 & 1208 & & 497 & 933 & 1256 & \\
\hline \multirow[t]{10}{*}{ N2 } & 25 & Outside & $487(476)$ & 994 (479) & $418(494)$ & 3.3 & 414 (494) & $393(472)$ & $408(481)$ & 2.9 & & 446 & 450 & 2.8 \\
\hline & & S1 & 271 & 313 & 305 & & 275 & 332 & 411 & & 275 & 317 & 415 & \\
\hline & & S2 & 311 & 350 & 453 & & 295 & 345 & 437 & & 287 & 347 & 451 & \\
\hline & & S3 & 269 & 304 & 398 & & 264 & 308 & 375 & & 261 & 309 & 391 & \\
\hline & & Return & 476 (469) & 994 (958) & $\begin{array}{r}1218 \\
\quad \quad(1189)\end{array}$ & & 375 & 549 & 1169 & & 461 & 1006 & 1237 & \\
\hline & 27 & Outside & $483(479)$ & 402 (487) & $434(479)$ & & 485 & 424 & $430(461)$ & 3.9 & 448 & 444 & 474 & 3.3 \\
\hline & & S1 & 325 & 385 & 5481 & & 319 & 360 & 464 & & 314 & 402 & 478 & \\
\hline & & $\mathrm{S} 2$ & 257 & 327 & 371 & & 254 & 285 & 400 & & 262 & 318 & 419 & \\
\hline & & S3 & 268 & 326 & $\begin{array}{r}405 \\
1431\end{array}$ & & 258 & 300 & 389 & & 252 & 327 & 404 & \\
\hline & & Return & $500(487)$ & $1148(1063)$ & (1346) & & 479 & 1018 & 1247 & & 321 & 1074 & 1329 & \\
\hline
\end{tabular}

\footnotetext{
"Fan" refers to measured airflow rates with fan only, "Stg1" and "Stg2" refer to measured airflow rates with fan and compressor on in stage
} 1 and stage 2, respectively. "Adj" refers to measurement after adjustment of flow rates. "ACH" refers to air exchange rates measured with fan on. 
Table 6. Outside Air Supply and Air Exchange Rates for Southern California IHPACs ${ }^{1}$.

\begin{tabular}{|c|c|c|c|c|c|c|c|c|c|c|c|c|c|}
\hline \multirow[b]{3}{*}{ School } & \multirow[b]{3}{*}{ Room } & \multirow[b]{3}{*}{ Location } & \multicolumn{11}{|c|}{ Flow Rates (CFM) and Air Exchange Rates $\left(\mathrm{h}^{-1}\right)$} \\
\hline & & & \multicolumn{4}{|c|}{ Spring 2005} & \multicolumn{3}{|c|}{ Summer 2005} & \multicolumn{4}{|c|}{ Fall 2005} \\
\hline & & & Fan (Adj) & Stg1 (Adj) & Stg2 (Adj) & $\mathrm{ACH}\left(\mathrm{h}^{-1}\right)$ & Fan (Adj) & Stg1 (Adj) & Stg2 (Adj) ACH $\left(h^{-1}\right)$ & Fan (Adj) & Stg1 (Adj) & Stg2 (Adj) & $\mathrm{ACH}\left(\mathrm{h}^{-1}\right)$ \\
\hline \multirow[t]{15}{*}{ S1 } & 13 & Outside & 481 & 492 & $538(476)$ & 2.8 & $436(496)$ & $416(487)$ & $416(490)$ & $553(464)$ & $572(500)$ & 644 (495) & 3.0 \\
\hline & & S1 & 339 & 345 & 472 & & 305 & $5 \quad 334$ & 439 & 304 & 341 & 451 & \\
\hline & & S2 & 268 & 281 & 364 & & 230 & 258 & 389 & 230 & 266 & 343 & \\
\hline & & S3 & 293 & 318 & 412 & & 265 & 295 & 391 & 278 & 293 & 384 & \\
\hline & & Return & 740 & 1041 & 1329 & & 639 & 970 & 1198 & 617 & 828 & 1138 & \\
\hline & 15 & Outside & $546(485)$ & 500 & $535(485)$ & 3.2 & $428(478)$ & 454 & $444(474)$ & 465 & 465 & $516(490)$ & 3.2 \\
\hline & & S1 & 268 & 278 & 389 & & 246 & 267 & 361 & 249 & 306 & 369 & \\
\hline & & S2 & 299 & 310 & 428 & & 264 & 302 & 411 & 281 & 315 & 424 & \\
\hline & & S3 & 278 & 304 & 410 & & 249 & 278 & 371 & 257 & 305 & 375 & \\
\hline & & Return & 752 & 1063 & 1381 & & 664 & 994 & 1247 & 634 & 958 & 1256 & \\
\hline & 17 & Outside & 487 & 465 & 477 & 3.8 & 469 & 490 & 487 & $540(536)$ & 444 & 448 & 3.5 \\
\hline & & S1 & 339 & 387 & 502 & & 248 & 277 & 363 & & & & \\
\hline & & S2 & 358 & 389 & 505 & & 232 & 265 & 348 & & & & \\
\hline & & S3 & 321 & 373 & 476 & & 209 & 226 & 298 & & & & \\
\hline & & Return & 720 & 1046 & 1355 & & 676 & 1006 & 1293 & & & & \\
\hline \multirow[t]{10}{*}{ S2 } & 35 & Outside & $556(494)$ & 490 & $541(476)$ & 1.7 & 472 & 460 & $436(476)$ & 504 & $534(507)$ & $559(476)$ & 3.1 \\
\hline & & S1 & 252 & 281 & 380 & & 233 & 265 & 333 & 236 & 265 & 329 & \\
\hline & & $\mathrm{S} 2$ & 246 & 284 & 359 & & 233 & 265 & 348 & 231 & 272 & 346 & \\
\hline & & S3 & 313 & 339 & 452 & & 299 & 337 & 454 & 289 & 344 & 443 & \\
\hline & & Return & 624 & 1006 & 1289 & & 652 & 1018 & 1284 & 652 & 1018 & 1256 & \\
\hline & 37 & Outside & 514 & 502 & 513 & 4.2 & 487 & 455 & 472 & 511 & 479 & 494 & 4.0 \\
\hline & & S1 & 249 & 275 & 366 & & 216 & 254 & 317 & & & & \\
\hline & & S2 & 284 & 313 & 400 & & 254 & 298 & 395 & & & & \\
\hline & & S3 & 329 & 356 & 463 & & 298 & 321 & 437 & & & & \\
\hline & & Return & 584 & 1029 & 1265 & & 543 & 970 & 1198 & & & & \\
\hline
\end{tabular}

1 "Fan" refers to measured airflow rates with fan only, "Stg1" and "Stg2" refer to measured airflow rates with fan and compressor on in stage 1 and stage 2, respectively. "Adj" refers to measurement after adjustment of flow rates. "ACH" refers to air exchange rates measured with fan on. 
Table 7. Acoustic noise levels $(\mathrm{dB}(\mathrm{A}))$ in unoccupied northern and southern California 10 SEER classrooms measured centered on and 10 feet from return grille and 5 feet high.

\begin{tabular}{|c|c|c|c|c|c|c|c|c|c|}
\hline \multirow[b]{3}{*}{ School } & \multirow[b]{3}{*}{ Room } & \multicolumn{8}{|c|}{ A-Weighted noise levels $(\mathrm{dB}(\mathrm{A}))$} \\
\hline & & \multicolumn{2}{|c|}{ Spring } & \multicolumn{2}{|c|}{ Summer } & \multicolumn{2}{|c|}{ Fall } & \multicolumn{2}{|c|}{ Average (Stdev) } \\
\hline & & Fan & Fan+Comp. & Fan & Fan+Comp. & Fan & Fan+Comp. & Fan & Fan+Comp. \\
\hline $\mathrm{N} 1$ & 21 & 51.5 & 52.6 & - & - & 50.7 & 52.5 & $51.1(0.6)$ & $52.5(0.1)$ \\
\hline & 23 & - & - & 52.5 & 53.4 & 50.6 & 51.1 & $51.6(1.3)$ & $52.3(1.6)$ \\
\hline N2 & 26 & 54.6 & 56.6 & - & - & 50.2 & 52.7 & $52.4(3.2)$ & $54.6(2.7)$ \\
\hline S1 & 14 & 46.3 & 53.1 & 46.8 & 49.9 & 48.0 & 51.1 & $47.0(0.9)$ & $51.3(1.6)$ \\
\hline & 16 & 42.8 & 54.9 & 38.4 & 54.8 & 39.4 & 56.1 & $40.2(2.3)$ & $55.3(0.7)$ \\
\hline S2 & 36 & 46.9 & 52.9 & 44.5 & 55.6 & 46.6 & 54.1 & $46.0(1.3)$ & $54.2(1.4)$ \\
\hline
\end{tabular}

Table 8. Acoustic noise levels $(\mathrm{dB}(\mathrm{A}))$ in unoccupied northern and southern California IHPAC classrooms measured centered on and 10 feet from return grille and 5 feet high.

\begin{tabular}{|c|c|c|c|c|c|c|c|c|c|c|c|c|c|}
\hline \multirow[b]{2}{*}{ School } & \multirow[b]{2}{*}{ Room } & \multicolumn{12}{|c|}{ A-Weighted noise levels (dB(A)) } \\
\hline & & Fan & $\begin{array}{c}\text { Spring } \\
\text { Fan + } \\
\text { Stage1 }\end{array}$ & $\begin{array}{c}\text { Fan + } \\
\text { Stage2 }\end{array}$ & Fan & $\begin{array}{c}\text { Summer } \\
\text { Fan + } \\
\text { Stage1 }\end{array}$ & $\begin{array}{c}\text { Fan + } \\
\text { Stage2 }\end{array}$ & Fan & $\begin{array}{c}\text { Fall } \\
\text { Fan + } \\
\text { Stage1 }\end{array}$ & $\begin{array}{c}\text { Fan + } \\
\text { Stage2 }\end{array}$ & Fan & $\begin{array}{c}\text { /erage (Sto } \\
\text { Fan + } \\
\text { Stage1 } \\
\end{array}$ & $\begin{array}{l}\text { ev) } \\
\text { Fan + } \\
\text { Stage2 }\end{array}$ \\
\hline \multirow[t]{3}{*}{$\mathrm{N} 1$} & 20 & 40.5 & 45.5 & - & - & - & - & 41.0 & 43.9 & 44.0 & $40.8(0.3)$ & $44.7(1.1)$ & $44.0(-)$ \\
\hline & 22 & 39.9 & - & - & & - & - & 41.5 & 45.7 & 47.7 & $40.7(1.1)$ & $45.7(-)$ & $47.7(-)$ \\
\hline & 24 & - & - & - & 37.0 & 41.8 & 44.1 & 39.7 & 42.5 & 45.2 & $38.3(1.9)$ & $42.1(0.5)$ & $44.7(0.8)$ \\
\hline \multirow[t]{2}{*}{ N2 } & 25 & 39.7 & 42.5 & 46.4 & 40.8 & 43.4 & & 39.9 & 43.0 & 45.4 & $40.1(0.6)$ & $43.0(0.4)$ & $45.9(0.7)$ \\
\hline & 27 & - & - & - & - & - & - & 39.8 & 43.9 & 45.8 & $39.8(-)$ & $43.9(-)$ & $45.8(-)$ \\
\hline \multirow[t]{3}{*}{ S1 } & 13 & 38.4 & 43.6 & 48.6 & 37.6 & 42.2 & 47.2 & 38.6 & 37.6 & 45.6 & $38.2(0.6)$ & $41.1(3.2)$ & $47.1(1.5)$ \\
\hline & 15 & 38.6 & 43.5 & 46.8 & 38.3 & 44.5 & 47.0 & 38.7 & 47.2 & 48.3 & $38.5(0.2)$ & $45.1(1.9)$ & $47.4(0.8)$ \\
\hline & 17 & 40.6 & 45.4 & 47.5 & - & - & - & - & - & - & $40.6(-)$ & $45.4(-)$ & $47.5(-)$ \\
\hline \multirow[t]{2}{*}{$\mathrm{S} 2$} & 35 & 39.5 & 48.4 & 49.0 & 42.6 & 47.6 & 49.5 & 38.4 & 44.5 & 46.2 & $40.2(2.2)$ & $46.8(2.1)$ & $48.2(1.8)$ \\
\hline & 37 & 40.0 & 46.6 & 51.8 & 37.7 & 41.1 & 44.7 & 37.3 & 44.5 & 45.2 & $38.3(1.5)$ & $44.1(2.8)$ & $47.2(3.9)$ \\
\hline
\end{tabular}


Table 9. Acoustic noise levels $(\mathrm{dB}(\mathrm{A}))$ in unoccupied northern and southern California 10 SEER classrooms measured centered on and 10 feet from return grille and 5 feet high with background adjusted to $25 \mathrm{~dB}(\mathrm{~A})$.

\begin{tabular}{|c|c|c|c|c|c|c|c|c|c|}
\hline \multirow[b]{3}{*}{ School } & \multirow[b]{3}{*}{ Room } & \multicolumn{8}{|c|}{ A-Weighted noise levels $(\mathrm{dB}(\mathrm{A}))$} \\
\hline & & \multicolumn{2}{|c|}{ Spring } & \multicolumn{2}{|c|}{ Summer } & \multicolumn{2}{|c|}{ Fall } & \multicolumn{2}{|c|}{ Average (Stdev) } \\
\hline & & Fan & Fan+Comp. & Fan & Fan+Comp. & Fan & Fan+Comp. & Fan & Fan+Comp. \\
\hline N1 & 21 & 51.4 & 52.5 & - & - & 50.3 & 52.3 & $50.9(0.8)$ & $52.4(0.2)$ \\
\hline & 23 & - & - & 52.4 & 53.3 & 50.5 & 51.0 & $51.5(1.4)$ & $52.2(1.6)$ \\
\hline N2 & 26 & 54.5 & 56.5 & - & - & 50.1 & 52.7 & $52.3(3.1)$ & $54.6(2.7)$ \\
\hline S1 & 14 & 46.1 & 53.1 & 46.6 & 49.8 & 47.7 & 50.9 & $46.8(0.8)$ & $51.3(1.7)$ \\
\hline & 16 & 41.3 & 54.8 & 36.5 & 54.8 & 37.0 & 56.1 & $38.3(2.6)$ & $55.2(0.7)$ \\
\hline S2 & 36 & 46.4 & 52.8 & 43.8 & 55.6 & 46.5 & 54.1 & $45.6(1.5)$ & $54.2(1.4)$ \\
\hline
\end{tabular}

Table 10. Acoustic noise levels $(\mathrm{dB}(\mathrm{A}))$ in unoccupied northern and southern California IHPAC classrooms measured centered on and 10 feet from return grille and 5 feet high with background adjusted to $25 \mathrm{~dB}(\mathrm{~A})$.

\begin{tabular}{|c|c|c|c|c|c|c|c|c|c|c|c|c|c|}
\hline \multirow[b]{2}{*}{ School } & \multirow[b]{2}{*}{ Room } & \multicolumn{12}{|c|}{ A-Weighted noise levels (dB(A)) } \\
\hline & & Fan & $\begin{array}{c}\text { Spring } \\
\text { Fan + } \\
\text { Stage1 }\end{array}$ & $\begin{array}{c}\text { Fan + } \\
\text { Stage2 }\end{array}$ & Fan & $\begin{array}{c}\text { Summer } \\
\text { Fan + } \\
\text { Stage1 }\end{array}$ & $\begin{array}{c}\text { Fan + } \\
\text { Stage2 }\end{array}$ & Fan & $\begin{array}{c}\text { Fall } \\
\text { Fan + } \\
\text { Stage1 }\end{array}$ & $\begin{array}{c}\text { Fan + } \\
\text { Stage2 }\end{array}$ & Fan & $\begin{array}{c}\text { ferage (Sto } \\
\text { Fan + } \\
\text { Stage1 }\end{array}$ & $\begin{array}{l}\text { ev) } \\
\text { Fan + } \\
\text { Stage2 }\end{array}$ \\
\hline \multirow[t]{3}{*}{$\mathrm{N} 1$} & 20 & 39.1 & 45.1 & - & - & - & - & 40.1 & 43.5 & 43.6 & $39.6(0.7)$ & $44.3(1.2)$ & $43.6(-)$ \\
\hline & 22 & 37.5 & - & - & - & - & - & 39.4 & 45.1 & 47.2 & $38.4(1.3)$ & $45.1(-)$ & $47.2(-)$ \\
\hline & 24 & - & - & - & 34.8 & 41.2 & 43.7 & 37.9 & 41.6 & 44.8 & $36.3(2.2)$ & - & $44.3(0.8)$ \\
\hline \multirow[t]{2}{*}{ N2 } & 25 & 36.0 & 40.9 & 45.9 & 32.9 & 40.8 & - & 37.9 & 42.1 & 44.9 & $35.6(2.5)$ & $41.3(0.7)$ & $45.4(0.7)$ \\
\hline & 27 & - & - & - & - & - & - & 39.4 & 43.7 & 45.7 & $39.4(-)$ & $43.7(-)$ & $45.7(-)$ \\
\hline \multirow[t]{3}{*}{$\mathrm{S} 1$} & 13 & 38.0 & 43.5 & 48.6 & 35.5 & 41.6 & 47.0 & 38.2 & 37.0 & 45.5 & $37.2(1.5)$ & $40.7(3.4)$ & $47.0(1.6)$ \\
\hline & 15 & 38.0 & 43.3 & 46.7 & 36.7 & 44.1 & 46.8 & 37.9 & 47.1 & 48.2 & $37.5(0.7)$ & $45.1(1.9)$ & $47.4(0.8)$ \\
\hline & 17 & 37.8 & 44.7 & 47.0 & - & - & - & - & - & - & - & $45.4(-)$ & $47.5(-)$ \\
\hline \multirow[t]{2}{*}{$\mathrm{S} 2$} & 35 & 38.8 & 48.3 & 48.9 & 38.9 & 46.8 & 49.0 & 38.1 & 44.4 & 46.2 & $38.6(0.4)$ & $46.8(2.1)$ & $48.2(1.8)$ \\
\hline & 37 & 39.9 & 46.6 & 51.7 & 37.1 & 40.8 & 44.6 & 36.9 & 44.4 & 45.1 & $38.0(1.7)$ & $44.1(2.8)$ & $47.2(3.9)$ \\
\hline
\end{tabular}


Table 11. Selected toxic and odorous volatile organic compounds, their odor thresholds and chronic toxicity for the State of California's Proposition 65, CalEPA's Toxic Air Contaminant, and USEPA's Hazardous Air Pollutant listings.

\begin{tabular}{|c|c|c|c|c|c|c|}
\hline Compound & Class & $\begin{array}{l}\text { Odor } \\
\text { Threshold } \\
\left(\mu \mathrm{g} \mathrm{m}^{-3}\right)^{1}\end{array}$ & $\begin{array}{l}\text { Prop } 65 \\
\text { List }^{2}\end{array}$ & $\begin{array}{l}\text { CalEPA } \\
\text { Chronic }^{3}\end{array}$ & $\begin{array}{l}\text { Cal EPA } \\
\text { Chronic REL } \\
\left(\mu \mathrm{g} \mathrm{m}^{-3}\right)^{3}\end{array}$ & $\begin{array}{c}\text { EPA } \\
\text { Chronic } \\
\text { HAPs }^{4}\end{array}$ \\
\hline Ethylene glycol & Alcohol & 25000 & & + & 400 & + \\
\hline Phenol & Alcohol & 423 & & + & 200 & + \\
\hline 1,2,4-Trimethylbenzene & Aromatic & 736 & & & & \\
\hline Naphthalene & Aromatic & 200 & & + & 9 & + \\
\hline Toluene & Aromatic & 5830 & + & + & 300 & + \\
\hline m-Xylene & Aromatic & 1430 & & + & 700 & + \\
\hline 1,4-Dichlorobenzene & Halo-Carbon & 730 & + & & & \\
\hline Dichloromethane & Halo-Carbon & 96000 & + & + & 400 & \\
\hline Tetrachloroethene & Halo-Carbon & 3900 & & & & + \\
\hline 2-Butanone & Ketone & 23000 & & & & + \\
\hline 2-Propanone & Ketone & 33000 & & & & \\
\hline 4-Methyl-2-pentanone & Ketone & 3600 & & & & + \\
\hline 1-Methyl-2-pyrrolidinone & Nitro-cmp & & + & & & \\
\hline Caprolactam & Nitro-cmp & & & & & $+^{5}$ \\
\hline d-Limonene & Terpene & 2430 & & & & \\
\hline Octanal & Aldehyde & 7 & & & & \\
\hline Pentanal & Aldehyde & 2 & & & & \\
\hline Acetaldehyde & Aldehyde & 335 & + & + & 9 & + \\
\hline Formaldehyde & Aldehyde & 1070 & + & + & 3 & + \\
\hline $\begin{array}{l}+ \text { Signifies listing of compo } \\
{ }^{1} \text { Odor thresholds from Dev } \\
{ }^{2} \text { Proposition } 65 \text { list of air c } \\
{ }^{3} \text { Chronic Reference Expost } \\
{ }^{4} \text { US EPA Hazardous Air P }\end{array}$ & $\begin{array}{l}\text { in relevant doc } \\
\text { t al. } 1990 \text {, AIH } \\
\text { aminants known } \\
\text { Level list 2005, } \\
\text { tant list USEPA }\end{array}$ & $\begin{array}{l}1989 . \\
\text { to cause cance } \\
\text { OEHHA, } 200 \\
(2005)\end{array}$ & or reproc & tive toxic & rom State of $\mathrm{Ca}$ & ornia (1986 \\
\hline
\end{tabular}


Table 12 VOC Concentrations $\left(\mu \mathrm{g} \mathrm{m}^{-3}\right)$ for All Schools.

\begin{tabular}{|c|c|c|c|c|c|c|c|}
\hline \multirow[b]{3}{*}{ Compound } & \multicolumn{7}{|c|}{ Spring 2005} \\
\hline & \multicolumn{3}{|c|}{ IHPAC } & \multicolumn{3}{|c|}{10 SEER } & \multirow{2}{*}{$\begin{array}{l}\text { Outside Air } \\
\text { Avg (Stdev) }\end{array}$} \\
\hline & Avg (Stdev) & Min & $\operatorname{Max}$ & Avg (Stdev) & Min & Max & \\
\hline 1-Butanol & $4.4(6.2)$ & 0.53 & 315 & $4.2(2.1)$ & 1.4 & 6.6 & $6 \quad 0.5(0.0)$ \\
\hline 2-(2-Butoxyethoxy)ethanol & $13(13)$ & 4.0 & 35 & $19(14)$ & 4.5 & 38 & $0.0(0.0)$ \\
\hline 2-Butoxyethanol & $4.8(3.4)$ & 1.4 & 11 & $57(58)$ & 10.0 & 170 & $0.6(0.1)$ \\
\hline 2-Ethyl-1-hexanol & $1.2(0.69)$ & 0.53 & 2.4 & $2.4(1.0)$ & 1.4 & 3.6 & $1.6(0.0)$ \\
\hline 2-Propanol & $15(20)$ & 1.3 & 344 & $25(48)$ & 1.3 & 120 & $1.6(0.4)$ \\
\hline $\mathrm{BHT}$ & $0.39(0.18)$ & 0.26 & 0.66 & $1.4(1.5)$ & 0.26 & 4.1 & $0.4(0.0)$ \\
\hline $\mathrm{DPGME}^{1}$ & $4.5(4.4)$ & 1.6 & 10 & $13(18)$ & 1.5 & 40 & $0.0(0.0)$ \\
\hline Ethanol & $5.5(7.5)$ & 0.0 & 190 & $9.5(8.5)$ & 27 & 240 & $8.8(10)$ \\
\hline Ethylene glycol & $13(1.0)$ & 12 & 2. 14 & & & & \\
\hline Phenol & $2.1(1.4)$ & 0.39 & 4.2 & $6.0(8.0)$ & 1.6 & 22 & $7.1(4.5)$ \\
\hline Propylene glycol & $17(8.9)$ & 10 & 29 & $21(21)$ & 2.7 & 55 & $0.0(0.0)$ \\
\hline Benzaldehyde & $2.0(1.3)$ & 0.40 & 3.8 & $3.5(1.1)$ & 2.2 & 4.9 & $27(18)$ \\
\hline Hexanal & $4.1(2.4)$ & 2.0 & 8.7 & $11(5.2)$ & 2.9 & 18 & $0.4(0.6)$ \\
\hline Octanal & $2.4(1.2)$ & 1.1 & 4.5 & $4.9(2.2)$ & 3.1 & 7.9 & $1.0(1.2)$ \\
\hline Pentanal & $1.4(1.1)$ & 0.27 & 3.3 & $3.5(1.9)$ & 1.3 & 6.0 & $0.2(0.3)$ \\
\hline n-Decane & $0.28(0.01)$ & 0.27 & 0.29 & $0.55(0.17)$ & 0.26 & 0.67 & $0.3(0.0)$ \\
\hline n-Dodecane & $0.41(0.25)$ & 0.26 & 0.70 & $2.7(2.6)$ & 0.68 & 5.6 & $0.2(0.0)$ \\
\hline n-Nonane & $0.27(0.01)$ & 0.25 & 0.29 & $0.35(0.10)$ & 0.26 & 0.47 & $0.4(0.1)$ \\
\hline $\mathrm{n}$-Undecane & $0.43(0.21)$ & 0.25 & 0.68 & $1.0(0.84)$ & 0.26 & 2.2 & $0.3(0.0)$ \\
\hline 1,2,4-Trimethylbenzene & $0.36(0.20)$ & 0.26 & 0.77 & $0.64(0.40)$ & 0.27 & 1.4 & $0.2(0.2)$ \\
\hline $\mathrm{m}$-Xylene & $1.3(0.79)$ & 0.64 & 2.8 & $2.1(0.49)$ & 1.5 & 2.7 & $1.0(0.6)$ \\
\hline Naphthalene & $0.27(0.01)$ & 0.26 & 0.29 & $0.33(0.15)$ & 0.26 & 0.63 & $0.3(0.0)$ \\
\hline Toluene & $3.4(1.8)$ & 1.2 & 6.0 & $6.5(4.8)$ & 2.0 & 16 & $2.5(1.8)$ \\
\hline Butyl acetate & $5.8(6.3)$ & 0.90 & 16 & $43(97)$ & 0.92 & 240 & $0.7(0.3)$ \\
\hline TMPD-DIB ${ }^{1}$ & $3.7(2.5)$ & 1.5 & 8.0 & $5.0(1.3)$ & 2.9 & 6.6 & $0.3(0.0)$ \\
\hline TMPD-MIB $^{1}$ & $5.1(2.2)$ & 3.3 & 9.2 & $9.9(5.3)$ & 3.9 & 18 & $0.0(0.0)$ \\
\hline 1,4-Dichlorober & $1.6(1.9)$ & 0.39 & 5.5 & $5.9(6.3)$ & 0.27 & 17 & $0.3(0.0)$ \\
\hline Dichloromethane & $1.9(1.1)$ & 1.2 & 3.6 & $2.8(2.0)$ & 1.3 & 6.1 & $1.5(0.4)$ \\
\hline Tetrachloroethene & $0.27(0.01)$ & 0.26 & 0.29 & $0.62(0.72)$ & 0.25 & 2.1 & $0.3(0.1)$ \\
\hline 2-Butanone & $1.2(0.54)$ & 0.51 & 1.8 & $1.7(0.48)$ & 1.2 & 2.2 & $1.2(0.7)$ \\
\hline 2-Propanone & $5.7(7.5)$ & 0.0 & 15 & $9.4(11)$ & -1.9 & 28 & $-1.8(2.1)$ \\
\hline 4-Methyl-2-pentanone & $1.3(1.1)$ & 1.0 & 29 & $7.4(17)$ & 0.67 & 430 & $1.1(0.7)$ \\
\hline Acetophenone & $1.4(1.3)$ & -0.17 & 3.0 & $2.1(1.6)$ & 0.59 & 4.7 & $21(16)$ \\
\hline Benzothiazole & $0.63(0.47)$ & 0.0 & 1.3 & $1.2(0.40)$ & 0.77 & 2.0 & $0.1(0.2)$ \\
\hline D5 Siloxane & $2.2(1.3)$ & 7.1 & 38 & $2.9(2.8)$ & 7.6 & 60 & $0.6(0.6)$ \\
\hline 1-Methyl-2-pyrrolidinone & $0.28(0.01)$ & 0.27 & 0.29 & $3.5(6.7)$ & 0.26 & 16 & $0.0(0.0)$ \\
\hline Caprolactam & $1.5(1.4)$ & 0.53 & 4.1 & $1.7(0.97)$ & 0.54 & 2.9 & $0.0(0.0)$ \\
\hline d-Limonene & $5.6(10)$ & 0.81 & 26 & $9.3(12)$ & 0.77 & 34 & $0.0(0.0)$ \\
\hline Acetaldehyde & $4.4(2.6)$ & 1.1 & 9.1 & $9.3(5.3)$ & 5.0 & 16 & $2.1(1.3)$ \\
\hline Formaldehyde & $16(11)$ & 7.4 & 38 & $22(5.7)$ & 15 & 28 & $2.0(0.8)$ \\
\hline
\end{tabular}

${ }^{1}$ TMPD-MIB $=2,2,4$-trimethyl-1,3-pentanediol monoisobutyrate; TMPD-DIB $=$ 2,2,4-trimethyl-1,3-pentanediol diisobutyrate DPGE $=$ Dipropylene glycol monomethyl ether 
Table 13. Summer sampling VOC Concentrations $\left(\mu \mathrm{g} \mathrm{m}^{-3}\right)$ for All Schools.

\begin{tabular}{|c|c|c|c|c|c|c|c|}
\hline \multirow[b]{3}{*}{ Compound } & \multicolumn{7}{|c|}{ Summer 2005} \\
\hline & \multicolumn{3}{|c|}{ IHPAC } & \multicolumn{3}{|c|}{10 SEER } & \multirow{2}{*}{$\begin{array}{l}\text { Outside Air } \\
\text { Avg.(Stdev) }\end{array}$} \\
\hline & Avg (Stdev) & Min & $\operatorname{Max}$ & Avg (Stdev) & Min & Max & \\
\hline 1-Butanol & $2.6(2.0)$ & 0.57 & 6.2 & $5.9(3.1)$ & 3.1 & 12 & \\
\hline 2-(2-Butoxyethoxy)ethanol & $4.2(0.16)$ & 4.0 & 4.4 & $7.5(4.2)$ & 4.2 & 13 & \\
\hline 2-Butoxyethanol & $7.0(5.7)$ & 2.6 & 17 & $24(24)$ & 4.1 & 67 & $1.2(0.5)$ \\
\hline 2-Ethyl-1-hexanol & $0.86(0.49)$ & 0.57 & 1.8 & $2.1(1.0)$ & 0.56 & 3.4 & $0.6(0.0)$ \\
\hline 2-Propanol & $1.4(1.6)$ & 0.0 & 4.0 & $14(19)$ & 0.0 & 48 & $0.5(0.8)$ \\
\hline $\mathrm{BHT}$ & $0.47(0.48)$ & 0.26 & 1.5 & $0.70(0.56)$ & 0.28 & 1.7 & $0.3(---)$ \\
\hline DPGME & $4.1(4.6)$ & 1.6 & 13 & $7.4(14)$ & 1.6 & 36 & \\
\hline Ethanol & $1.3(0.45)$ & 6.4 & 19 & $54(91)$ & & 2300 & $6(7.3)$ \\
\hline \multicolumn{8}{|l|}{ Ethylene glycol } \\
\hline Phenol & $3.3(2.3)$ & 0.0 & 6.3 & $5.9(3.0)$ & 3.1 & 9.7 & $4.0(2.3)$ \\
\hline Propylene glycol & & & & $4.5(3.0)$ & 2.7 & 8.0 & \\
\hline Benzaldehyde & $5.0(2.9)$ & 2.2 & 8.7 & $6.9(2.2)$ & 3.8 & 9.7 & $17(8.6)$ \\
\hline Hexanal & $2.4(4.2)$ & -1.5 & 7.7 & $7.9(7.5)$ & -2.4 & 16 & $-1.0(2.1)$ \\
\hline Octanal & $1.7(0.33)$ & 1.2 & 2.0 & $3.8(2.8)$ & 0.20 & 8.2 & $1.6(0.9)$ \\
\hline Pentanal & $0.00(0.93)$ & -0.85 & 1.3 & $1.5(1.3)$ & -0.83 & 2.8 & $-0.4(0.8)$ \\
\hline n-Decane & $-0.61(0.60)$ & -1.2 & 0.01 & $0.33(0.98)$ & -1.2 & 1.5 & $-0.5(0.6)$ \\
\hline n-Dodecane & $0.12(0.51)$ & -0.52 & 0.60 & $3.4(3.0)$ & 0.63 & 8.2 & $1.0(1.3)$ \\
\hline n-Nonane & $0.62(0.36)$ & 0.28 & 1.1 & $0.60(0.29)$ & 0.27 & 1.0 & $0.4(0.1)$ \\
\hline n-Undecane & $0.52(0.22)$ & 0.28 & 0.82 & $2.0(1.9)$ & 0.75 & 5.8 & $0.7(---)$ \\
\hline 1,2,4-Trimethylbenzene & $1.0(0.78)$ & 0.28 & 1.8 & $1.2(0.71)$ & 0.28 & 2.1 & $1.2(0.8)$ \\
\hline m-Xylene & $3.8(2.9)$ & 0.87 & 6.6 & $4.2(2.5)$ & 1.5 & 7.7 & $4.2(3.4)$ \\
\hline Naphthalene & $0.0(0.0)$ & 0.0 & 0.0 & $0.45(0.90)$ & 0.0 & 2.3 & $0.0(---)$ \\
\hline Toluene & $11(8.4)$ & 1.7 & 20 & $16(7.3)$ & 5.8 & 23 & $29(32)$ \\
\hline Butyl acetate & $8.1(13)$ & 0.83 & 33 & $1.5(0.92)$ & 0.78 & 3.2 & $0.6(0.3)$ \\
\hline TMPD-DIB ${ }^{1}$ & $3.6(3.6)$ & 2.0 & 11 & $6.1(2.8)$ & 2.9 & 9.7 & $0.1(0.2)$ \\
\hline TMPD-MIB ${ }^{1}$ & $2.7(0.78)$ & 1.6 & 4.0 & $5.5(4.3)$ & 1.9 & 12 & $0.6(0.0)$ \\
\hline 1,4-Dichlorobenzene & $0.88(0.28)$ & 0.57 & 1.3 & $3.0(4.6)$ & 0.28 & 12 & $0.3(0.0)$ \\
\hline Dichloromethane & $-2.8(2.6)$ & -5.0 & 0.0 & $-2.4(2.7)$ & -5.0 & 0.0 & $-3.4(2.9)$ \\
\hline Tetrachloroethene & $0.44(0.24)$ & 0.28 & 0.77 & $0.78(0.63)$ & 0.27 & 1.7 & $0.5(0.3)$ \\
\hline 2-Butanone & $3.3(3.0)$ & 0.57 & 6.1 & $3.2(2.6)$ & 0.57 & 6.7 & $2.9(2.0)$ \\
\hline 2-Propanone & $-4.6(9.4)$ & -19 & 4.6 & $16(32)$ & -15 & 56 & $1.0(12)$ \\
\hline 4-Methyl-2-pentanone & $15(26)$ & 0.80 & 68 & $1.8(1.9)$ & 0.80 & 5.7 & $0.6(0.3)$ \\
\hline Acetophenone & $1.2(0.37)$ & 0.69 & 1.8 & $2.5(1.1)$ & 1.0 & 3.9 & $10.5(5.2)$ \\
\hline Benzothiazole & $0.79(0.69)$ & 0.0 & 1.9 & $1.8(1.1)$ & 1.0 & 3.2 & ) \\
\hline D5 Siloxane & $5.2(3.6)$ & 12 & 115 & $3.7(3.8)$ & 3.8 & 110 & $1.7(1.5)$ \\
\hline 1-Methyl-2-pyrrolidinone & $0.28(0.01)$ & 0.26 & 0.29 & $2.7(5.7)$ & 0.27 & 14 & \\
\hline Caprolactam & $1.1(0.83)$ & 0.53 & 2.5 & $1.5(0.79)$ & 0.57 & 2.4 & \\
\hline d-Limonene & $2.1(2.1)$ & 0.79 & 6.0 & $12(19)$ & 0.97 & 49 & $0.3(0.0)$ \\
\hline Acetaldehyde & $7.9(3.2)$ & 4.9 & 12 & $13(4.8)$ & 7.5 & 19 & $7.3(2.6)$ \\
\hline Formaldehyde & $18(7.7)$ & 10 & 27 & $26(5.0)$ & 21 & 33 & 7.4(4.3) \\
\hline
\end{tabular}


Table 14. Fall Sampling VOC Concentrations $\left(\mu \mathrm{g} \mathrm{m}^{-3}\right)$ for All Schools.

\begin{tabular}{|c|c|c|c|c|c|c|c|}
\hline \multirow[b]{3}{*}{ Compound } & \multicolumn{7}{|c|}{ Fall 2005} \\
\hline & \multicolumn{3}{|c|}{ IHPAC } & \multicolumn{3}{|c|}{10 SEER } & \multirow{2}{*}{$\begin{array}{l}\text { Outside Air } \\
\text { Avg.(Stdev) }\end{array}$} \\
\hline & Avg (Stdev) & Min & $\operatorname{Max}$ & Avg (Stdev) & Min & Max & \\
\hline 1-Butanol & $2.6(3.8)$ & 0.56 & 10 & $4.9(7.7)$ & 0.59 & 20 & \\
\hline 2-(2-Butoxyethoxy)ethanol & $4.4(0.09)$ & ) 4.3 & 4.5 & $7.3(3.6)$ & 4.0 & 10 & \\
\hline 2-Butoxyethanol & $22(43)$ & 2.2 & 110 & $16(10)$ & 2.2 & 33 & $0.6(0.0)$ \\
\hline 2-Ethyl-1-hexanol & $0.77(0.32)$ & 0.57 & 1.4 & $2.3(0.93)$ & 0.59 & 3.4 & $0.6(0.0)$ \\
\hline 2-Propanol & $9.1(13)$ & ) 1.4 & 35 & $20(34)$ & 3.2 & 89 & $1.5(0.0)$ \\
\hline $\mathrm{BHT}$ & $0.52(0.25)$ & 0.29 & 0.88 & $0.98(0.80)$ & 0.29 & 2.4 & $0.3(---)$ \\
\hline DPGME & $4.4(6.4)$ & ) 1.7 & 17 & $14(21)$ & 1.6 & 54 & \\
\hline Ethanol & $6.4(5.7)$ & 27 & 160 & $9.8(4.9)$ & 27 & 160 & $11(3.6)$ \\
\hline \multicolumn{8}{|l|}{ Ethylene glycol } \\
\hline Phenol & $2.3(1.4)$ & 0.59 & 4.1 & $4.7(1.8)$ & 2.3 & 6.9 & $4.6(1.6)$ \\
\hline Propylene glycol & & & & $16(13)$ & 6.5 & 25 & \\
\hline Benzaldehyde & $4.2(1.3)$ & ) 2.7 & 6.0 & $6.5(1.4)$ & 5.0 & 8.2 & 19(6.2) \\
\hline Hexanal & $0.25(4.6)$ & -3.9 & 6.9 & $9.1(8.3)$ & -5.2 & 17 & $-2.1(2.8)$ \\
\hline Octanal & $0.69(1.1)$ & -1.1 & 1.7 & $2.5(2.1)$ & -1.2 & 4.9 & $-0.1(1.0)$ \\
\hline Pentanal & $-0.90(1.1)$ & ) -1.9 & 0.30 & $1.1(1.7)$ & -2.0 & 2.5 & $-1.3(1.1)$ \\
\hline n-Decane & $-0.86(0.27)$ & -1.1 & -0.42 & $0.25(0.68)$ & -0.77 & 1.1 & $-1.1(0.0)$ \\
\hline n-Dodecane & $1.3(1.2)$ & 0.28 & 3.1 & $1.9(1.9)$ & 0.44 & 5.1 & $0.0(0.4)$ \\
\hline n-Nonane & $0.41(0.10)$ & 0.29 & 0.54 & $0.63(0.22)$ & 0.30 & 0.87 & $0.2(0.2)$ \\
\hline n-Undecane & $0.86(0.42)$ & 0.43 & 1.5 & $1.5(0.97)$ & 0.46 & 3.3 & 0.3(---) \\
\hline 1,2,4-Trimethylbenzene & $1.3(0.55)$ & 0.67 & 1.9 & $2.7(1.1)$ & 1.7 & 4.6 & $0.9(0.4)$ \\
\hline m-Xylene & $6.5(3.6)$ & 2.0 & 10 & $12(8.2)$ & 4.9 & 26 & $4.6(2.9)$ \\
\hline Naphthalene & $0.29(0.00)$ & 0.28 & 0.29 & $0.44(0.24)$ & 0.28 & 0.85 & $0.3(---)$ \\
\hline Toluene & $13(5.0)$ & 6.0 & 18 & $25(12)$ & 13 & 46 & $9.4(3.7)$ \\
\hline Butyl acetate & $6.2(7.7)$ & 0.74 & 19 & $7.9(6.7)$ & 1.3 & 18 & $0.6(0.3)$ \\
\hline TMPD-DIB ${ }^{1}$ & $3.0(2.2)$ & 1.9 & 7.4 & $6.0(4.9)$ & 2.1 & 15 & $0.3(0.0)$ \\
\hline TMPD-MIB $^{1}$ & $3.3(1.6)$ & 1.7 & 5.5 & $6.2(3.9)$ & 1.8 & 12 & $0.6(0.0)$ \\
\hline 1,4-Dichlorobenzene & $1.1(1.0)$ & 0.28 & 2.5 & $2.1(1.9)$ & 0.28 & 5.7 & $0.3(0.0)$ \\
\hline Dichloromethane & $0.26(0.65)$ & 0.0 & 1.6 & $0.28(0.69)$ & 0.0 & 1.7 & $0.0(0.0)$ \\
\hline Tetrachloroethene & $0.34(0.17)$ & 0.16 & 0.66 & $0.43(0.31)$ & 0.0 & 0.88 & $0.3(0.2)$ \\
\hline 2-Butanone & $1.3(0.42)$ & 0.59 & 1.6 & $1.7(0.28)$ & 1.3 & 2.2 & $1.5(0.2)$ \\
\hline 2-Propanone & $6.9(14)$ & -7.2 & 27 & $18(16)$ & -7.5 & 32 & $-1.6(10)$ \\
\hline 4-Methyl-2-pentanone & $17(18)$ & 0.28 & 39 & $11(9.9)$ & 0.89 & 22 & $0.3(0.0)$ \\
\hline Acetophenone & $0.76(1.3)$ & -1.3 & 2.6 & $2.2(1.9)$ & 0.23 & 5.3 & $13.2(5.9)$ \\
\hline Benzothiazole & $0.46(0.26)$ & 0.29 & 0.82 & $1.2(0.36)$ & 0.61 & 1.7 & $0.3(0.0)$ \\
\hline D5 Siloxane & $6.4(5.5)$ & 9.8 & 140 & $12(10)$ & 4.5 & 290 & $1.9(1.0)$ \\
\hline 1-Methyl-2-pyrrolidinone & $0.28(0.01)$ & 0.27 & 0.29 & $3.6(5.6)$ & 0.27 & 10 & \\
\hline Caprolactam & $0.76(0.44)$ & 0.57 & 1.7 & $0.92(0.55)$ & 0.53 & 1.8 & \\
\hline d-Limonene & $8.6(15)$ & 1.6 & 40 & $38(81)$ & 1.2 & 200 & $0.3(0.0)$ \\
\hline Acetaldehyde & $11(4.4)$ & 5.5 & 16 & $14(5.1)$ & 8.1 & 21 & $7.3(3.1)$ \\
\hline Formaldehyde & $13(2.9)$ & 9.2 & 16 & $24(8.4)$ & 11 & 35 & $3.2(1.8)$ \\
\hline
\end{tabular}

TMPD-MIB = 2,2,4-trimethyl-1,3-pentanediol monoisobutyrate;

TMPD-DIB = 2,2,4-trimethyl-1,3-pentanediol diisobutyrate 
Table 15. VOC Concentrations $\left(\mu \mathrm{g} \mathrm{m}^{-3}\right)$ averaged across three seasons, two climate zones, and four schools.

\begin{tabular}{|c|c|c|c|c|c|c|c|}
\hline \multirow[b]{3}{*}{ Max } & \multicolumn{7}{|c|}{ All Measurements } \\
\hline & \multicolumn{2}{|c|}{ IHPAC } & & \multicolumn{3}{|c|}{10 SEER } & \multirow{2}{*}{$\begin{array}{l}\text { Outside Air } \\
\text { Avg (Stdev) }\end{array}$} \\
\hline & Avg (Stdev) & Min & $\operatorname{Max}$ & Avg (Stdev) & Min & Max & \\
\hline 1-Butanol & $3.2(4.0)$ & 0.53 & 15 & $5.0(4.7)$ & 0.59 & 20 & $1.0(0.6)$ \\
\hline 2-(2-Butoxyethoxy)ethanol & $7.1(7.9)$ & 4.0 & 35 & $11(9.1)$ & 4.0 & 38 & 4.3(---) \\
\hline 2-Butoxyethanol & $11(25)$ & 1.4 & 110 & $32(39)$ & 2.2 & 170 & $0.8(0.4)$ \\
\hline 2-Ethyl-1-hexanol & $0.94(0.53)$ & 0.53 & 2.4 & $2.3(0.93)$ & 0.56 & 3.6 & $0.8(0.5)$ \\
\hline 2-Propanol & $9.0(14)$ & 0.0 & 44 & $20(34)$ & 0.0 & 120 & $1.1(0.7)$ \\
\hline $\mathrm{BHT}$ & $0.46(0.31)$ & 0.26 & 1.5 & $1.0(1.0)$ & 0.26 & 4.1 & $0.3(0.0)$ \\
\hline DPGME & $4.3(4.9)$ & 1.6 & 17 & $12(17)$ & 1.5 & 54 & \\
\hline Ethanol & $4.3(5.6)$ & 0.0 & 190 & $26(57)$ & 11 & 2300 & $8.9(6.8)$ \\
\hline Ethylene glycol & $13(1.0)$ & 12 & 14 & & & & \\
\hline Phenol & $2.6(1.7)$ & 0.0 & 6.3 & $5.5(4.7)$ & 1.6 & 22 & $5.3(3.1)$ \\
\hline Propylene glycol & 17 (8.9) & 10 & 29 & $15(17)$ & 2.7 & 55 & \\
\hline Benzaldehyde & $3.7(2.3)$ & 0.40 & 8.7 & $5.6(2.2)$ & 2.2 & 9.7 & 22(12) \\
\hline Hexanal & $2.3(4.0)$ & -3.9 & 8.7 & $9.5(6.9)$ & -5.2 & 18 & $-0.9(2.1)$ \\
\hline Octanal & $1.6(1.1)$ & -1.1 & 4.5 & $3.7(2.4)$ & -1.2 & 8.2 & $0.8(1.2)$ \\
\hline Pentanal & $0.16(1.4)$ & -1.9 & 3.3 & $2.0(1.9)$ & -2.0 & 6.0 & $-0.6(1.0)$ \\
\hline n-Decane & $-0.53(0.58)$ & -1.2 & 0.29 & $0.37(0.68)$ & -1.2 & 1.5 & $-0.6(0.6)$ \\
\hline n-Dodecane & $0.61(0.92)$ & -0.52 & 3.1 & $2.7(2.4)$ & 0.44 & 8.2 & $0.4(0.9)$ \\
\hline n-Nonane & $0.43(0.24)$ & 0.25 & 1.1 & $0.55(0.24)$ & 0.26 & 1.0 & $0.3(0.2)$ \\
\hline n-Undecane & $0.62(0.35)$ & 0.25 & 1.5 & $1.5(1.3)$ & 0.26 & 5.8 & $0.4(0.2)$ \\
\hline 1,2,4-Trimethylbenzene & $0.89(0.67)$ & 0.26 & 1.9 & $1.5(1.2)$ & 0.27 & 4.6 & $0.8(0.6)$ \\
\hline m-Xylene & $3.9(3.3)$ & 0.64 & 10 & $6.2(6.5)$ & 1.5 & 26 & $3.2(2.8)$ \\
\hline Naphthalene & $0.19(0.14)$ & 0.0 & 0.29 & $0.41(0.51)$ & 0.0 & 2.3 & $0.2(0.1)$ \\
\hline Toluene & $9.1(6.9)$ & 1.2 & 20 & $16(11)$ & 2.0 & 46 & 12(18) \\
\hline Butyl acetate & $6.7(8.8)$ & 0.74 & 33 & $17(56)$ & 0.78 & 240 & $0.6(0.3)$ \\
\hline TMPD-DIB ${ }^{1}$ & $3.4(2.7)$ & 1.5 & 11 & $5.7(3.2)$ & 2.1 & 15 & $0.2(0.1)$ \\
\hline TMPD-MIB $^{1}$ & 3.7 (1.9) & 1.6 & 9.2 & $7.2(4.7)$ & 1.8 & 18 & $0.6(0.0)$ \\
\hline 1,4-Dichlorobenzene & $1.2(1.3)$ & 0.28 & 5.5 & $3.7(4.7)$ & 0.27 & 17 & $0.3(0.0)$ \\
\hline Dichloromethane & $-0.34(2.5)$ & -5.0 & 3.6 & $0.22(2.9)$ & -5.0 & 6.1 & $-0.6(2.5)$ \\
\hline Tetrachloroethene & $0.36(0.18)$ & 0.16 & 0.77 & $0.61(0.56)$ & 0.0 & 2.1 & $0.3(0.2)$ \\
\hline 2-Butanone & $1.9(2.0)$ & 0.51 & 6.1 & $2.2(1.6)$ & 0.57 & 6.7 & $1.8(1.2)$ \\
\hline 2-Propanone & $2.2(11)$ & -19 & 27 & $14(19)$ & -15 & 56 & $-1.0(7.8)$ \\
\hline 4-Methyl-2-pentanone & $15(19)$ & 0.28 & 68 & $30(100)$ & 0.67 & 430 & $0.7(0.5)$ \\
\hline Acetophenone & $1.1(1.1)$ & -1.3 & 3.0 & $2.3(1.5)$ & 0.23 & 5.3 & $15(11)$ \\
\hline Benzothiazole & $0.63(0.49)$ & 0.0 & 1.9 & $1.4(0.72)$ & 0.61 & 3.2 & $0.1(0.1)$ \\
\hline D5 Siloxane & $46(41)$ & 7.1 & 142 & $67(78)$ & 3.8 & 290 & $1.4(1.1)$ \\
\hline 1-Methyl-2-pyrrolidinone & $0.28(0.01)$ & 0.26 & 0.29 & $3.2(5.6)$ & 0.26 & 16 & \\
\hline Caprolactam & $1.1(0.95)$ & 0.53 & 4.1 & $1.4(0.82)$ & 0.53 & 2.9 & \\
\hline d-Limonene & $5.4(10)$ & 0.79 & 40 & $20(47)$ & 0.77 & 200 & $0.2(0.1)$ \\
\hline Acetaldehyde & $7.8(4.3)$ & 1.1 & 16 & $12(5.2)$ & 5.0 & 21 & $5.4(3.4)$ \\
\hline Formaldehyde & $16(7.9)$ & 7.4 & 38 & $24(6.5)$ & 11 & 35 & $3.9(3.2)$ \\
\hline
\end{tabular}


Table 16. Particle Mass Concentrations $\left(\mu \mathrm{g} / \mathrm{m}^{3}\right)$ for School N1

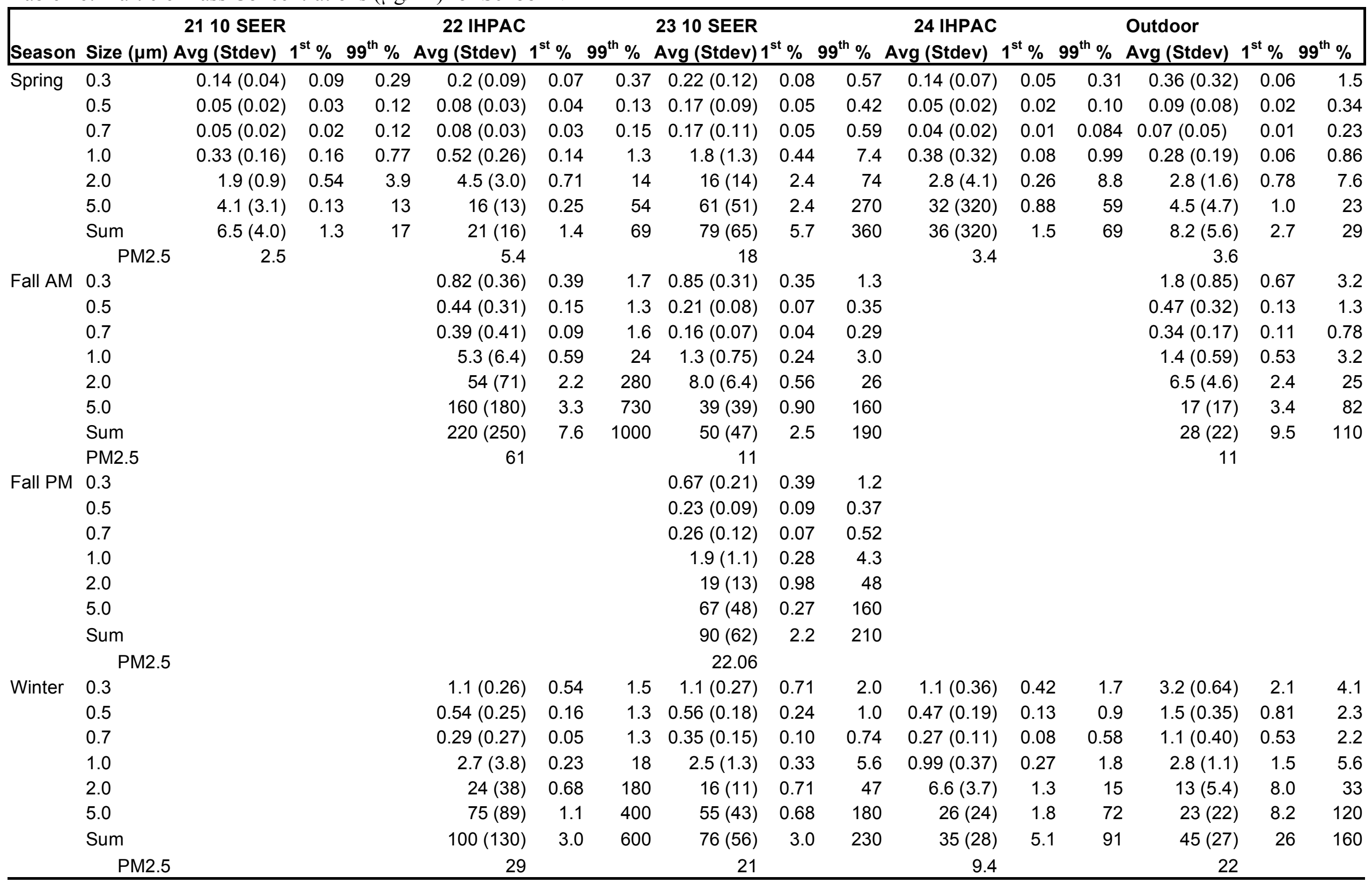


Table 17. Binned and summed particle mass concentrations $\left(\mu \mathrm{g} / \mathrm{m}^{3}\right)$ for School S1

\begin{tabular}{|c|c|c|c|c|c|c|c|c|c|c|c|c|c|c|c|c|}
\hline Season & Size $(\mu \mathrm{m})$ & $\begin{array}{c}13 \text { IHPAC } \\
\text { Avg (Stdev) } 1\end{array}$ & st $\%$ & $99^{\text {th }} \%$ & $\begin{array}{c}1410 \text { SEER } \\
\text { Avg (Stdev) } 1\end{array}$ & st $\%$ & $99^{\text {th }} \%$ & $\begin{array}{c}15 \text { IHPAC } \\
\text { Avg (Stdev) } 1\end{array}$ & st $\%$ & $99^{\text {th }} \%$ & $\begin{array}{r}1610 \text { SEER } \\
\text { Avg (Stdev) }\end{array}$ & $1^{\text {st }} \%$ & $99^{\text {th }} \%$ & $\begin{array}{l}\text { Outdoor } \\
\text { Avg (Stdev) }\end{array}$ & $1^{\text {st }} \% 99^{t}$ & th $\%$ \\
\hline \multirow[t]{8}{*}{ Spring } & 0.3 & $3.1(0.25)$ & 0.27 & 3.3 & $1.8(0.70)$ & 0.99 & 3.0 & $3.0(0.39)$ & 1.9 & 3.7 & $3.4(0.35)$ & 2.2 & 3.9 & $4.2(0.2)$ & 3.8 & 4.6 \\
\hline & 0.5 & $1.7(0.30)$ & 0.14 & 2.1 & $0.69(0.39)$ & 0.31 & 1.6 & $2.9(1.0)$ & 1.3 & 4.2 & $1.6(0.62)$ & 0.54 & 2.5 & $7.3(0.43)$ & 6.5 & 8.2 \\
\hline & 0.7 & $0.47(0.09)$ & 0.04 & 0.57 & $0.27(0.10)$ & 0.13 & 0.44 & $1.0(0.45)$ & 0.35 & 1.7 & $0.61(0.23)$ & 0.20 & 0.93 & $6.0(0.67)$ & 5.0 & 7.3 \\
\hline & 1.0 & $1.6(0.32)$ & 0.12 & 2.0 & $1.9(1.1)$ & 0.58 & 4.7 & $2.7(1.0)$ & 0.93 & 4.4 & $2.7(0.88)$ & 1.0 & 4.4 & $13(1.7)$ & 10 & 16 \\
\hline & 2.0 & $3.7(2.3)$ & 0.16 & 5.1 & $11(8.7)$ & 0.74 & 32 & $6.8(3.5)$ & 0.7 & 16 & $5.9(3.1)$ & 1.7 & 14 & $47(6.6)$ & 35 & 61 \\
\hline & 5.0 & $17(20)$ & 0.44 & 20 & $39(28)$ & 1.3 & 110 & $23(20)$ & 0.0 & 91 & $22(16)$ & 1.8 & 69 & $15(28)$ & 1.9 & 98 \\
\hline & Sum & $28(22)$ & 1.2 & 33 & $55(37)$ & 6.9 & 150 & $40(24)$ & 5.5 & 110 & $36(19)$ & 12 & 93 & $93(32)$ & 66 & 190 \\
\hline & PM2.5 & 11 & & & 16 & & & 16 & & & 14 & & & 78 & & \\
\hline \multirow[t]{8}{*}{ Fall } & 0.3 & $3.1(0.84)$ & 1.7 & 4.1 & $2.7(0.97)$ & 1.1 & 4.0 & $2.9(0.66)$ & 1.6 & 3.8 & & & & $5.7(1.3)$ & 3.1 & 7.0 \\
\hline & 0.5 & $1.9(0.99)$ & 0.5 & 3.5 & $1.4(0.76)$ & 0.37 & 3.4 & $1.7(0.72)$ & 0.49 & 2.9 & & & & $4.5(2.0)$ & 1.2 & 7.6 \\
\hline & 0.7 & $0.76(0.37)$ & 0.2 & 1.5 & $0.88(0.5)$ & 0.26 & 2.1 & $0.69(0.24)$ & 0.25 & 1.1 & & & & $2.2(1.1)$ & 0.62 & 4.3 \\
\hline & 1.0 & $2.0(0.81)$ & 0.58 & 3.9 & $3.1(1.9)$ & 0.96 & 6.8 & $2.6(0.73)$ & 1.2 & 4.7 & & & & $4.7(1.6)$ & 2.1 & 8.2 \\
\hline & 2.0 & $10(8.4)$ & 1.2 & 38 & $16(10)$ & 0.89 & 38 & $10(7.8)$ & 1.2 & 38 & & & & $30(6.4)$ & 16 & 43 \\
\hline & 5.0 & $32(34)$ & 0.0 & 150 & $40(26)$ & 0.31 & 110 & $38(39)$ & 0.0 & 180 & & & & $35(32)$ & 10 & 140 \\
\hline & Sum & $50(43)$ & 6.7 & 200 & $64(38)$ & 5.8 & 160 & $56(46)$ & 9.5 & 230 & & & & $82(36)$ & 40 & 200 \\
\hline & PM2.5 & 18 & & & 24 & & & 18 & & & & & & 47 & & \\
\hline \multirow[t]{8}{*}{ Winter } & 0.3 & $2.1(0.47)$ & 1.3 & 3.1 & $1.2(0.6)$ & 0.56 & 2.6 & $1.5(0.40)$ & 0.68 & 2.2 & $0.99(0.36)$ & 0.41 & 1.8 & $2.7(0.54)$ & 1.8 & 3.7 \\
\hline & 0.5 & $1.9(0.54)$ & 0.89 & 2.8 & $0.83(0.37)$ & 0.49 & 1.9 & $1.6(0.61)$ & 0.23 & 2.4 & $0.71(0.44)$ & 0.083 & 1.6 & $2.5(0.64)$ & 1.5 & 3.5 \\
\hline & 0.7 & $1.5(0.65)$ & 0.45 & 2.4 & $0.46(0.16)$ & 0.22 & 0.91 & $1.0(0.53)$ & 0.08 & 1.8 & $0.36(0.16)$ & 0.046 & 0.73 & $0.88(0.31)$ & 0.43 & 1.4 \\
\hline & 1.0 & $2.8(1.1)$ & 1.0 & 4.8 & $3.1(1.5)$ & 0.50 & 6.0 & $2.6(1.2)$ & 0.31 & 4.8 & $2.0(0.9)$ & 0.22 & 3.8 & $3.2(0.96)$ & 1.3 & 5.0 \\
\hline & 2.0 & $17(9.0)$ & 5.1 & 46 & $17(12)$ & 0.38 & 43 & $6.5(5.1)$ & 0.46 & 24 & $10(6.4)$ & 0.62 & 25 & $7.6(5.0)$ & 2.6 & 23 \\
\hline & 5.0 & $35(31)$ & 0.78 & 140 & $66(52)$ & 0.00 & 230 & $23(31)$ & 0.0 & 140 & $28(20)$ & 0.77 & 92 & $42(52)$ & 10 & 280 \\
\hline & Sum & $60(41)$ & 11 & 200 & $89(64)$ & 2.5 & 270 & $36(37)$ & 1.8 & 180 & $43(27)$ & 2.5 & 120 & $59(57)$ & 19 & 320 \\
\hline & PM2.5 & 25 & & & 23 & & & 13 & & & 14 & & & 17 & & \\
\hline
\end{tabular}


Table 18. Binned and summed particle mass concentrations $\left(\mu \mathrm{g} / \mathrm{m}^{3}\right)$ for School N2

\begin{tabular}{|c|c|c|c|c|c|c|c|c|c|c|}
\hline Season & Size $(\mu \mathrm{m}$ & $\begin{array}{r}25 \text { IHPAC } \\
\text { Avg (Stdev) } \\
\end{array}$ & $1^{\text {st }} \%$ & $99^{\text {th }} \%$ & $\begin{array}{l}2610 \text { SEER } \\
\text { Avg (Stdev) }\end{array}$ & $1^{\text {st }} \%$ & $99^{\text {th }} \%$ & $\begin{array}{l}\text { Outdoor } \\
\text { Avg (Stdev) }\end{array}$ & $1^{\text {st }} \%$ & $99^{\text {th }} \%$ \\
\hline \multirow[t]{8}{*}{ Spring } & 0.3 & $0.18(0.10)$ & 0.05 & 0.37 & $0.21(0.086)$ & 0.067 & 0.3 & $\begin{array}{r}0.21(0.12) \\
0.037\end{array}$ & 0.071 & 0.42 \\
\hline & 0.5 & $0.09(0.05)$ & 0.022 & 0.19 & $0.15(0.087)$ & 0.018 & 0.27 & $(0.018)$ & 0.015 & 0.088 \\
\hline & 0.7 & $0.06(0.034)$ & 0.012 & 0.15 & $0.16(0.11)$ & 0.014 & 0.31 & $0.03(0.014)$ & 0.013 & 0.075 \\
\hline & 1.0 & $0.63(0.41)$ & 0.083 & 1.7 & $1.7(1.2)$ & 0.093 & 3.5 & $0.17(0.076)$ & 0.068 & 0.41 \\
\hline & 2.0 & $5.9(4.4)$ & 0.37 & 17 & $8.6(6.4)$ & 0.22 & 20 & $0.93(0.4)$ & 0.32 & 2.2 \\
\hline & 5.0 & $29(25)$ & 0.13 & 94 & $33(27)$ & 0.13 & 95 & $3.0(1.9)$ & 0.13 & 9.4 \\
\hline & Sum & $36(30)$ & 0.84 & 110 & $44(35)$ & 0.67 & 120 & $4.4(2.3)$ & 0.79 & 1 \\
\hline & PM2.5 & 6.9 & & & 11 & & & 1.4 & & \\
\hline \multirow[t]{8}{*}{ Fall } & 0.3 & $0.80(0.27)$ & 0.38 & 1.3 & $0.73(0.16)$ & 0.45 & 1.1 & $1.6(0.62)$ & 0.74 & 2.5 \\
\hline & 0.5 & $0.19(0.05)$ & 0.09 & 0.28 & $0.21(0.06)$ & 0.12 & 0.35 & $0.35(0.15)$ & 0.17 & 0.71 \\
\hline & 0.7 & $0.14(0.05)$ & 0.05 & 0.24 & $0.15(0.07)$ & 0.06 & 0.29 & $0.24(0.05)$ & 0.16 & 0.37 \\
\hline & 1.0 & $1.0(0.54)$ & 0.28 & 2.3 & $1.4(0.82)$ & 0.30 & 2.9 & $0.92(0.17)$ & 0.69 & 1 \\
\hline & 2.0 & $6.0(4.7)$ & 0.6 & 18 & 11 (8.1) & 0.85 & 26 & $8.2(2.4)$ & 5.8 & \\
\hline & 5.0 & 20 (19) & 0.0 & 68 & $39(32)$ & 0.79 & 100 & 15 (8.5) & 3.4 & \\
\hline & Sum & $28(24)$ & 1.8 & 90 & $52(41)$ & 3.3 & 130 & $26(11)$ & 14 & \\
\hline & PM2.5 & 8.1 & & & 13 & & & 11 & & \\
\hline \multirow[t]{8}{*}{ Winter } & 0.3 & $1.7(0.43)$ & 1.1 & 2.4 & & & & $2.9(0.74)$ & 1.6 & 3 \\
\hline & 0.5 & $0.79(0.23)$ & 0.37 & 1.3 & & & & $1.5(0.40)$ & 0.89 & 2. \\
\hline & 0.7 & $0.38(0.11)$ & 0.16 & 0.56 & & & & $0.98(0.32)$ & 0.48 & 1. \\
\hline & 1.0 & $1.4(0.35)$ & 0.65 & 2.4 & & & & $2.8(0.86)$ & 1.4 & 4. \\
\hline & 2.0 & $4.4(3.1)$ & 0.94 & 13 & & & & $5.8(0.84)$ & 3.9 & 7.8 \\
\hline & 5.0 & $15(14)$ & 0.38 & 59 & & & & $15(4.4)$ & 7.9 & 30 \\
\hline & Sum & 24 (17) & 4.6 & 77 & & & & $29(5.2)$ & 21 & \\
\hline & PM2.5 & 8.7 & & & & & & 14 & & \\
\hline
\end{tabular}


Table 19. Binned and summed particle mass concentrations $\left(\mu \mathrm{g} / \mathrm{m}^{3}\right)$ for School S2

\begin{tabular}{|c|c|c|c|c|c|c|c|c|c|c|}
\hline \multirow[b]{2}{*}{ Season } & \multirow[b]{2}{*}{$\begin{array}{l}\text { Size } \\
(\mu \mathrm{m})\end{array}$} & \multicolumn{6}{|c|}{$\begin{array}{l}3610 \\
\text { SEER }\end{array}$} & \multirow{2}{*}{$\begin{array}{l}\text { Outdoor } \\
\text { Avg } \\
\text { (Stdev) }\end{array}$} & \multirow[b]{2}{*}{$\begin{array}{l}1^{\text {st }} \\
\%\end{array}$} & \multirow[b]{2}{*}{$\begin{array}{l}99^{\text {th }} \\
\%\end{array}$} \\
\hline & & $\begin{array}{l}\text { Avg } \\
\text { (Stdev) }\end{array}$ & $1^{\text {st }} \%$ & $\begin{array}{l}99^{\text {th }} \\
\%\end{array}$ & $\begin{array}{l}\text { Avg } \\
\text { (Stdev) }\end{array}$ & $1^{\text {st }} \%$ & $\begin{array}{l}99^{\text {th }} \\
\%\end{array}$ & & & \\
\hline \multirow[t]{8}{*}{ Spring } & 0.3 & $2.0(0.77)$ & 0.96 & 3.3 & $1.9(0.96)$ & 0.8 & 3.8 & & & \\
\hline & 0.5 & $1.2(0.86)$ & 0.35 & 3.0 & $0.92(0.58)$ & 0.43 & 2.4 & & & \\
\hline & 0.7 & $0.55(0.36)$ & 0.19 & 1.3 & $0.51(0.22)$ & 0.20 & 1.0 & & & \\
\hline & 1.0 & $2.3(1.3)$ & 0.69 & 5.3 & $2.4(1.6)$ & 0.44 & 5.0 & & & \\
\hline & 2.0 & $7.6(7.2)$ & 0.63 & 35 & 17 (14) & 0.51 & 41 & & & \\
\hline & 5.0 & $19(25)$ & 0.0 & 140 & 38 (39) & 0.13 & 130 & & & \\
\hline & Sum & $33(32)$ & 4.4 & 180 & $61(53)$ & 4.7 & 180 & & & \\
\hline & PM2.5 & 14 & & & 23 & & & & & \\
\hline \multirow[t]{8}{*}{ Fall } & 0.3 & & & & & & & $3.9(1.3)$ & 0.48 & 4.9 \\
\hline & 0.5 & & & & & & & $3.3(2.0)$ & 0.05 & 5.4 \\
\hline & 0.7 & & & & & & & $1.4(0.9)$ & 0.02 & 2.7 \\
\hline & 1.0 & & & & & & & $4.9(2.8)$ & 0.18 & 8.5 \\
\hline & 2.0 & & & & & & & $10(5.4)$ & 1.0 & 20 \\
\hline & 5.0 & & & & & & & $32(22)$ & 6.6 & 93 \\
\hline & Sum & & & & & & & $56(29)$ & 8.8 & 130 \\
\hline & PM2.5 & & & & & & & 24 & & \\
\hline \multirow[t]{8}{*}{ Winter } & 0.3 & $1.6(0.34)$ & 1.0 & 2.3 & $1.3(0.34)$ & 0.43 & 1.9 & $2.6(0.38)$ & 2.0 & 3.4 \\
\hline & 0.5 & $1.3(0.54)$ & 0.36 & 2.2 & $1.0(0.46)$ & 0.14 & 1.7 & $1.9(0.28)$ & 1.3 & 2.4 \\
\hline & 0.7 & $0.54(0.25)$ & 0.16 & 0.97 & $0.46(0.23)$ & 0.07 & 0.79 & $1.1(0.22)$ & 0.64 & 1.6 \\
\hline & 1.0 & $1.6(0.63)$ & 0.53 & 2.7 & $0.83(0.34)$ & 0.27 & 1.3 & $2.7(0.5)$ & 1.6 & 3.9 \\
\hline & 2.0 & $3.8(2.3)$ & 0.64 & 9.3 & $3.5(2.7)$ & 0.45 & 9.0 & $4.6(1.6)$ & 2.5 & 10 \\
\hline & 5.0 & $10(11)$ & 0.23 & 37 & $13(15)$ & 0.0 & 34 & $14(12)$ & 4.0 & 61 \\
\hline & Sum & $19(14)$ & 3.2 & 54 & 20 (18) & 4.1 & 47 & 27 (13) & 14 & 82 \\
\hline & PM2.5 & 8.8 & & & 7.1 & & & 13 & & \\
\hline
\end{tabular}


Table 20. School day hours Indoor and Outdoor Temperatures in Northern California Classrooms.

\begin{tabular}{|c|c|c|c|c|c|c|c|c|}
\hline \multirow{2}{*}{\multicolumn{2}{|c|}{ Site Room }} & \multirow[b]{2}{*}{ Season } & \multicolumn{3}{|c|}{ Temperature $\left({ }^{\circ} \mathrm{F}\right)$} & \multicolumn{3}{|c|}{ RH (\%) } \\
\hline & & & Avg (Stdev) & 1 st $\%$ & 99th \% & Avg (Stdev) & 1 st $\%$ & 99th \% \\
\hline \multirow[t]{30}{*}{$\mathrm{N} 1$} & 20 & All & $71.0(4.9)$ & 57.4 & 84.0 & $46.7(10.1)$ & 25.7 & 69.7 \\
\hline & IHPAC & Winter & $70.4(5.3)$ & 55.6 & 84.5 & $44.1(10.4)$ & 24.3 & 73.6 \\
\hline & & Spring & $71.0(4.0)$ & 62.7 & 83.4 & $47.0(10.3)$ & 26.4 & 69.7 \\
\hline & & Summer & $73.3(4.8)$ & 66.3 & 85.2 & $53.6(7.6)$ & 37.5 & 70.1 \\
\hline & & Fall & $69.8(4.7)$ & 57.6 & 79.3 & $44.3(8.6)$ & 25.9 & 64.6 \\
\hline & 21 & All & $72.1(7.6)$ & 51.9 & 93.1 & $48.3(9.6)$ & 27.7 & 73.6 \\
\hline & 10 SEER & Winter & $69.3(7.2)$ & 48.8 & 82.8 & $51.8(11.3)$ & 26.6 & 77.6 \\
\hline & & Spring & 74.5 (5.1) & 63.3 & 86.9 & $47.6(7.8)$ & 31.9 & 65.6 \\
\hline & & Summer & $78.3(7.6)$ & 66.0 & 96.8 & $44.4(7.7)$ & 30.1 & 59.8 \\
\hline & & Fall & $68.8(5.8)$ & 55.7 & 82.7 & $47.5(8.5)$ & 25.5 & 73.2 \\
\hline & 22 & All & $70.9(4.0)$ & 59.0 & 82.5 & $48.2(10.0)$ & 26.4 & 69.1 \\
\hline & IHPAC & Winter & $70.5(4.9)$ & 58.0 & 82.3 & $45.4(9.6)$ & 25.5 & 68.5 \\
\hline & & Spring & $72.1(3.4)$ & 66.0 & 82.9 & $45.4(10.0)$ & 24.7 & 69.5 \\
\hline & & Summer & $71.3(3.7)$ & 66.5 & 84.0 & $56.7(6.5)$ & 40.2 & 70.7 \\
\hline & & Fall & $70.1(3.1)$ & 61.9 & 77.1 & $47.5(9.2)$ & 28.1 & 67.9 \\
\hline & 23 & All & $71.3(5.7)$ & 53.4 & 84.6 & $53.5(7.3)$ & 32.1 & 68.5 \\
\hline & 10 SEER & Winter & $71.0(7.1)$ & 49.1 & 81.1 & $54.6(8.2)$ & 31.3 & 70.9 \\
\hline & & Spring & & 62 & 80.1 & & 34.5 & 65.6 \\
\hline & & Summer & & 63 & 89.0 & & 34.4 & 64.2 \\
\hline & & Fall & & 57.1 & 81.3 & 51.0 & 30.0 & 67.1 \\
\hline & 24 & All & 71. & 62.3 & 81.8 & 49.2 & 28.5 & 68.5 \\
\hline & IHPAC & Winter & (3.5) & 59.5 & 77.0 & 48.8 & 27.0 & 69.1 \\
\hline & & Spring & $(3.1)$ & 63.4 & 79.6 & $48.6(9.1)$ & 28.1 & 68.7 \\
\hline & & Summer & 72.9 (4.1) & 66.1 & 83.6 & $54.4(6.5)$ & 38.8 & 66.6 \\
\hline & & Fall & $71.3(3.7)$ & 63.2 & 79.1 & $46.0(7.8)$ & 29.4 & 63.8 \\
\hline & Outdoor & All & $67.2(13.5)$ & 41.3 & 98.7 & $55.6(18.1)$ & 23.7 & 92.5 \\
\hline & & Winter & $58.4(8.5)$ & 40.6 & 78.7 & $66.2(17.1)$ & 27.4 & 94.6 \\
\hline & & Spring & $69.8(9.9)$ & 50.3 & 94.1 & $49.5(14.1)$ & 24.0 & 83.3 \\
\hline & & Summer & $82.8(10.1)$ & 59.5 & 102.8 & $42.6(11.9)$ & 22.1 & 73.9 \\
\hline & & Fall & $63.7(12.3)$ & 39.2 & 93.4 & $57.6(17.7)$ & 23.6 & 91.8 \\
\hline \multirow[t]{20}{*}{ N2 } & 25 & All & $72.8(5.8)$ & 63.3 & 96.0 & $45.6(9.2)$ & 26.3 & 67.5 \\
\hline & IHPAC & Winter & 70.7 (3.4) & 62.4 & 81.2 & $45.4(9.5)$ & 25.3 & 67.9 \\
\hline & & Spring & $71.3(3.8)$ & 64.2 & 82.5 & $46.6(9.3)$ & 27.6 & 68.2 \\
\hline & & Summer & & 63.4 & 100.9 & 44.8 & 26.5 & 65.7 \\
\hline & & Fall & 72.1 & 64.7 & 78.8 & 45.7 (8.3) & 28.6 & 66.8 \\
\hline & 26 & All & 71.7 (1 & 32.0 & 94.8 & $44.9(14.4)$ & 0.0 & 65.6 \\
\hline & 10 SEER & Winter & 68.3 & 32.0 & 88.5 & $48.7(1$ & 0.0 & 66.2 \\
\hline & & Spring & 73.4 & 58.3 & 88.7 & $48.3(7.7)$ & 31.0 & 63.6 \\
\hline & & Summer & $80.4(9.2)$ & 61.3 & 97.7 & $41.2(8.7)$ & 28.0 & 64.4 \\
\hline & & Fall & $67.2(16.7)$ & 32.0 & 84.2 & $38.3(19.2)$ & 0.0 & 59.8 \\
\hline & 27 & All & $71.4(6.0)$ & 60.6 & 92.3 & $45.4(10.2)$ & 25.2 & 69.6 \\
\hline & IHPAC & Winter & $70.0(4.3)$ & 59.2 & 80.8 & $44.2(10.2)$ & 23.7 & 67.5 \\
\hline & & Spring & $69.8(4.2)$ & 61.0 & 81.2 & $46.7(10.4)$ & 26.9 & 71.6 \\
\hline & & Summer & 75.8 (8.9) & 60.2 & 97.3 & $46.1(10.0)$ & 29.0 & 68.3 \\
\hline & & Fall & $71.0(3.8)$ & 62.7 & 81.2 & $45.4(9.8)$ & 24.2 & 66.7 \\
\hline & Outdoor & All & $68.3(13.7)$ & 43.2 & 100.4 & $54.1(22.0)$ & 20.9 & 99.5 \\
\hline & & Winter & $58.9(8.5)$ & 41.6 & 80.8 & $67.1(23.8)$ & 25.1 & 163.8 \\
\hline & & Spring & $70.0(10.2)$ & 50.2 & 94.6 & $47.3(15.3)$ & 21.5 & 86.0 \\
\hline & & Summer & $83.7(10.5)$ & 60.5 & 105.1 & $39.3(12.3)$ & 19.0 & 73.5 \\
\hline & & Fall & $66.4(12.2)$ & 41.7 & 95.2 & 55.1 (19.8) & 21.0 & 96.1 \\
\hline
\end{tabular}


Table 21. Schoolday Hours Indoor and Outdoor Temperatures in Southern California Classrooms.

\begin{tabular}{|c|c|c|c|c|c|c|c|c|}
\hline \multirow{2}{*}{\multicolumn{2}{|c|}{ Site Room }} & \multirow[b]{2}{*}{ Season } & \multicolumn{3}{|c|}{ Temperature $\left({ }^{\circ} \mathrm{F}\right)$} & \multicolumn{3}{|c|}{$\begin{array}{l}\mathrm{RH}(\%) \\
\end{array}$} \\
\hline & & & $\operatorname{Avg}$ (Stdev) & $1 \mathrm{st} \%$ & 99th \% & Avg (Stdev) & 1 st $\%$ & 99th \% \\
\hline \multirow[t]{30}{*}{ S1 } & 13 & All & $72.4(3.9)$ & 61.4 & 83.4 & $44.8(12.6)$ & 18.6 & 66.5 \\
\hline & IHPAC & Winter & $71.5(4.2)$ & 60.0 & 79.2 & $39.2(11.9)$ & 16.8 & 65.2 \\
\hline & & Spring & $72.3(2.9)$ & 64.6 & 80.6 & $49.2(9.4)$ & 23.2 & 65.1 \\
\hline & & Summer & $74.1(4.6)$ & 67.5 & 92.3 & $54.4(6.6)$ & 34.5 & 69.3 \\
\hline & & Fall & $72.2(3.0)$ & 63.7 & 78.8 & $39.1(13.7)$ & 18.3 & 64.9 \\
\hline & 14 & All & $74.1(6.2)$ & 54.4 & 86.0 & $46.4(9.6)$ & 23.1 & 63.8 \\
\hline & 10 SEER & Winter & $71.4(8.1)$ & 53.1 & 85.1 & $43.6(9.5)$ & 21.5 & 62.4 \\
\hline & & Spring & $75.1(4.1)$ & 63.1 & 83.9 & $48.2(7.0)$ & 28.8 & 62.8 \\
\hline & & Summer & $76.7(3.6)$ & 70.1 & 89.6 & $52.5(7.3)$ & 36.7 & 65.7 \\
\hline & & Fall & $74.4(5.2)$ & 58.6 & 84.7 & $42.7(10.5)$ & 21.9 & 62.0 \\
\hline & 15 & All & $72.5(4.1)$ & 61.9 & 84.8 & $46.4(218.8)$ & 18.6 & 65.1 \\
\hline & IHPAC & Winter & $71.4(4.7)$ & 57.8 & 80.1 & $45.0(376.9)$ & 18.0 & 59.1 \\
\hline & & Spring & $72.5(3.0)$ & 65.7 & 79.9 & $47.6(10.1)$ & 21.7 & 65.0 \\
\hline & & Summer & $74.5(4.4)$ & 68.2 & 90.5 & $54.6(6.3)$ & 37.3 & 67.3 \\
\hline & & Fall & $72.2(2$ & 64.5 & 79.2 & $39.0(13.3)$ & 18.7 & 63.5 \\
\hline & 16 & All & 74.2 & 54.5 & 91.7 & 40.3 & 17.7 & 58.8 \\
\hline & 10 SEER & Winter & & 53.2 & 98.7 & 36.8 & 15.8 & 56.9 \\
\hline & & Spring & 75. & 61.5 & 84.4 & & 26.1 & 59.3 \\
\hline & & Summer & 77. & 69.9 & 89.1 & 45.1 & 34.0 & 60.9 \\
\hline & & Fall & $74.0(5.2)$ & 57.2 & 82.6 & $37.8(9.9)$ & 18.3 & 56.3 \\
\hline & 17 & All & $73.6(4.2)$ & 61.9 & 87.7 & $43.9(12.3)$ & 20.2 & 65.1 \\
\hline & IHPAC & Winter & $72.4(4.1)$ & 59.7 & 80.7 & $37.5(11.0)$ & 19.3 & 60.5 \\
\hline & & Spring & $73.0(2.9)$ & 68.0 & 81.4 & $48.5(10.7)$ & 20.2 & 66.3 \\
\hline & & Summer & $76.1(5.1)$ & 68.7 & 93.7 & $52.9(6.1)$ & 34.5 & 65.2 \\
\hline & & Fall & $73.2(3.0)$ & 64.9 & 82.0 & 39.1 (12.9) & 21.0 & 66.2 \\
\hline & Outdoor & All & $72.1(15.9)$ & 32.0 & 103.7 & $36.3(22.3)$ & 0.0 & 87.4 \\
\hline & & Winter & $66.0(9.0)$ & 49.9 & 90.5 & $38.7(25.5)$ & 1.6 & 92.6 \\
\hline & & Sprir & 73.6 & & 96.2 & 42.8 & 10.7 & 80.6 \\
\hline & & Sumn & 87.7 & 64.1 & 106.6 & 36.5 & 10.0 & 75.0 \\
\hline & & Fall & 64.4 & 32. & 101.2 & 25. & 0.0 & 81.8 \\
\hline \multirow[t]{20}{*}{ S2 } & 35 & All & & 56.7 & 84.3 & 44.3 & 15.9 & 67.9 \\
\hline & IHPAC & Winter & & 53 & 80.2 & & 14.5 & 60.7 \\
\hline & & & & 59. & 81.1 & 48. & 20.6 & 67.7 \\
\hline & & Summer & $74.2(4.7)$ & 66.2 & 86.0 & $53.7(7.7)$ & 34.5 & 70.1 \\
\hline & & Fall & $70.8(4.3)$ & 59.2 & 80.9 & $39.7(14.8)$ & 16.3 & 68.6 \\
\hline & 36 & All & $73.1(8.3)$ & 51.5 & 92.4 & $40.2(11.5)$ & 16.2 & 64.7 \\
\hline & 10 SEER & Winter & $69.3(8.9)$ & 49.8 & 88.2 & $37.7(11.5)$ & 15.3 & 56.2 \\
\hline & & Spring & $73.8(7.1)$ & 51.9 & 89.2 & $42.2(9.7)$ & 19.0 & 58.9 \\
\hline & & Summer & $79.7(5.6)$ & 69.8 & 97.3 & $44.6(9.1)$ & 27.8 & 64.6 \\
\hline & & Fall & $71.9(6.3)$ & 55.2 & 84.1 & $37.5(13.4)$ & 15.0 & 69.1 \\
\hline & 37 & All & $71.7(5.5)$ & 56.0 & 85.2 & 45.5 (12.5) & 17.8 & 68.3 \\
\hline & & Winte & $69.5(5.6)$ & 54.8 & 80.6 & $40.6(12.1)$ & 16.1 & 64.1 \\
\hline & & Sprir & $70.7(4.7)$ & 56.4 & 81.8 & $49.6(10.7)$ & 22.7 & 67.9 \\
\hline & & Summer & $75.6(4.7)$ & 67.2 & 86.7 & $52.3(8.2)$ & 32.3 & 72.6 \\
\hline & & Fall & 72.1 (4.3) & 60.6 & 82.7 & $41.8(13.7)$ & 17.8 & 68.9 \\
\hline & Outdoor & All & $76.2(14.4)$ & 51.7 & 108.6 & $38.7(18.6)$ & 10.8 & 83.9 \\
\hline & & Winter & $65.8(8.0)$ & 50.7 & 86.5 & $44.0(20.6)$ & 9.8 & 88.6 \\
\hline & & Spring & 78.1 (11.3) & 56.6 & 102.3 & $39.0(15.2)$ & 13.8 & 77.0 \\
\hline & & Summer & $93.8(11.0)$ & 66.0 & 113.0 & $32.3(12.9)$ & 12.1 & 71.1 \\
\hline & & Fall & 73.7 (10.7) & 52.6 & 99.8 & $36.0(20.5)$ & 10.8 & 81.5 \\
\hline
\end{tabular}


Table 22. Northern and Southern California schools daily energy consumption statistics by classroom.

\begin{tabular}{|c|c|c|c|c|c|c|c|c|c|c|c|}
\hline \multicolumn{12}{|c|}{ Energy Consumption (Watt-Hours) } \\
\hline Site & Room & Season & Avg (Stdev) & 1 st $\%$ & 99 th \% & Site & Room & Season & Avg (Stdev) & 1 st \% & 9th \% \\
\hline \multirow{5}{*}{\multicolumn{2}{|c|}{ N1 20}} & All & $2730(1900)$ & 12.0 & 7790 & S1 & 13 & All & 3880 (3360) & 3.00 & 12100 \\
\hline & & Winter & $2560(1230)$ & 0.00 & 5740 & & IHPAC & Winter & $1640(1220)$ & 0.00 & 5600 \\
\hline & & Spring & $2510(2060)$ & 16.9 & 8790 & & & Spring & $3640(2250)$ & 18.4 & 10800 \\
\hline & & Summer & $4280(2220)$ & 19.1 & 8810 & & & Summer & $7770(3740)$ & 0.00 & 13800 \\
\hline & & Fall & $1680(1160)$ & 12.0 & 6190 & & & Fall & $3680(2750)$ & 8.00 & 10900 \\
\hline & 21 & All & $1860(1690)$ & 62.2 & 6180 & & 14 & All & $4090(4640)$ & 18.0 & 18300 \\
\hline \multicolumn{3}{|c|}{10 SEER Winter } & $1610(1300)$ & 68.0 & 5300 & & 10 SEER & Winter & $904(1420)$ & 18.0 & 4710 \\
\hline & & Spring & $1670(1640)$ & 31.0 & 7040 & & & Spring & 3850 (3090) & 1.60 & 12600 \\
\hline & & Summer & $2890(2060)$ & 61.5 & 6320 & & & Summer & $9500(5340)$ & 19.4 & 20100 \\
\hline & & Fall & $1420(1470)$ & 65.1 & 5210 & & & Fall & 3860 (3570) & 19.0 & 14200 \\
\hline & IHPAC & All & $4160(3020)$ & 91.3 & 12500 & & 15 & All & $3970(4500)$ & 2.00 & 11600 \\
\hline \multirow{4}{*}{\multicolumn{2}{|c|}{22}} & Winter & $2870(1460)$ & 52.6 & 7050 & & IHPAC & Winter & 2150 (5750) & 0.00 & 6130 \\
\hline & & Spring & 3240 (1780) & 91.3 & 8250 & & & Spring & 3850 (2710) & 18.6 & 12100 \\
\hline & & Summer & 7830 (3840) & 183 & 14400 & & & Summer & 7240 (3350) & 36.5 & 12000 \\
\hline & & Fall & $3490(1860)$ & 99.0 & 8220 & & & Fall & 363 & 3.00 & 11600 \\
\hline & 23 & All & $3910(3600)$ & 71.7 & 13800 & & 16 & All & 2830 & 0.00 & 13300 \\
\hline \multicolumn{3}{|c|}{10 SEER Winter } & $1670(1210)$ & 77.0 & 4750 & & 10 SEER & Winter & $1070(1$ & 0.00 & 5060 \\
\hline & & Spring & $3950(2950)$ & 34.0 & 10700 & & & Spring & 50) & 0.00 & 8840 \\
\hline & & Summer & $8560(3680)$ & 71.0 & 14800 & & & Summer & 6990 (4010) & 0.00 & 13500 \\
\hline & & Fall & $2680(1970)$ & 77.0 & 7140 & & & Fall & 214 & 0.00 & 11000 \\
\hline & 24 & All & $4090(3370)$ & 100 & 13700 & & 17 & All & 4020 (4940) & 1.00 & 11400 \\
\hline \multirow{4}{*}{\multicolumn{2}{|c|}{ IHPAC }} & Winter & $2250(1190)$ & 46.2 & 5400 & & IHPAC & Winter & 2150 (6920) & 0.00 & 5820 \\
\hline & & Spring & $4280(2490)$ & 96.1 & 9900 & & & Spring & $3960(2720)$ & 42.3 & 11400 \\
\hline & & Summer & $8250(4020)$ & 119 & 15600 & & & Summer & 7160 (33 & 0.00 & 12300 \\
\hline & & Fall & $2560(1710)$ & 100 & 7700 & & & Fall & $3780(2290)$ & 19.0 & 9170 \\
\hline \multirow{15}{*}{ N2 } & & All & $3120(2660)$ & 0.00 & 13100 & $S 2$ & 35 & All & $2960(2670)$ & 142 & 12100 \\
\hline & IHPAC & Winter & $2520(1730)$ & 95.0 & 7870 & & IHPAC & Winter & 1870 & 142 & 4690 \\
\hline & & Spring & $3510(2970)$ & 6.90 & 12100 & & & Spring & 2480 (1580) & 70.4 & 7600 \\
\hline & & Summer & 3970 (3860) & 0.00 & 13600 & & & Summer & $5230(3750)$ & 98.3 & 12600 \\
\hline & & Fall & $2840(1750)$ & 95.0 & 7240 & & & Fall & $2900(2730)$ & 186 & 13200 \\
\hline & 26 & All & $2350(2460)$ & 0.00 & 10200 & & 36 & All & $2190(2070)$ & 0.00 & 8840 \\
\hline & 10 SEER & Winter & 2040 (1660) & 65.0 & 6560 & & 10 SEER & Winter & 1760 (1530) & 0.00 & 4590 \\
\hline & & Spring & $1950(2120)$ & 8.30 & 8900 & & & Spring & 2060 (1430) & 0.00 & 5860 \\
\hline & & Summer & $2920(3780)$ & 0.00 & 12700 & & & Summer & $3240(2990)$ & 0.00 & 8930 \\
\hline & & Fall & $2740(2110)$ & 62.9 & 7990 & & & Fall & 1970 (1950) & 0.00 & 9560 \\
\hline & 27 & All & $3070(2240)$ & 0.00 & 10400 & & 37 & All & 2060 (1900) & 2.00 & 8340 \\
\hline & IHPAC & Winter & $3110(1660)$ & 145 & 7450 & & IHPAC & Winter & $1370(1000)$ & 6.00 & 3460 \\
\hline & & Spring & $2700(2100)$ & 7.00 & 9030 & & & Spring & $1880(1350)$ & 12.0 & 6600 \\
\hline & & Summer & 3750 (3290) & 0.00 & 11500 & & & Summer & $3380(2600)$ & 5.60 & 8700 \\
\hline & & Fall & $2690(1750)$ & 153 & 6710 & & & Fall & $2000(2020)$ & 0.00 & 9560 \\
\hline
\end{tabular}


Table 23. IHPAC operation mode seasonally and annually. The statistics indicate the percentage of time the IHPAC units operated in each of the following modes: supply fan only, fan plus stage one compressor, fan plus stage 2 compressor, or system off. The statistics are provided for 24 hours/7 days per week, and scheduled school hours only.

\begin{tabular}{|c|c|c|c|c|c|c|c|c|c|c|}
\hline \multirow[b]{2}{*}{ Location } & \multirow[b]{2}{*}{ Room } & \multirow[b]{2}{*}{ Season } & \multicolumn{4}{|c|}{ All Hours } & \multicolumn{4}{|c|}{ School Hours } \\
\hline & & & Off & Fan & Stage 1 & Stage 2 & Off & Fan & Stage 1 & Stage 2 \\
\hline \multirow[t]{15}{*}{$\mathrm{N} 1$} & 20 & All Year & $68.5 \%$ & $17.4 \%$ & $10.7 \%$ & $3.4 \%$ & $31.7 \%$ & $39.4 \%$ & $21.4 \%$ & $7.1 \%$ \\
\hline & & Winter & $42.2 \%$ & $37.6 \%$ & $16.6 \%$ & $3.6 \%$ & $6.1 \%$ & $67.9 \%$ & $18.4 \%$ & $5.4 \%$ \\
\hline & & Spring & $76.5 \%$ & $13.9 \%$ & $7.8 \%$ & $1.8 \%$ & $33.1 \%$ & $40.7 \%$ & $23.0 \%$ & $3.2 \%$ \\
\hline & & Summer & $69.1 \%$ & $10.9 \%$ & $13.0 \%$ & $7.0 \%$ & $35.6 \%$ & $21.3 \%$ & $26.8 \%$ & $16.4 \%$ \\
\hline & & Fall & $81.9 \%$ & $12.0 \%$ & $6.0 \%$ & $0.2 \%$ & $49.6 \%$ & $36.2 \%$ & $13.8 \%$ & $0.5 \%$ \\
\hline & 22 & All Year & $64.3 \%$ & $19.8 \%$ & $11.2 \%$ & $4.8 \%$ & $17.1 \%$ & $46.5 \%$ & $23.8 \%$ & $12.2 \%$ \\
\hline & & Winter & $53.5 \%$ & $28.6 \%$ & $13.8 \%$ & $4.1 \%$ & $8.9 \%$ & $62.2 \%$ & $21.8 \%$ & $4.8 \%$ \\
\hline & & Spring & $70.8 \%$ & $18.2 \%$ & $8.1 \%$ & $2.9 \%$ & $22.4 \%$ & $51.3 \%$ & $20.1 \%$ & $6.3 \%$ \\
\hline & & Summer & $65.4 \%$ & $12.1 \%$ & $13.8 \%$ & $8.8 \%$ & $22.6 \%$ & $21.3 \%$ & $27.9 \%$ & $28.1 \%$ \\
\hline & & Fall & $63.5 \%$ & $24.7 \%$ & $9.5 \%$ & $2.3 \%$ & $8.6 \%$ & $62.2 \%$ & $24.9 \%$ & $4.3 \%$ \\
\hline & 24 & All Year & $68.0 \%$ & $0.1 \%$ & $28.9 \%$ & $3.1 \%$ & $19.0 \%$ & $0.1 \%$ & $69.7 \%$ & $10.7 \%$ \\
\hline & & Winter & $56.4 \%$ & $0.1 \%$ & $42.8 \%$ & $0.7 \%$ & $4.0 \%$ & $0.1 \%$ & $92.7 \%$ & $1.0 \%$ \\
\hline & & Spring & $73.2 \%$ & $0.0 \%$ & $26.4 \%$ & $0.3 \%$ & $16.5 \%$ & $0.0 \%$ & $82.3 \%$ & $1.2 \%$ \\
\hline & & Summer & $67.2 \%$ & $0.1 \%$ & $23.8 \%$ & $8.9 \%$ & $32.9 \%$ & $0.2 \%$ & $35.4 \%$ & $31.5 \%$ \\
\hline & & Fall & $72.7 \%$ & $0.1 \%$ & $26.1 \%$ & $1.1 \%$ & $16.8 \%$ & $0.2 \%$ & $80.3 \%$ & $2.8 \%$ \\
\hline \multirow[t]{10}{*}{ N2 } & 25 & All Year & $67.9 \%$ & $16.3 \%$ & $8.8 \%$ & $7.0 \%$ & $27.9 \%$ & $44.0 \%$ & $18.0 \%$ & $10.1 \%$ \\
\hline & & Winter & $67.9 \%$ & $19.2 \%$ & $8.9 \%$ & $4.0 \%$ & $26.6 \%$ & $58.6 \%$ & $10.6 \%$ & $4.2 \%$ \\
\hline & & Spring & $71.8 \%$ & $18.2 \%$ & $6.8 \%$ & $3.2 \%$ & $23.0 \%$ & $48.8 \%$ & $19.9 \%$ & $8.3 \%$ \\
\hline & & Summer & $60.1 \%$ & $9.8 \%$ & $12.5 \%$ & $17.6 \%$ & $43.7 \%$ & $12.4 \%$ & $21.8 \%$ & $22.1 \%$ \\
\hline & & Fall & $73.5 \%$ & $18.5 \%$ & $6.4 \%$ & $1.5 \%$ & $12.9 \%$ & $63.1 \%$ & $20.9 \%$ & $3.1 \%$ \\
\hline & 27 & All Year & $67.4 \%$ & $15.5 \%$ & $12.1 \%$ & $5.0 \%$ & $27.3 \%$ & $45.8 \%$ & $18.5 \%$ & $8.5 \%$ \\
\hline & & Winter & $65.2 \%$ & $18.2 \%$ & $12.1 \%$ & $4.4 \%$ & $26.9 \%$ & $52.6 \%$ & $14.6 \%$ & $5.9 \%$ \\
\hline & & Spring & $73.7 \%$ & $18.6 \%$ & $5.2 \%$ & $2.5 \%$ & $23.8 \%$ & $56.7 \%$ & $13.8 \%$ & $5.8 \%$ \\
\hline & & Summer & $58.5 \%$ & $6.8 \%$ & $24.2 \%$ & $10.5 \%$ & $37.2 \%$ & $14.7 \%$ & $30.0 \%$ & $18.0 \%$ \\
\hline & & Fall & $74.5 \%$ & $19.5 \%$ & $4.6 \%$ & $1.3 \%$ & $17.8 \%$ & $66.9 \%$ & $13.6 \%$ & $1.8 \%$ \\
\hline \multirow[t]{10}{*}{ S1 } & 35 & All Year & $63.9 \%$ & $24.9 \%$ & $7.3 \%$ & $3.9 \%$ & $26.1 \%$ & $47.3 \%$ & $17.6 \%$ & $9.0 \%$ \\
\hline & & Winter & $60.5 \%$ & $28.3 \%$ & $8.3 \%$ & $2.9 \%$ & $15.0 \%$ & $68.9 \%$ & $14.5 \%$ & $1.6 \%$ \\
\hline & & Spring & $72.6 \%$ & $19.3 \%$ & $5.9 \%$ & $2.2 \%$ & $20.8 \%$ & $57.7 \%$ & $17.8 \%$ & $3.8 \%$ \\
\hline & & Summer & $72.4 \%$ & $12.5 \%$ & $9.6 \%$ & $5.4 \%$ & $41.1 \%$ & $21.3 \%$ & $21.4 \%$ & $16.3 \%$ \\
\hline & & Fall & $41.3 \%$ & $48.5 \%$ & $5.0 \%$ & $5.1 \%$ & $21.7 \%$ & $51.3 \%$ & $14.4 \%$ & $12.7 \%$ \\
\hline & 37 & All Year & $75.7 \%$ & $15.7 \%$ & $6.4 \%$ & $2.2 \%$ & $40.8 \%$ & $37.1 \%$ & $15.0 \%$ & $7.1 \%$ \\
\hline & & Winter & $53.0 \%$ & $37.5 \%$ & $8.8 \%$ & $0.7 \%$ & $31.2 \%$ & $56.6 \%$ & $10.2 \%$ & $2.0 \%$ \\
\hline & & Spring & $80.2 \%$ & $14.0 \%$ & $4.2 \%$ & $1.6 \%$ & $33.0 \%$ & $48.4 \%$ & $13.7 \%$ & $4.9 \%$ \\
\hline & & Summer & $78.4 \%$ & $8.8 \%$ & $9.1 \%$ & $3.7 \%$ & $47.0 \%$ & $20.2 \%$ & $21.2 \%$ & $11.6 \%$ \\
\hline & & Fall & $86.7 \%$ & $7.6 \%$ & $3.5 \%$ & $2.3 \%$ & $52.6 \%$ & $27.2 \%$ & $12.0 \%$ & $8.2 \%$ \\
\hline \multirow[t]{15}{*}{ S2 } & 13 & All Year & $67.0 \%$ & $18.4 \%$ & $7.2 \%$ & $7.4 \%$ & $17.2 \%$ & $39.1 \%$ & $21.8 \%$ & $21.5 \%$ \\
\hline & & Winter & $57.2 \%$ & $34.5 \%$ & $6.8 \%$ & $1.5 \%$ & $14.3 \%$ & $67.3 \%$ & $13.6 \%$ & $2.4 \%$ \\
\hline & & Spring & $69.2 \%$ & $19.6 \%$ & $7.4 \%$ & $3.8 \%$ & $17.1 \%$ & $46.2 \%$ & $25.0 \%$ & $11.7 \%$ \\
\hline & & Summer & $66.4 \%$ & $9.9 \%$ & $7.0 \%$ & $16.7 \%$ & $20.1 \%$ & $15.2 \%$ & $18.6 \%$ & $46.1 \%$ \\
\hline & & Fall & $74.2 \%$ & $13.3 \%$ & $7.7 \%$ & $4.8 \%$ & $15.5 \%$ & $38.1 \%$ & $29.7 \%$ & $16.7 \%$ \\
\hline & 15 & All Year & $69.7 \%$ & $16.4 \%$ & $8.2 \%$ & $5.7 \%$ & $19.1 \%$ & $40.4 \%$ & $21.2 \%$ & $18.8 \%$ \\
\hline & & Winter & $67.1 \%$ & $24.9 \%$ & $6.4 \%$ & $1.7 \%$ & $18.8 \%$ & $73.2 \%$ & $7.4 \%$ & $0.7 \%$ \\
\hline & & Spring & $69.0 \%$ & $18.8 \%$ & $8.1 \%$ & $4.1 \%$ & $14.0 \%$ & $46.9 \%$ & $25.3 \%$ & $12.3 \%$ \\
\hline & & Summer & $68.3 \%$ & $10.9 \%$ & $9.7 \%$ & $11.1 \%$ & $25.2 \%$ & $15.5 \%$ & $20.5 \%$ & $38.8 \%$ \\
\hline & & Fall & $75.2 \%$ & $12.8 \%$ & $7.8 \%$ & $4.2 \%$ & $17.8 \%$ & $38.1 \%$ & $29.2 \%$ & $15.0 \%$ \\
\hline & 17 & All Year & $59.8 \%$ & $25.7 \%$ & $7.6 \%$ & $6.6 \%$ & $16.3 \%$ & $44.8 \%$ & $17.1 \%$ & $21.8 \%$ \\
\hline & & Winter & $64.3 \%$ & $28.4 \%$ & $6.1 \%$ & $1.2 \%$ & $9.9 \%$ & $76.5 \%$ & $11.5 \%$ & $2.1 \%$ \\
\hline & & Spring & $69.5 \%$ & $17.5 \%$ & $7.9 \%$ & $5.1 \%$ & $14.6 \%$ & $47.4 \%$ & $22.4 \%$ & $15.6 \%$ \\
\hline & & Summer & $58.9 \%$ & $18.9 \%$ & $9.4 \%$ & $12.8 \%$ & $25.7 \%$ & $18.7 \%$ & $12.9 \%$ & $42.6 \%$ \\
\hline & & Fall & $41.9 \%$ & $45.4 \%$ & $5.9 \%$ & $5.1 \%$ & $10.3 \%$ & $51.1 \%$ & $20.8 \%$ & $17.8 \%$ \\
\hline
\end{tabular}


Table 24. 10 SEER operation mode, seasonally and annually. The statistics indicate the percentage of time the IHPAC units operated in each of the following modes: supply fan only, fan plus compressor, or system off. The statistics are provided for 24 hours/7 days per week, and scheduled school hours only.

\begin{tabular}{|c|c|c|c|c|c|c|c|c|}
\hline \multirow[b]{2}{*}{ Location } & \multirow[b]{2}{*}{ Room } & \multirow[b]{2}{*}{ Season } & \multicolumn{3}{|c|}{ All Hours } & \multicolumn{3}{|c|}{ School Hours } \\
\hline & & & Off & Fan & Fan + Comp & Off & Fan & Fan + Comp \\
\hline \multirow[t]{10}{*}{$\mathrm{N} 1$} & 21 & All Year & $93.4 \%$ & $1.9 \%$ & $4.6 \%$ & $80.1 \%$ & $5.7 \%$ & $13.8 \%$ \\
\hline & & Winter & $95.8 \%$ & $0.4 \%$ & $3.8 \%$ & $86.8 \%$ & $1.4 \%$ & $9.5 \%$ \\
\hline & & Spring & $93.2 \%$ & $1.9 \%$ & $4.9 \%$ & $82.8 \%$ & $4.2 \%$ & $13.1 \%$ \\
\hline & & Summer & $91.4 \%$ & $1.7 \%$ & $6.9 \%$ & $72.9 \%$ & $5.1 \%$ & $22.0 \%$ \\
\hline & & Fall & $94.3 \%$ & $3.9 \%$ & $1.9 \%$ & $80.1 \%$ & $13.2 \%$ & $6.6 \%$ \\
\hline & 23 & All Year & $89.1 \%$ & $1.5 \%$ & $9.4 \%$ & $68.7 \%$ & $3.8 \%$ & $27.1 \%$ \\
\hline & & Winter & $95.7 \%$ & $1.4 \%$ & $2.9 \%$ & $85.1 \%$ & $4.9 \%$ & $8.5 \%$ \\
\hline & & Spring & $89.3 \%$ & $1.7 \%$ & $9.0 \%$ & $71.2 \%$ & $3.6 \%$ & $25.3 \%$ \\
\hline & & Summer & $79.9 \%$ & $1.4 \%$ & $18.6 \%$ & $44.8 \%$ & $3.7 \%$ & $51.5 \%$ \\
\hline & & Fall & $92.6 \%$ & $1.4 \%$ & $6.0 \%$ & $77.4 \%$ & $2.8 \%$ & $19.8 \%$ \\
\hline \multirow[t]{5}{*}{ N2 } & 26 & All Year & $92.5 \%$ & $0.5 \%$ & $7.0 \%$ & $82.6 \%$ & $0.9 \%$ & $16.1 \%$ \\
\hline & & Winter & $97.6 \%$ & $0.3 \%$ & $2.0 \%$ & $88.8 \%$ & $1.5 \%$ & $8.2 \%$ \\
\hline & & Spring & $96.1 \%$ & $0.5 \%$ & $3.4 \%$ & $87.7 \%$ & $0.6 \%$ & $11.7 \%$ \\
\hline & & Summer & $82.5 \%$ & $0.5 \%$ & $17.0 \%$ & $71.7 \%$ & $0.8 \%$ & $27.5 \%$ \\
\hline & & Fall & $94.2 \%$ & $0.8 \%$ & $5.0 \%$ & $82.2 \%$ & $0.8 \%$ & $16.9 \%$ \\
\hline \multirow[t]{5}{*}{ S1 } & 36 & All Year & $87.1 \%$ & $9.6 \%$ & $3.3 \%$ & $46.0 \%$ & $40.2 \%$ & $13.4 \%$ \\
\hline & & Winter & $88.2 \%$ & $10.7 \%$ & $1.1 \%$ & $45.8 \%$ & $47.7 \%$ & $4.9 \%$ \\
\hline & & Spring & $84.4 \%$ & $12.4 \%$ & $3.2 \%$ & $35.9 \%$ & $51.4 \%$ & $12.7 \%$ \\
\hline & & Summer & $87.6 \%$ & $6.6 \%$ & $5.8 \%$ & $50.9 \%$ & $26.2 \%$ & $22.9 \%$ \\
\hline & & Fall & $89.0 \%$ & $8.1 \%$ & $2.9 \%$ & $54.1 \%$ & $33.9 \%$ & $12.0 \%$ \\
\hline \multirow[t]{10}{*}{ S2 } & 14 & All Year & $89.1 \%$ & $4.6 \%$ & $6.3 \%$ & $57.7 \%$ & $16.8 \%$ & $24.7 \%$ \\
\hline & & Winter & $97.2 \%$ & $2.1 \%$ & $0.8 \%$ & $85.7 \%$ & $8.6 \%$ & $2.7 \%$ \\
\hline & & Spring & $88.5 \%$ & $5.7 \%$ & $5.7 \%$ & $57.1 \%$ & $20.5 \%$ & $22.5 \%$ \\
\hline & & Summer & $80.7 \%$ & $6.8 \%$ & $12.5 \%$ & $28.3 \%$ & $24.0 \%$ & $47.7 \%$ \\
\hline & & Fall & $90.3 \%$ & $3.4 \%$ & $6.3 \%$ & $62.1 \%$ & $12.1 \%$ & $25.8 \%$ \\
\hline & 16 & All Year & $87.8 \%$ & $5.1 \%$ & $7.1 \%$ & $54.3 \%$ & $18.2 \%$ & $27.5 \%$ \\
\hline & & Winter & $94.4 \%$ & $4.1 \%$ & $1.5 \%$ & $76.3 \%$ & $17.9 \%$ & $5.8 \%$ \\
\hline & & Spring & $89.9 \%$ & $5.2 \%$ & $5.0 \%$ & $64.7 \%$ & $17.1 \%$ & $18.2 \%$ \\
\hline & & Summer & $80.2 \%$ & $5.8 \%$ & $14.0 \%$ & $26.9 \%$ & $19.8 \%$ & $53.4 \%$ \\
\hline & & Fall & $89.6 \%$ & $5.0 \%$ & $5.5 \%$ & $59.5 \%$ & $17.8 \%$ & $22.6 \%$ \\
\hline
\end{tabular}


Table 25. 10 SEER operation mode, seasonally and annually. The statistics indicate the average ( \pm standard deviation) of time the IHPAC units operated in each of the following modes: supply fan only, fan plus compressor, or system off. The statistics are provided for 24 hours/7 days per week, and scheduled school hours only.

\begin{tabular}{|c|c|c|c|c|c|c|c|}
\hline \multirow[b]{2}{*}{ Location } & \multirow[b]{2}{*}{ Season } & \multicolumn{3}{|c|}{ All Hours } & \multicolumn{3}{|c|}{ School Hours } \\
\hline & & Off & Fan & Fan + Comp & Off & Fan & Fan + Comp \\
\hline \multirow[t]{5}{*}{ North } & All Year & $92 \% \pm 2 \%$ & $1 \% \pm 1 \%$ & $7 \% \pm 2 \%$ & $77 \% \pm 7 \%$ & $3 \% \pm 2 \%$ & $19 \% \pm 7 \%$ \\
\hline & Fall & $94 \% \pm 1 \%$ & $2 \% \pm 2 \%$ & $4 \% \pm 2 \%$ & $80 \% \pm 2 \%$ & $6 \% \pm 7 \%$ & $14 \% \pm 7 \%$ \\
\hline & Spring & $93 \% \pm 3 \%$ & $1 \% \pm 1 \%$ & $6 \% \pm 3 \%$ & $81 \% \pm 8 \%$ & $3 \% \pm 2 \%$ & $17 \% \pm 7 \%$ \\
\hline & Summer & $85 \% \pm 6 \%$ & $1 \% \pm 1 \%$ & $14 \% \pm 6 \%$ & $63 \% \pm 16 \%$ & $3 \% \pm 2 \%$ & $34 \% \pm 16 \%$ \\
\hline & Winter & $96 \% \pm 1 \%$ & $1 \% \pm 1 \%$ & $3 \% \pm 1 \%$ & $87 \% \pm 2 \%$ & $3 \% \pm 2 \%$ & $9 \% \pm 1 \%$ \\
\hline \multirow[t]{5}{*}{ South } & All Year & $88 \% \pm 1 \%$ & $6 \% \pm 3 \%$ & $6 \% \pm 2 \%$ & $53 \% \pm 6 \%$ & $25 \% \pm 13 \%$ & $22 \% \pm 7 \%$ \\
\hline & Fall & $90 \% \pm 1 \%$ & $6 \% \pm 2 \%$ & $5 \% \pm 2 \%$ & $59 \% \pm 4 \%$ & $21 \% \pm 11 \%$ & $20 \% \pm 7 \%$ \\
\hline & Spring & $88 \% \pm 3 \%$ & $8 \% \pm 4 \%$ & $5 \% \pm 1 \%$ & $53 \% \pm 15 \%$ & $30 \% \pm 19 \%$ & $18 \% \pm 5 \%$ \\
\hline & Summer & $83 \% \pm 4 \%$ & $6 \% \pm 1 \%$ & $11 \% \pm 4 \%$ & $35 \% \pm 13 \%$ & $23 \% \pm 3 \%$ & $41 \% \pm 16 \%$ \\
\hline & Winter & $93 \% \pm 5 \%$ & $6 \% \pm 5 \%$ & $1 \% \pm 0 \%$ & $69 \% \pm 21 \%$ & $25 \% \pm 20 \%$ & $4 \% \pm 2 \%$ \\
\hline \multirow[t]{5}{*}{ All } & All Year & $90 \% \pm 3 \%$ & $4 \% \pm 3 \%$ & $6 \% \pm 2 \%$ & $65 \% \pm 15 \%$ & $14 \% \pm 15 \%$ & $20 \% \pm 7 \%$ \\
\hline & Fall & $92 \% \pm 2 \%$ & $4 \% \pm 3 \%$ & $5 \% \pm 2 \%$ & $69 \% \pm 12 \%$ & $13 \% \pm 12 \%$ & $17 \% \pm 7 \%$ \\
\hline & Spring & $90 \% \pm 4 \%$ & $5 \% \pm 4 \%$ & $5 \% \pm 2 \%$ & $67 \% \pm 19 \%$ & $16 \% \pm 19 \%$ & $17 \% \pm 6 \%$ \\
\hline & Summer & $84 \% \pm 5 \%$ & $4 \% \pm 3 \%$ & $12 \% \pm 5 \%$ & $49 \% \pm 20 \%$ & $13 \% \pm 11 \%$ & $38 \% \pm 15 \%$ \\
\hline & Winter & $95 \% \pm 3 \%$ & $3 \% \pm 4 \%$ & $2 \% \pm 1 \%$ & $78 \% \pm 16 \%$ & $14 \% \pm 18 \%$ & $7 \% \pm 3 \%$ \\
\hline
\end{tabular}

Table 26. IHPAC operation mode, seasonally and annually. The statistics indicate the average ( \pm standard deviation) percentage of time the IHPAC units operated in each of the following modes: supply fan only, fan plus stage one compressor, fan plus stage 2 compressor, or system off. The statistics are provided for 24 hours/7 days per week, and scheduled school hours only.

\begin{tabular}{|c|c|c|c|c|c|c|c|c|c|}
\hline & \multicolumn{4}{|c|}{ All Hours } & \multicolumn{4}{|c|}{ School Hours } \\
\hline & & Off & Fan & Stage 1 & Stage 2 & Off & Fan & Stage 1 & Stage 2 \\
\hline \multirow[t]{5}{*}{ North } & All Year & $67 \% \pm 2 \%$ & $14 \% \pm 8 \%$ & $14 \% \pm 8 \%$ & $5 \% \pm 2 \%$ & $25 \% \pm 6 \%$ & $35 \% \pm 20 \%$ & $30 \% \pm 22 \%$ & $10 \% \pm 2 \%$ \\
\hline & Fall & $73 \% \pm 7 \%$ & $15 \% \pm 9 \%$ & $11 \% \pm 9 \%$ & $1 \% \pm 1 \%$ & $21 \% \pm 16 \%$ & $46 \% \pm 28^{\circ}$ & $31 \% \pm 28 \%$ & $1 \%$ \\
\hline & Spring & $73 \% \pm$ & $14 \% \pm 8 \%$ & $11 \%$ & $2 \% \pm 1 \%$ & $24 \% \pm 6 \%$ & $40 \% \pm 23 \%$ & $28 \%$ & $3 \%$ \\
\hline & Summer & $64 \%$ & $8 \% \pm 5 \%$ & & & $34 \%$ & $14 \% \pm$ & $5 \%$ & 23 \\
\hline & & $57 \% \pm 10 \%$ & $21 \% \pm 14 \%$ & $19 \%$ & & $15 \%$ & $48 \% \pm$ & $34 \%$ & \\
\hline \multirow[t]{5}{*}{ South } & & & $20 \% \pm 5 \%$ & & & & & $\pm 3 \%$ & $\pm 7 \%$ \\
\hline & Fall & $64 \% \pm 21 \%$ & $26 \% \pm 20 \%$ & $\pm 2 \%$ & $\pm 1 \%$ & $24 \% \pm$ & $41 \% \pm 10 \%$ & $=8 \%$ & $\pm 4 \%$ \\
\hline & Spring & $72 \% \pm 5 \%$ & $18 \% \pm 2 \%$ & $7 \% \pm 2 \%$ & $3 \% \pm 1 \%$ & $20 \% \pm 8 \%$ & $49 \% \pm 5 \%$ & $21 \% \pm 5 \%$ & $10 \% \pm 5 \%$ \\
\hline & Summer & $69 \% \pm 7 \%$ & $12 \% \pm 4 \%$ & $9 \% \pm 1 \%$ & $55 \%$ & $32 \% \pm 12 \%$ & $18 \% \pm 3 \%$ & $19 \% \pm 4 \%$ & $=16 \%$ \\
\hline & Winter & $60 \% \pm 6 \%$ & $31 \% \pm 5 \%$ & $7 \% \pm 1 \%$ & $2 \% \pm 1 \%$ & $18 \% \pm 8 \%$ & $69 \% \pm 8 \%$ & $11 \% \pm 3 \%$ & $2 \% \pm 1 \%$ \\
\hline \multirow[t]{5}{*}{ All } & & $67 \% \pm 4 \%$ & $17 \% \pm 7 \%$ & & $\pm 2 \%$ & $24 \%$ & $38 \% \pm 14$ & $24 \% \pm 16 \%$ & $\pm 6 \%$ \\
\hline & & $69 \% \pm 15 \%$ & $20 \% \pm 16 \%$ & $8 \% \pm 7 \%$ & & $22 \% \pm$ & $43 \% \pm 20$ & $26 \% \pm 20 \%$ & $8 \% \pm 7 \%$ \\
\hline & Spr & $73 \% \pm 4 \%$ & $16 \% \pm 6 \%$ & $9 \% \pm 6 \%$ & $3 \% \pm 1 \%$ & $22 \% \pm 7 \%$ & $44 \% \pm 16 \%$ & $26 \% \pm 20 \%$ & $7 \% \pm 5 \%$ \\
\hline & & $66 \% \pm 6 \%$ & $10 \% \pm 5 \%$ & $13 \% \pm 6 \%$ & & $33 \% \pm 9 \%$ & $16 \% \pm 6 \%$ & $24 \% \pm 6 \%$ & $27 \%$ \\
\hline & Winter & $59 \% \pm 8 \%$ & $26 \% \pm 11 \%$ & $13 \% \pm 11 \%$ & $2 \% \pm 1 \%$ & $16 \% \pm 9 \%$ & $58 \% \pm 22 \%$ & $22 \% \pm 25 \%$ & $3 \% \pm 2 \%$ \\
\hline
\end{tabular}


Table 27. Predicted annual classroom 10 SEER and IHPAC energy consumption for traditional ninemonth school schedule in 16 California Climate zones using DOE-2. Both continuous and intermittent 10 SEER fan operation modes are shown.

\begin{tabular}{|c|c|c|c|c|c|c|}
\hline $\begin{array}{c}\text { Climate } \\
\text { Zone }\end{array}$ & System & Fan Mode & $\begin{array}{c}\text { Heating } \\
\text { (kWh) }\end{array}$ & $\begin{array}{c}\text { Cooling } \\
\text { (kWh) }\end{array}$ & $\begin{array}{c}\text { Fan } \\
\text { (kWh) }\end{array}$ & $\begin{array}{l}\text { Total } \\
\text { (kWh) }\end{array}$ \\
\hline 1 & 10 SEER & Continuous & 899 & 27 & 1197 & 2123 \\
\hline 2 & & & 868 & 450 & 1369 & 2687 \\
\hline 3 & & & 463 & 149 & 1033 & 1645 \\
\hline 4 & & & 430 & 255 & 1083 & 1768 \\
\hline 5 & & & 452 & 190 & 1056 & 1698 \\
\hline 6 & & & 226 & 438 & 1048 & 1712 \\
\hline 7 & & & 126 & 386 & 973 & 1484 \\
\hline 8 & & & 203 & 466 & 1079 & 1749 \\
\hline 9 & & & 263 & 499 & 1097 & 1859 \\
\hline 10 & & & 348 & 618 & 1255 & 2220 \\
\hline 11 & & & 820 & 616 & 1514 & 2950 \\
\hline 12 & & & 635 & 472 & 1343 & 2451 \\
\hline 13 & & & 690 & 683 & 1487 & 2861 \\
\hline 14 & & & 523 & 913 & 1573 & 3009 \\
\hline 15 & & & 164 & 1258 & 1557 & 2979 \\
\hline 16 & & & 1727 & 260 & 1593 & 3580 \\
\hline 1 & IHPAC & Continuous & 453 & 23 & 748 & 1224 \\
\hline 2 & & & 577 & 282 & 859 & 1718 \\
\hline 3 & & & 215 & 101 & 647 & 963 \\
\hline 4 & & & 218 & 167 & 678 & 1063 \\
\hline 5 & & & 264 & 126 & 659 & 1049 \\
\hline 6 & & & 108 & 274 & 657 & 1039 \\
\hline 7 & & & 60 & 247 & 608 & 916 \\
\hline 8 & & & 97 & 292 & 675 & 1064 \\
\hline 9 & & & 125 & 311 & 688 & 1124 \\
\hline 10 & & & 181 & 382 & 791 & 1354 \\
\hline 11 & & & 495 & 385 & 953 & 1834 \\
\hline 12 & & & 344 & 294 & 844 & 1481 \\
\hline 13 & & & 430 & 427 & 934 & 1791 \\
\hline 14 & & & 339 & 580 & 1005 & 1924 \\
\hline 15 & & & 81 & 787 & 999 & 1868 \\
\hline 16 & & & 1127 & 162 & 996 & 2285 \\
\hline 1 & 10 SEER & Intermittent & 855 & 66 & 181 & 1103 \\
\hline 2 & & & 811 & 421 & 331 & 1562 \\
\hline 3 & & & 436 & 169 & 183 & 788 \\
\hline 4 & & & 418 & 258 & 229 & 904 \\
\hline 5 & & & 492 & 192 & 198 & 882 \\
\hline 6 & & & 221 & 400 & 261 & 881 \\
\hline 7 & & & 128 & 359 & 230 & 718 \\
\hline 8 & & & 217 & 434 & 284 & 935 \\
\hline 9 & & & 240 & 468 & 307 & 1015 \\
\hline 10 & & & 391 & 570 & 379 & 1340 \\
\hline 11 & & & 818 & 557 & 413 & 1788 \\
\hline 12 & & & 612 & 423 & 321 & 1355 \\
\hline 13 & & & 659 & 622 & 412 & 1693 \\
\hline 14 & & & 544 & 880 & 585 & 2009 \\
\hline 15 & & & 194 & 1213 & 678 & 2084 \\
\hline 16 & & & 1708 & 223 & 327 & 2258 \\
\hline
\end{tabular}


Table 28. DOE-2 Predicted annual classroom 10 SEER and IHPAC energy consumption for traditional nine-month school schedule in 37 U.S. Cities. Both 10 SEER and IHPAC systems were operated in continuous ventilation mode during classroom occupancy.

\begin{tabular}{|c|c|c|c|c|c|c|c|c|}
\hline City & $\begin{array}{l}10 \text { SEE } \\
\text { Heating } \\
\text { (kWh) }\end{array}$ & $\begin{array}{l}\text { R (Conti } \\
\text { Cooling } \\
\text { (kWh) }\end{array}$ & $\begin{array}{l}\text { inuous } \\
\text { Fan } \\
\text { (kWh) }\end{array}$ & $\begin{array}{l}\text { Fan) } \\
\text { Total } \\
\text { (kWh) }\end{array}$ & $\begin{array}{l}\text { Heating } \\
\text { (kWh) }\end{array}$ & $\begin{array}{l}\text { IHPA } \\
\text { Cooling } \\
\text { (kWh) }\end{array}$ & $\begin{array}{l}\text { Can } \\
\text { (kWh) }\end{array}$ & $\begin{array}{l}\text { Total } \\
\text { (kWh) }\end{array}$ \\
\hline Albuquerque & 1259 & 448 & 1523 & 3231 & 881 & 279 & 954 & 2114 \\
\hline Anchorage & 7272 & 18 & 1868 & 9158 & 6481 & 11 & 1163 & 7655 \\
\hline Atlanta & 1025 & 560 & 1374 & 2959 & 706 & 343 & 863 & 1912 \\
\hline Birmingham & 771 & 624 & 1362 & 2757 & 487 & 381 & 854 & 1722 \\
\hline Boston & 2416 & 231 & 1572 & 4219 & 1788 & 143 & 983 & 2915 \\
\hline Brownsville & 136 & 1264 & 1272 & 2673 & 68 & 751 & 799 & 1617 \\
\hline Charleston & 583 & 773 & 1280 & 2637 & 377 & 466 & 805 & 1649 \\
\hline Chicago & 3355 & 297 & 1656 & 5308 & 2746 & 181 & 1035 & 3962 \\
\hline Dayton & 3157 & 285 & 1576 & 5017 & 2619 & 174 & 985 & 3779 \\
\hline Denver & 2541 & 280 & 1577 & 4398 & 2067 & 172 & 987 & 3226 \\
\hline EIPaso & 555 & 740 & 1443 & 2738 & 351 & 457 & 909 & 1717 \\
\hline EIToro & 203 & 466 & 1079 & 1749 & 97 & 292 & 675 & 1064 \\
\hline FortWorth & 633 & 835 & 1425 & 2893 & 387 & 507 & 893 & 1787 \\
\hline Jacksonville & 338 & 1022 & 1289 & 2648 & 202 & 610 & 809 & 1621 \\
\hline KansasCity & 2479 & 469 & 1621 & 4569 & 1988 & 286 & 1014 & 3288 \\
\hline LakeCharles & 471 & 963 & 1317 & 2751 & 285 & 579 & 827 & 1691 \\
\hline LasVegas & 396 & 916 & 1529 & 2840 & 217 & 578 & 974 & 1768 \\
\hline Miami & 28 & 1467 & 1266 & 2761 & 13 & 871 & 795 & 1678 \\
\hline Minneapolis & 5927 & 236 & 1751 & 7914 & 5373 & 146 & 1089 & 6608 \\
\hline Nashville & 1686 & 619 & 1510 & 3816 & 1320 & 377 & 946 & 2643 \\
\hline NewYork & 2030 & 292 & 1510 & 3832 & 1468 & 180 & 945 & 2592 \\
\hline Oakland & 463 & 149 & 1033 & 1645 & 215 & 101 & 647 & 963 \\
\hline Omaha & 3628 & 380 & 1648 & 5656 & 3179 & 234 & 1028 & 4441 \\
\hline Pasadena & 263 & 499 & 1097 & 1859 & 125 & 311 & 688 & 1124 \\
\hline Philadelphia & 2055 & 372 & 1564 & 3991 & 1481 & 227 & 979 & 2686 \\
\hline Phoenix & 248 & 1189 & 1605 & 3042 & 133 & 742 & 1022 & 1897 \\
\hline Raleigh & 1185 & 516 & 1382 & 3082 & 849 & 314 & 868 & 2031 \\
\hline RedBluff & 820 & 616 & 1514 & 2950 & 495 & 385 & 953 & 1834 \\
\hline Reno & 1850 & 317 & 1560 & 3727 & 1407 & 197 & 977 & 2581 \\
\hline Riverside & 348 & 618 & 1255 & 2220 & 181 & 382 & 791 & 1354 \\
\hline Sacramento & 649 & 454 & 1341 & 2443 & 357 & 282 & 841 & 1481 \\
\hline SaltLakeCity & 2036 & 341 & 1648 & 4025 & 1521 & 213 & 1031 & 2765 \\
\hline SanAntonio & 467 & 974 & 1397 & 2839 & 299 & 587 & 877 & 1763 \\
\hline SanDiego & 108 & 437 & 1006 & 1551 & 51 & 278 & 629 & 958 \\
\hline Seattle & 1435 & 106 & 1421 & 2961 & 843 & 68 & 889 & 1800 \\
\hline Sunnyvale & 430 & 255 & 1083 & 1768 & 218 & 167 & 678 & 1063 \\
\hline Washington & 1853 & 394 & 1535 & 3781 & 881 & 279 & 954 & 2114 \\
\hline
\end{tabular}


Table 29. Regression of Nose and Fuji measurements collected from three one-week periods following Fuji calibrations conducted during spring, summer, and fall field visits . The regression model is Nose $(\mathrm{ppm})=$ Slope * Fuji $(\mathrm{ppm})+$ Intercept. The "Shared" column refers to whether the sampling line for a particular Fuji paired with that room's Nose was multiplexed with another room or outdoor site. Multiplexed sampling lines switched between up to 3 sites on a six-minute sample cycle - the first three minutes of each locations data were dropped to accommodate instrument stabilization.

\begin{tabular}{|lccccc|}
\hline \multicolumn{2}{|c}{ Location Room Slope } & Intercept & $\mathbf{R}^{\mathbf{2}}$ & Shared \\
\hline $\mathrm{N} 1$ & 21 & 1.16 & 34 & 0.944 & $\mathrm{~N}$ \\
& 22 & 1.05 & 38 & 0.970 & $\mathrm{Y}$ \\
& 23 & 1.00 & 58 & 0.980 & $\mathrm{Y}$ \\
$\mathrm{N} 2$ & 24 & 1.12 & 26 & 0.976 & $\mathrm{~N}$ \\
& 25 & 1.04 & 73 & 0.917 & $\mathrm{Y}$ \\
$\mathrm{S} 1$ & 26 & 1.00 & 94 & 0.994 & $\mathrm{Y}$ \\
& 13 & 0.98 & 33 & 0.978 & $\mathrm{Y}$ \\
& 14 & 0.96 & 24 & 0.992 & $\mathrm{Y}$ \\
& 15 & 1.01 & 48 & 0.986 & $\mathrm{~N}$ \\
$\mathrm{~S} 2$ & 16 & 0.95 & 74 & 0.996 & $\mathrm{~N}$ \\
& 35 & 0.85 & 119 & 0.996 & $\mathrm{Y}$ \\
& 36 & 0.99 & 72 & 0.982 & $\mathrm{Y}$ \\
& 37 & 1.14 & 13 & 0.963 & $\mathrm{~N}$ \\
\hline
\end{tabular}




\section{Figures}

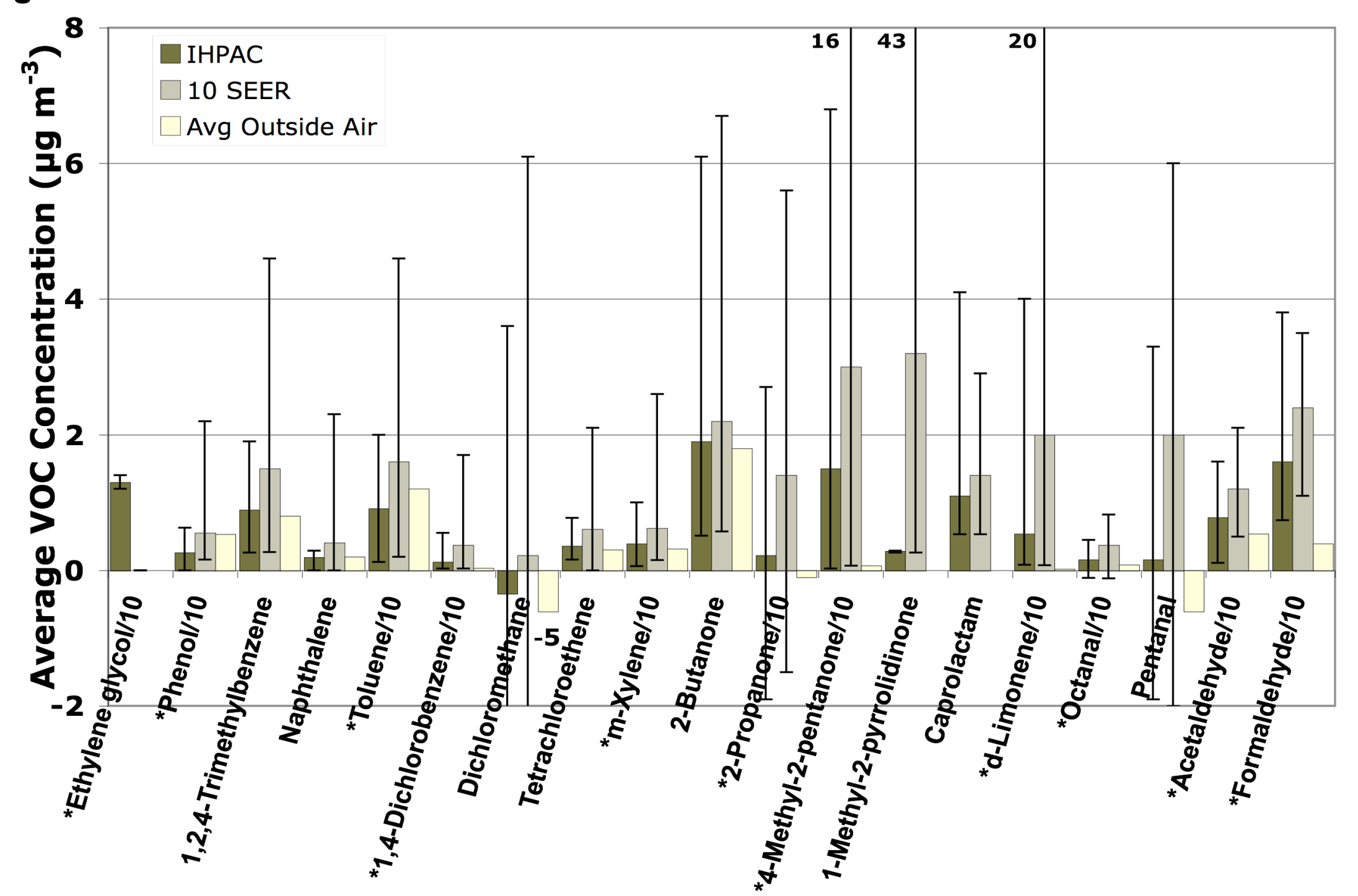

Figure 1. Selected toxic and odorous VOCs measured indoors, averaged across two school districts, four schools and three seasons of data collection. Data for IHPAC and 10 SEER classrooms, and outdoor air are shown. Error bars indicate minimum and maximum VOC concentrations observed during the study. Note that many compound concentrations have been scaled by a factor of 10 to fit on the plot. 

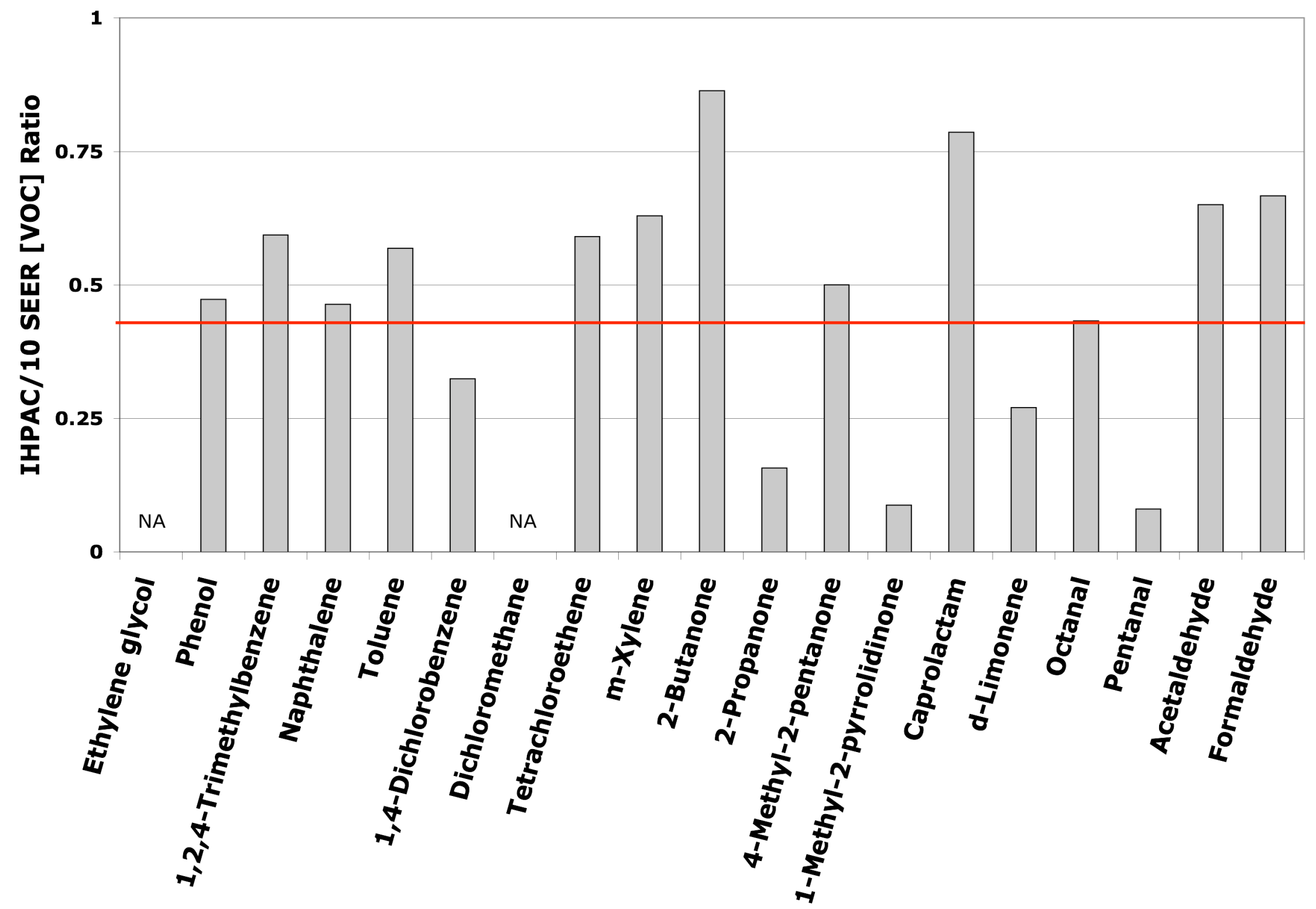

Figure 2. Ratio of Average VOC concentrations measured in IHAPC classrooms to those measured in 10 SEER classrooms. The horizontal line represents the average ratio (0.43) across the 19 compounds. 


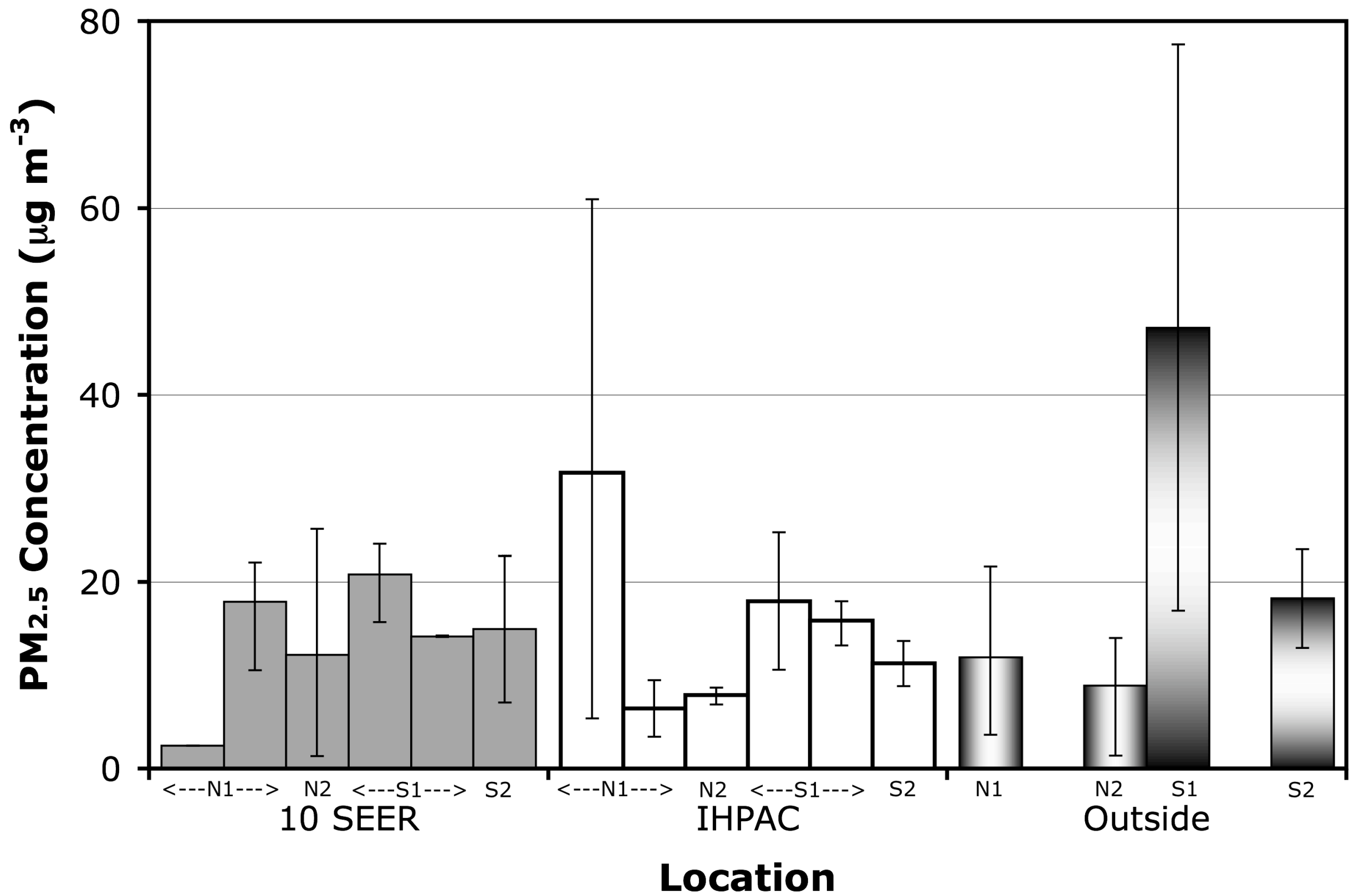

Figure 3. Approximate $\mathrm{PM}_{2.5}$ concentrations in the study classrooms and outside averaged across seasonal measurements. Classrooms are arranged by HVAC type. Error bars depict minimum and maximum average concentrations across seasons for each measurement location. 


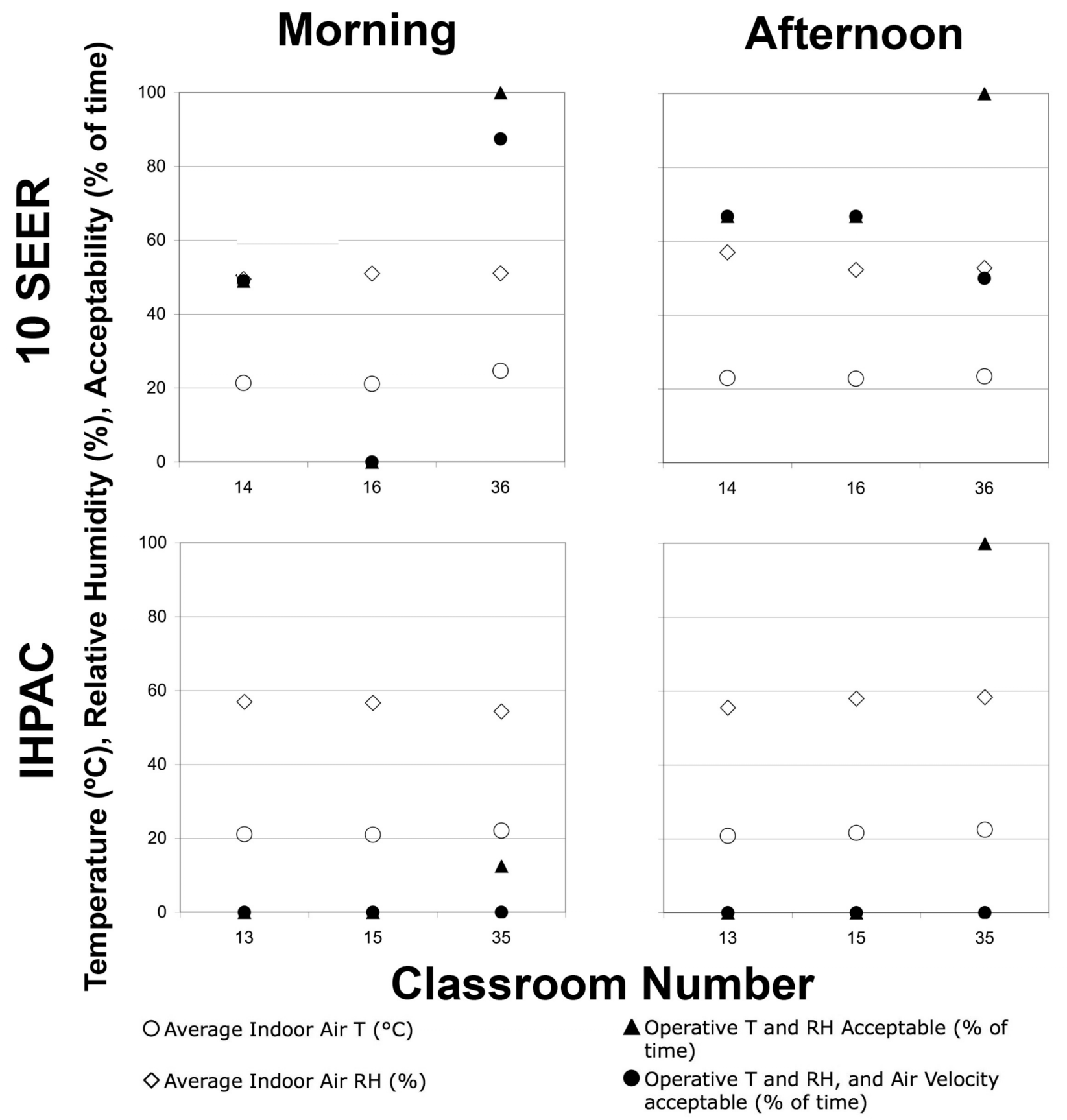

Figure 4. Morning and afternoon thermal comfort (TC) related measurements and ASHRAE Standard 55 calculated acceptable TC levels for study classrooms during the spring of 2005 field measurement visits. Percent time during school day of acceptable TC both with and without air velocity in the ASHRAE 55 calculation are shown 


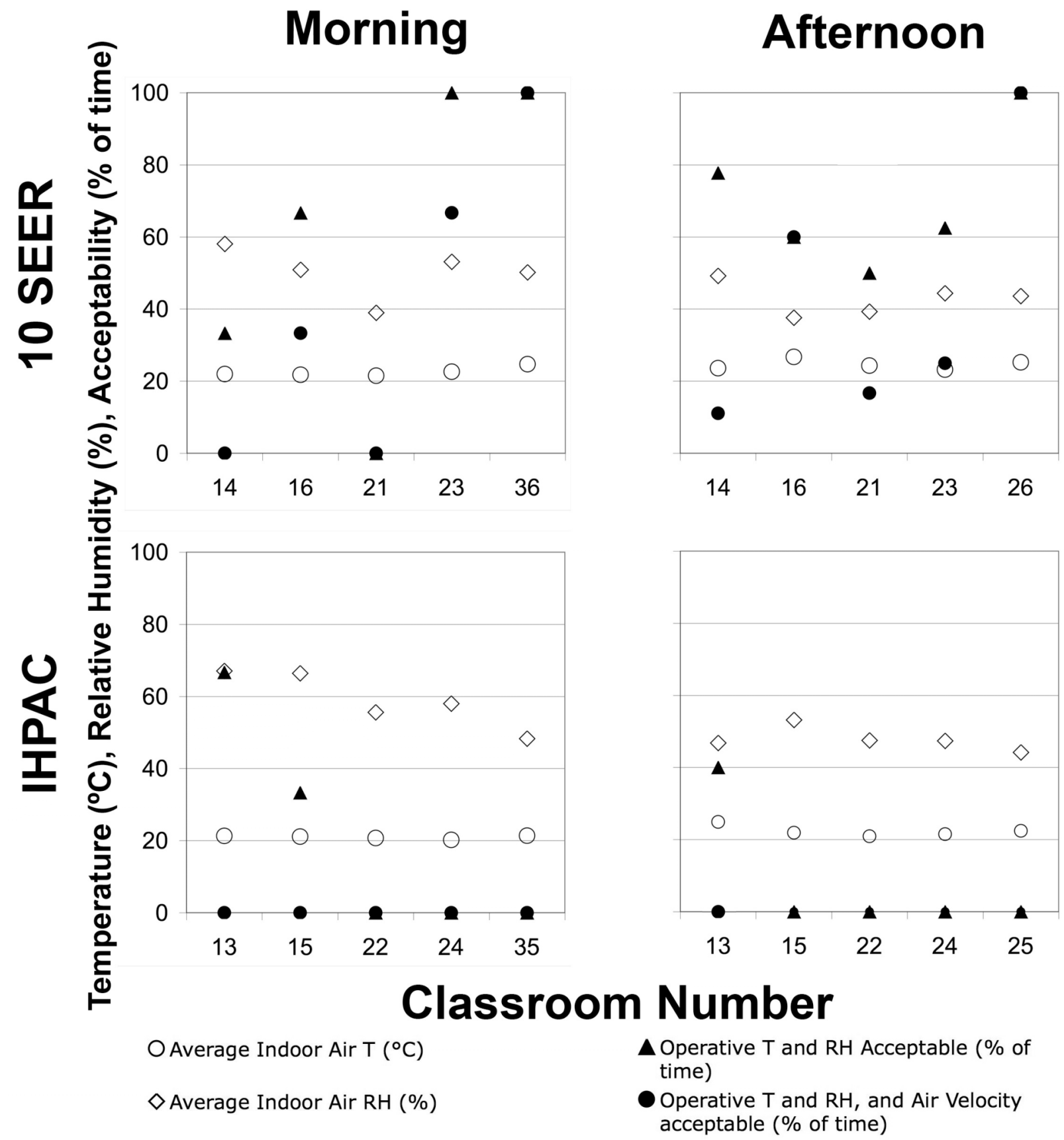

Figure 5. Morning and afternoon thermal comfort (TC) related measurements and ASHRAE Standard 55 calculated acceptable TC levels for study classrooms during the summer of 2005 field measurement visits. Percent time during school day of acceptable TC both with and without air velocity in the ASHRAE 55 calculation are shown 


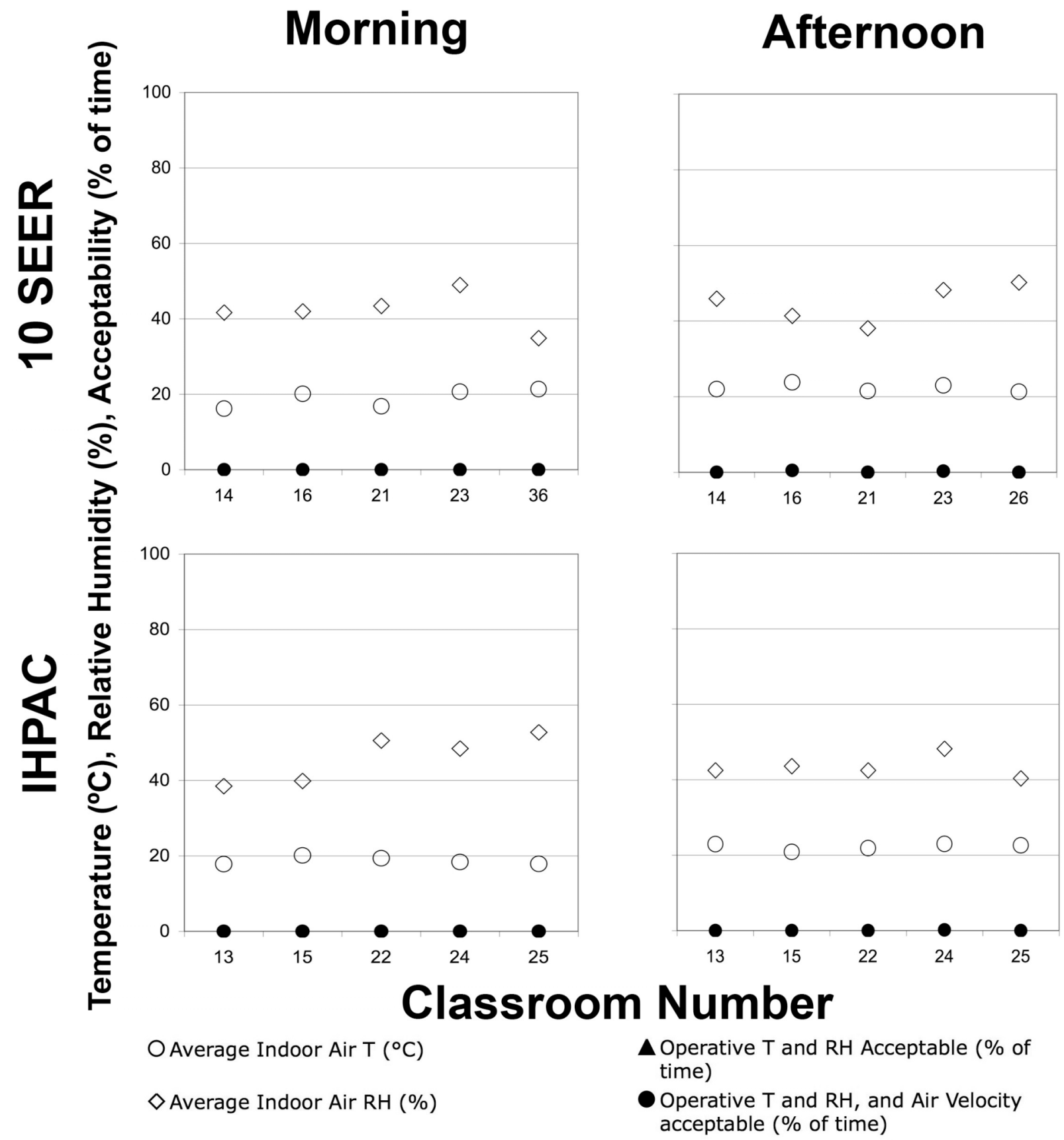

Figure 6. Morning and afternoon thermal comfort (TC) related measurements and ASHRAE Standard 55 calculated acceptable TC levels for study classrooms during the fall of 2005 field measurement visits Percent time during school day of acceptable TC both with and without air velocity in the ASHRAE 55 calculation are shown (no difference in this case). 


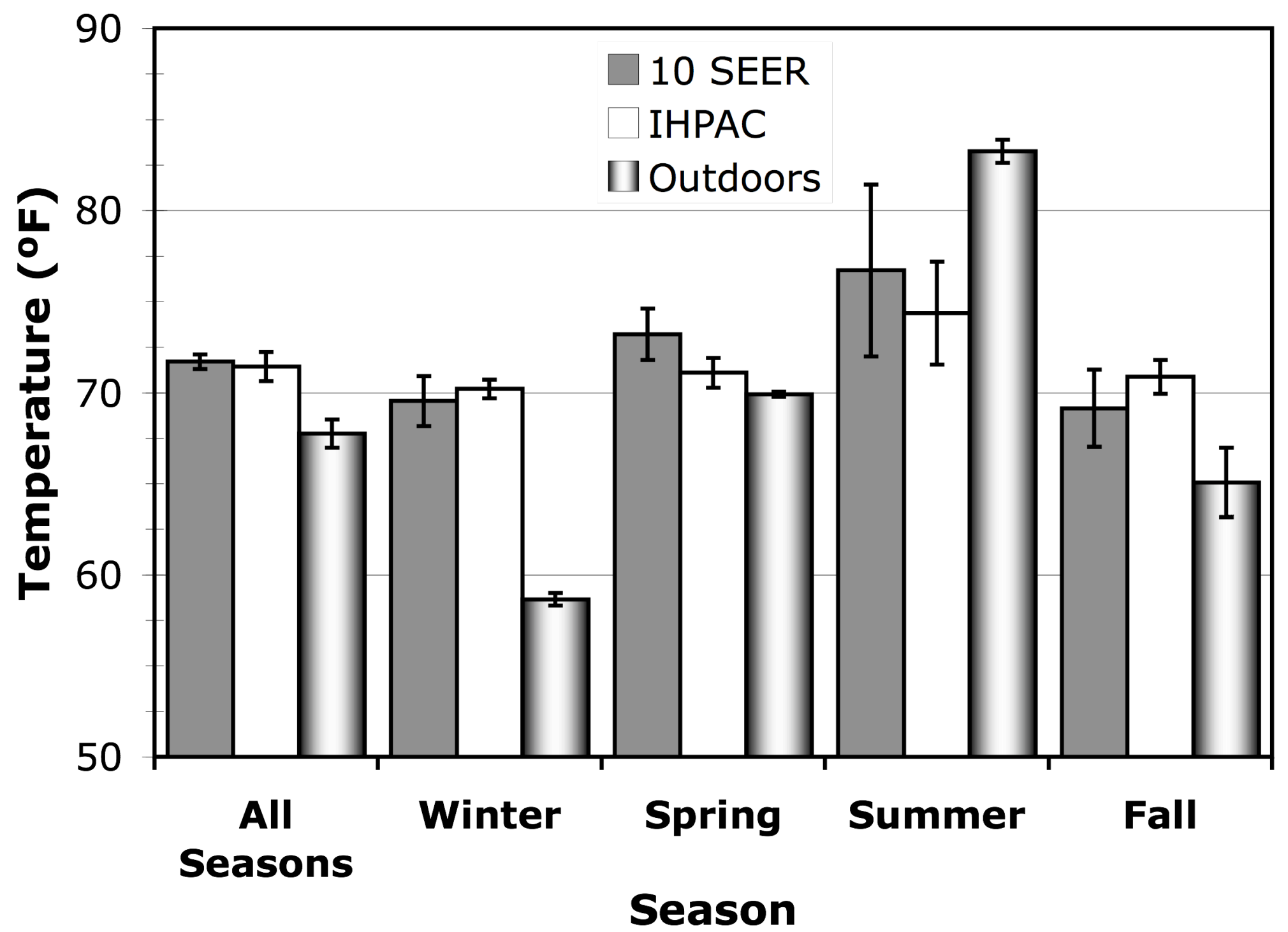

Figure 7. Average seasonal schoolday hour indoor and outdoor temperatures across 10 SEER and IHPAC classrooms in the northern California school district. Error bars indicate \pm 1 standard deviation. 


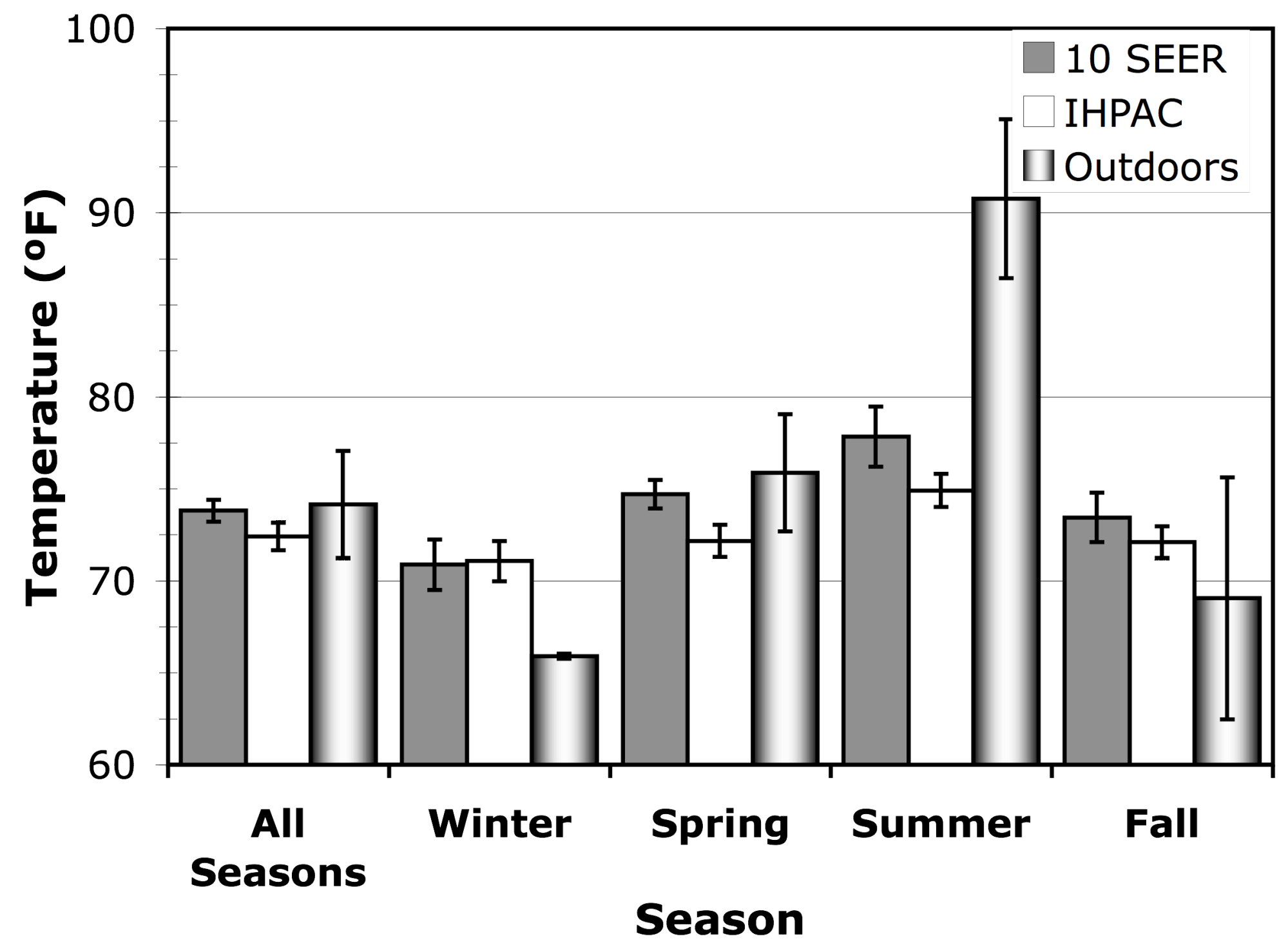

Figure 8. Average seasonal schoolday hour indoor and outdoor temperatures across 10 SEER and IHPAC classrooms in the southern California school district. Error bars indicate \pm 1 standard deviation. 


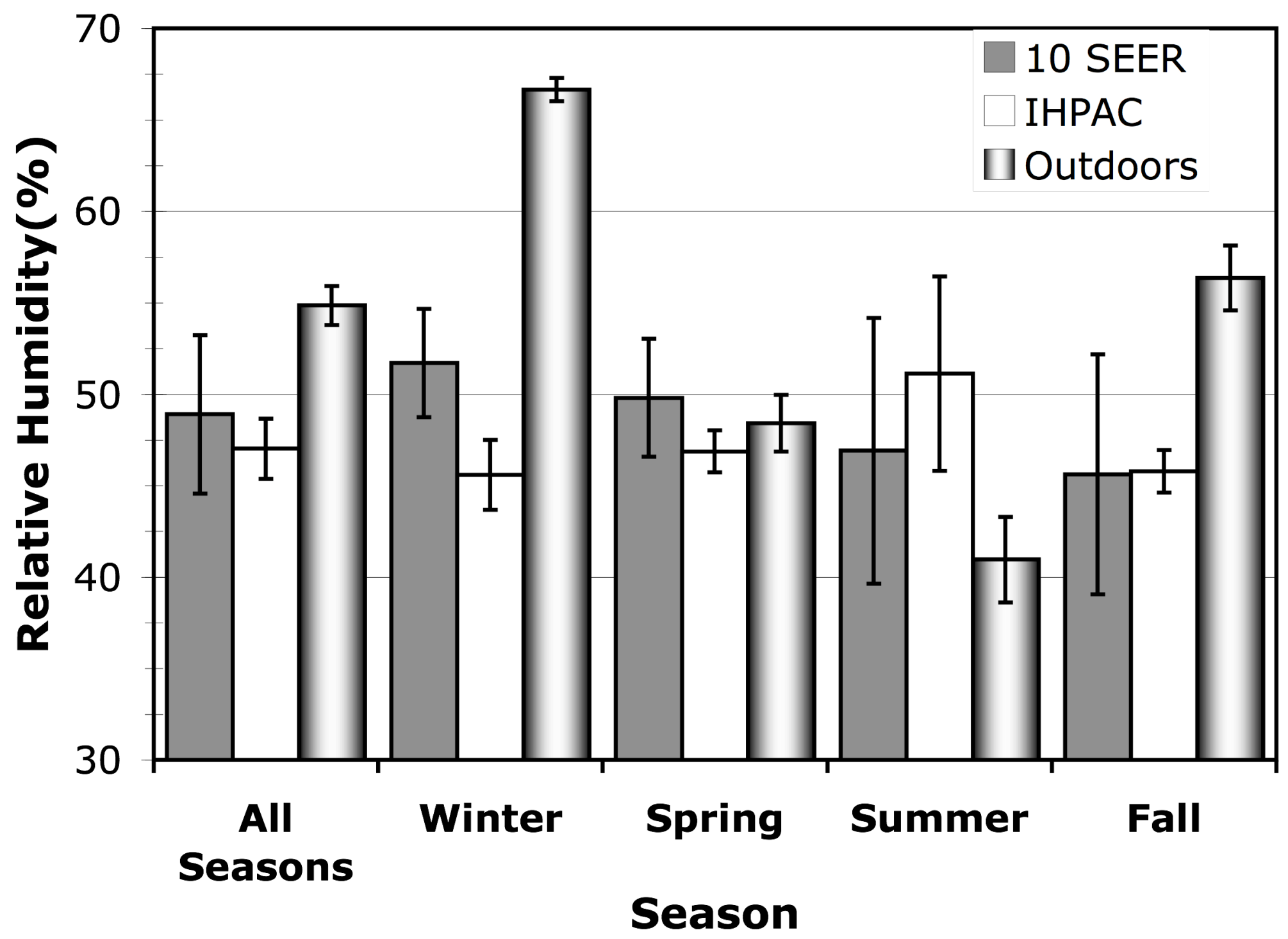

Figure 9. Average seasonal schoolday hour indoor and outdoor relative humidity across 10 SEER and IHPAC classrooms in the northern California school district. Error bars indicate \pm 1 standard deviation. 


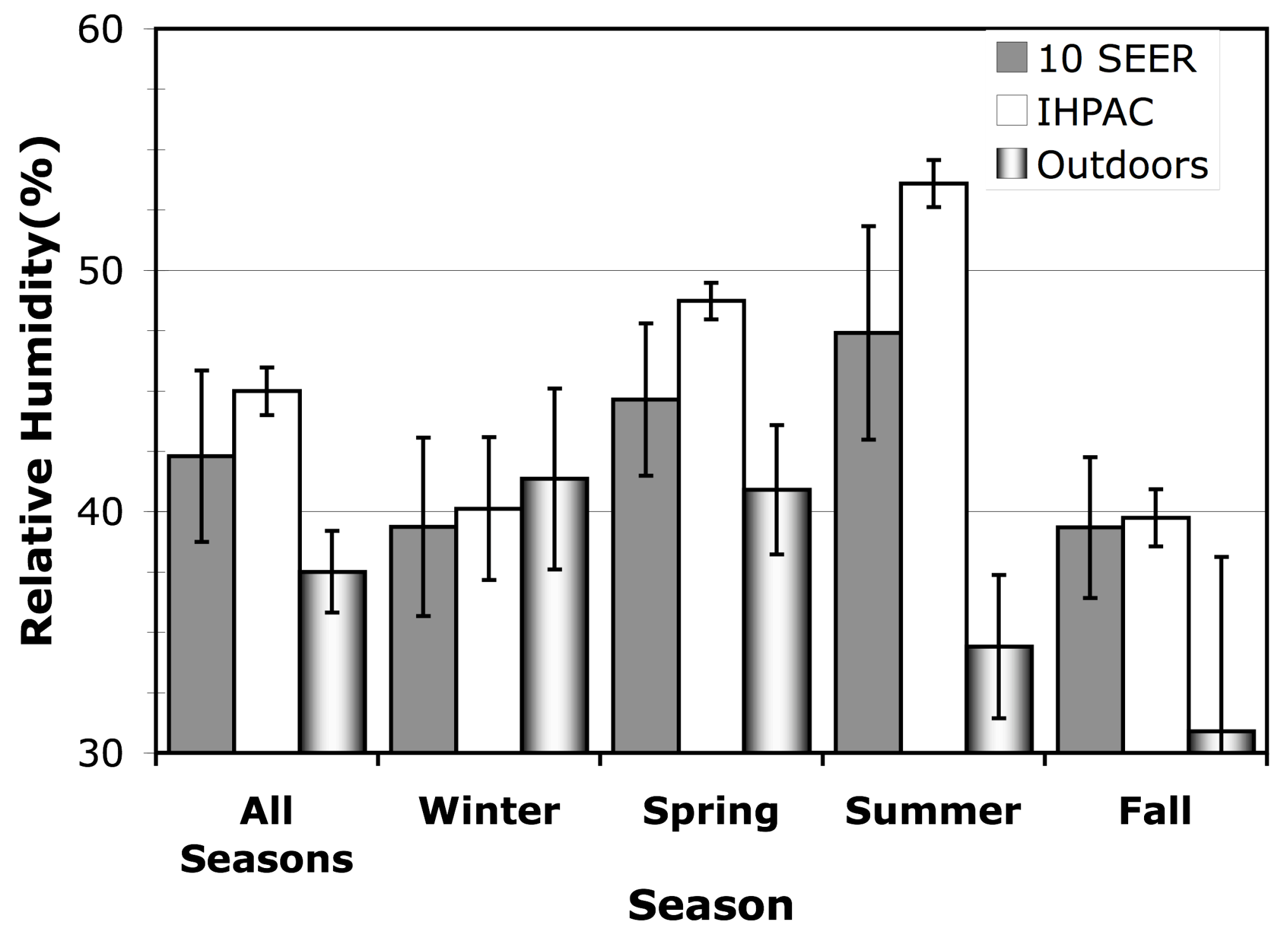

Figure 10. Average seasonal schoolday hour indoor and outdoor relative humidity across 10 SEER and IHPAC classrooms in the southern California school district. Error bars indicate \pm 1 standard deviation. 

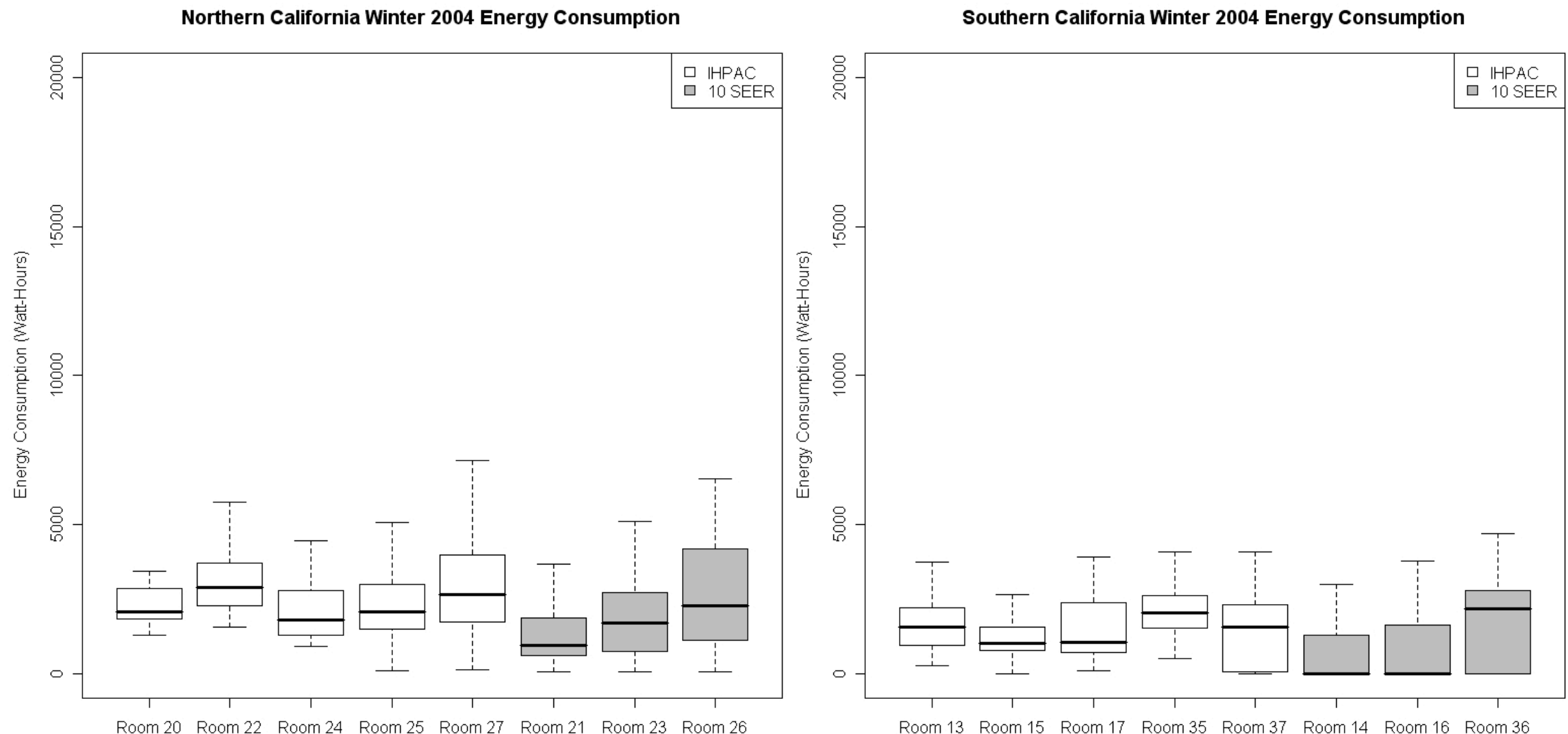

Figure 11. Box and whisker plots of measured daily energy consumption distributions for Northern and Southern California classroom in the 2004Winter season. The dark center line is the median value and the boxes bound the first and third quartiles. The whiskers mark the minimum and maximum measured values. 
Northern California Spring 2005 Energy Consumption

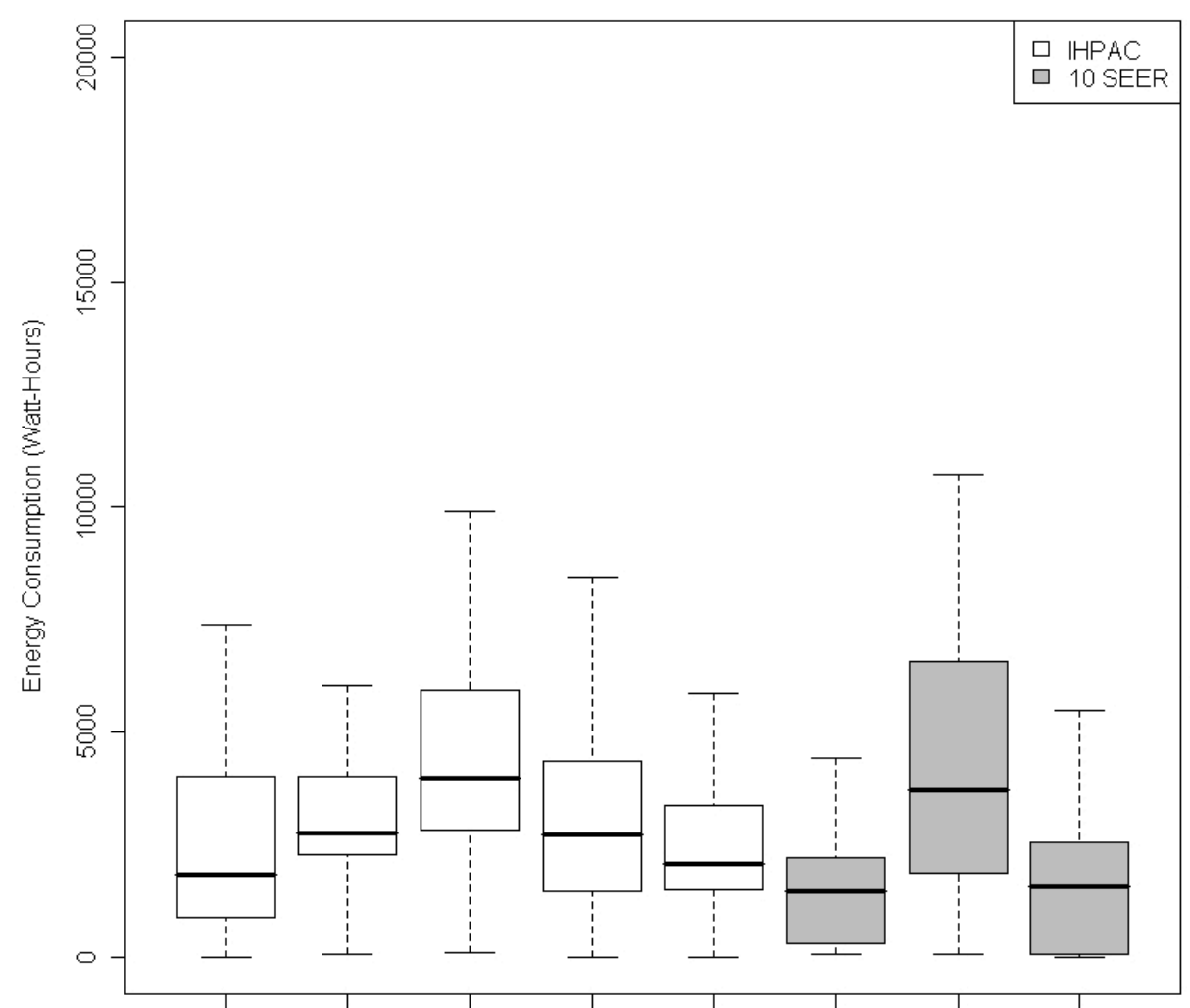

Room 20 Room 22 Room 24 Room 25 Room 27 Room 21 Room 23 Room 26
Southern California Spring 2005 Energy Consumption

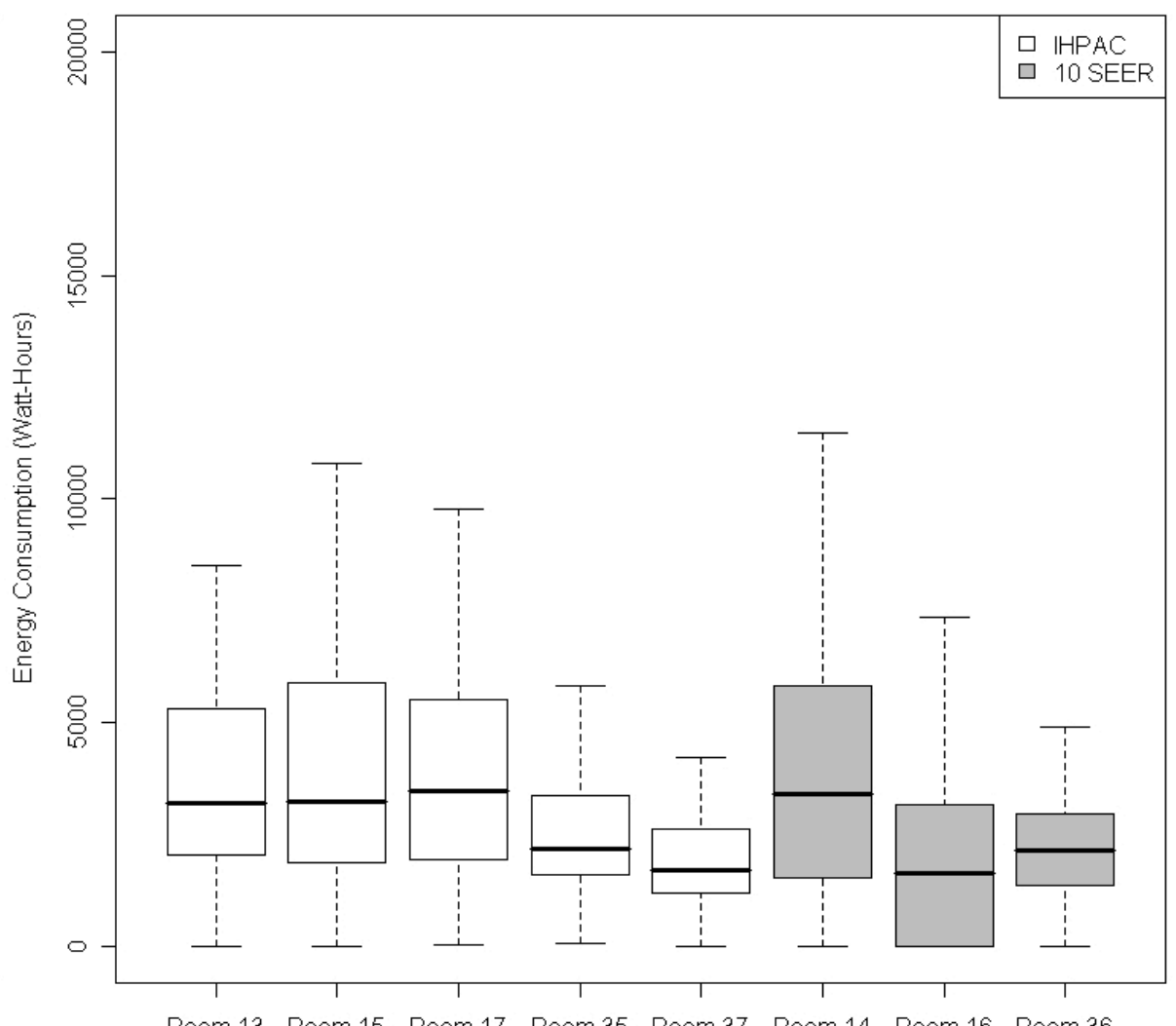

Figure 12. Box and whisker plots of measured daily energy consumption distributions for Northern and Southern California classroom in Spring 2005. The dark center line is the median value and the boxes bound the first and third quartiles. The whiskers mark the minimum and maximum measured values. 
Northern California Summer 2005 Energy Consumption

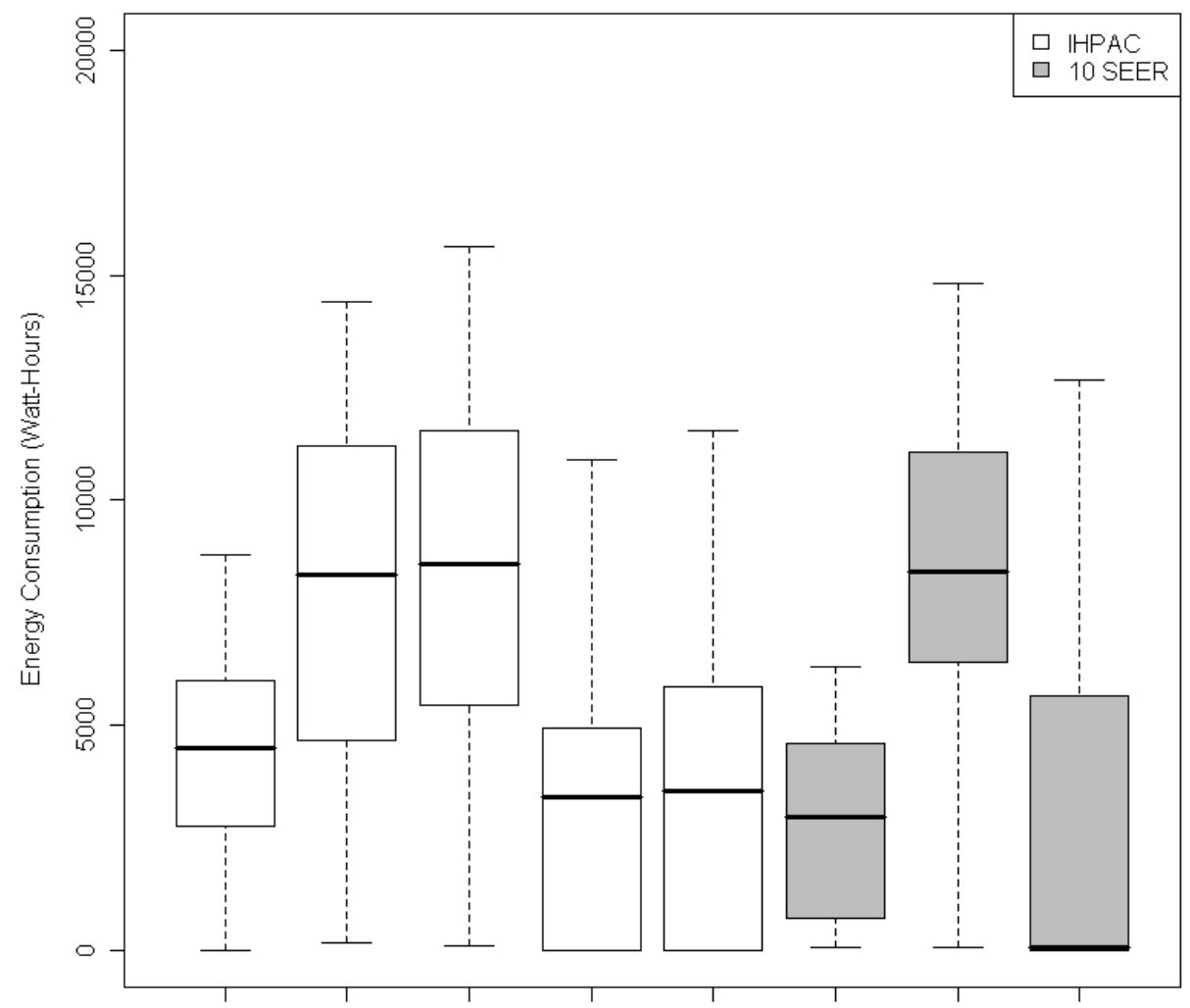

Room 20 Room 22 Room 24 Room 25 Room 27 Room 21 Room 23 Room 26
Southern California Summer 2005 Energy Consumption

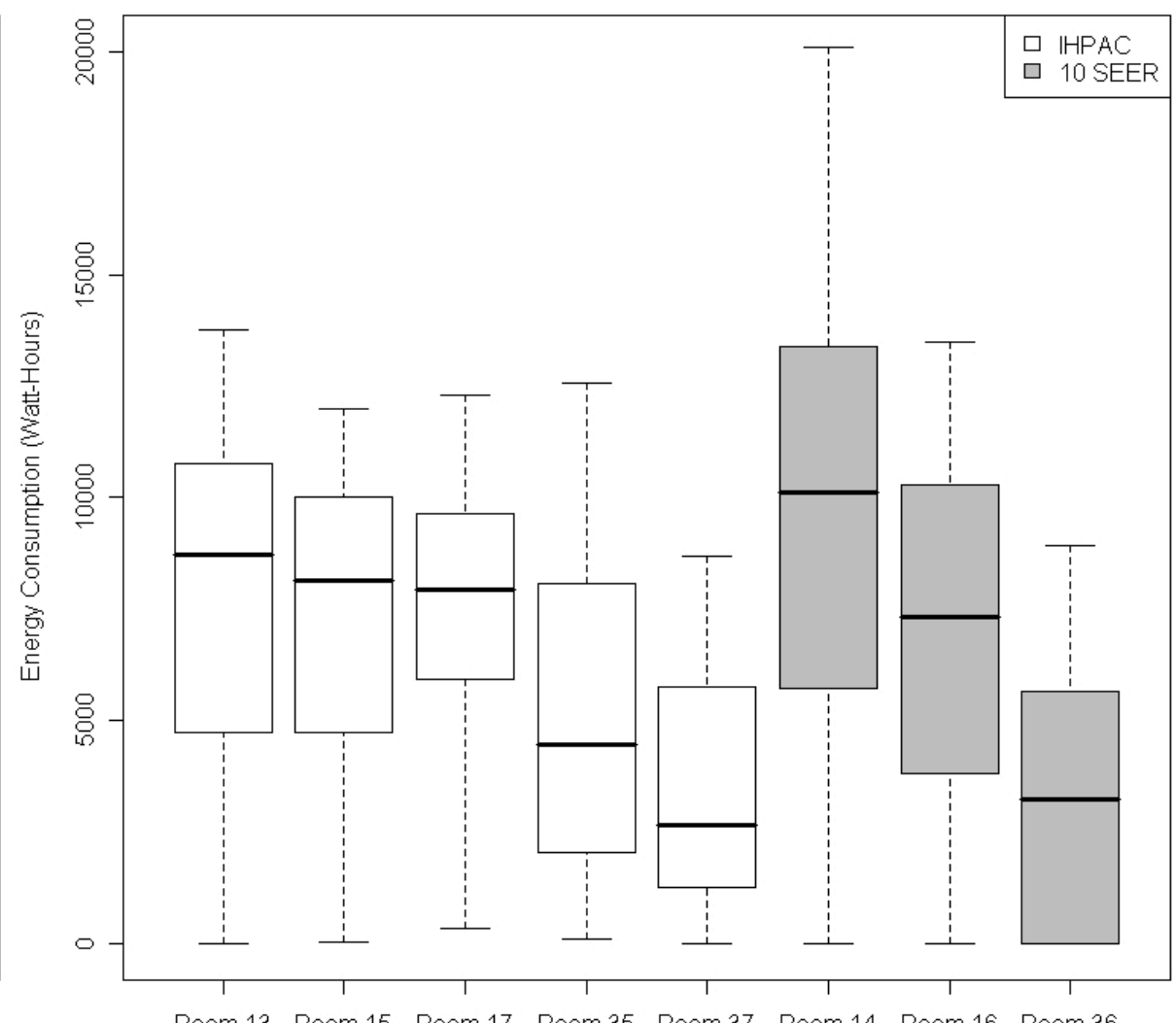

Room 13 Room 15 Room 17 Room 35 Room 37 Room 14 Room 16 Room 36

Figure 13. Box and whisker plots of measured daily energy consumption distributions for Northern and Southern California classroom in Summer 2005. The dark center line is the median value and the boxes bound the first and third quartiles. The whiskers mark the minimum and maximum measured values. 
Northern California Fall 2005 Energy Consumption

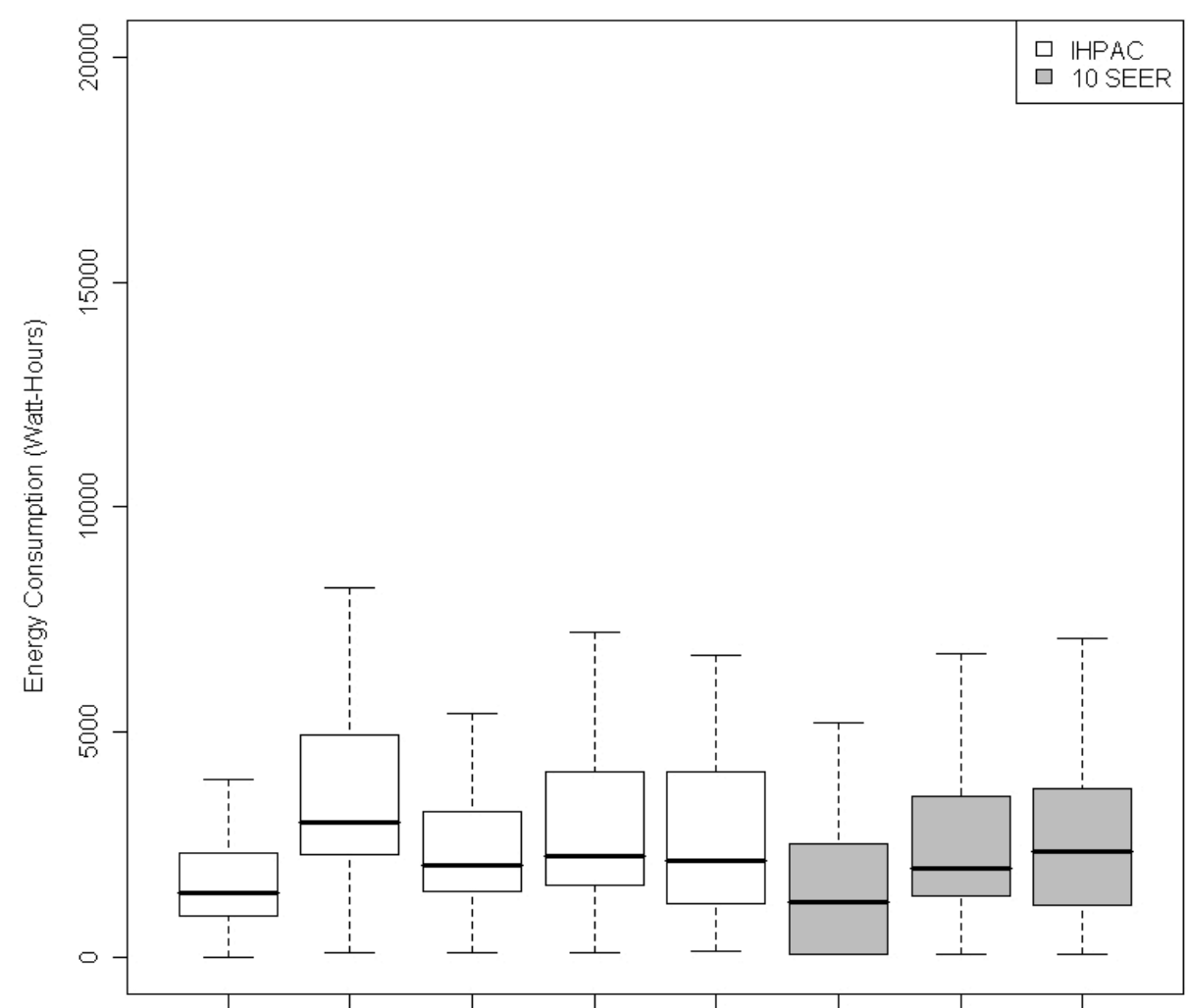

Room 20 Room 22 Room 24 Room 25 Room 27 Room 21 Room 23 Room 26
Southern California Fall 2005 Energy Consumption

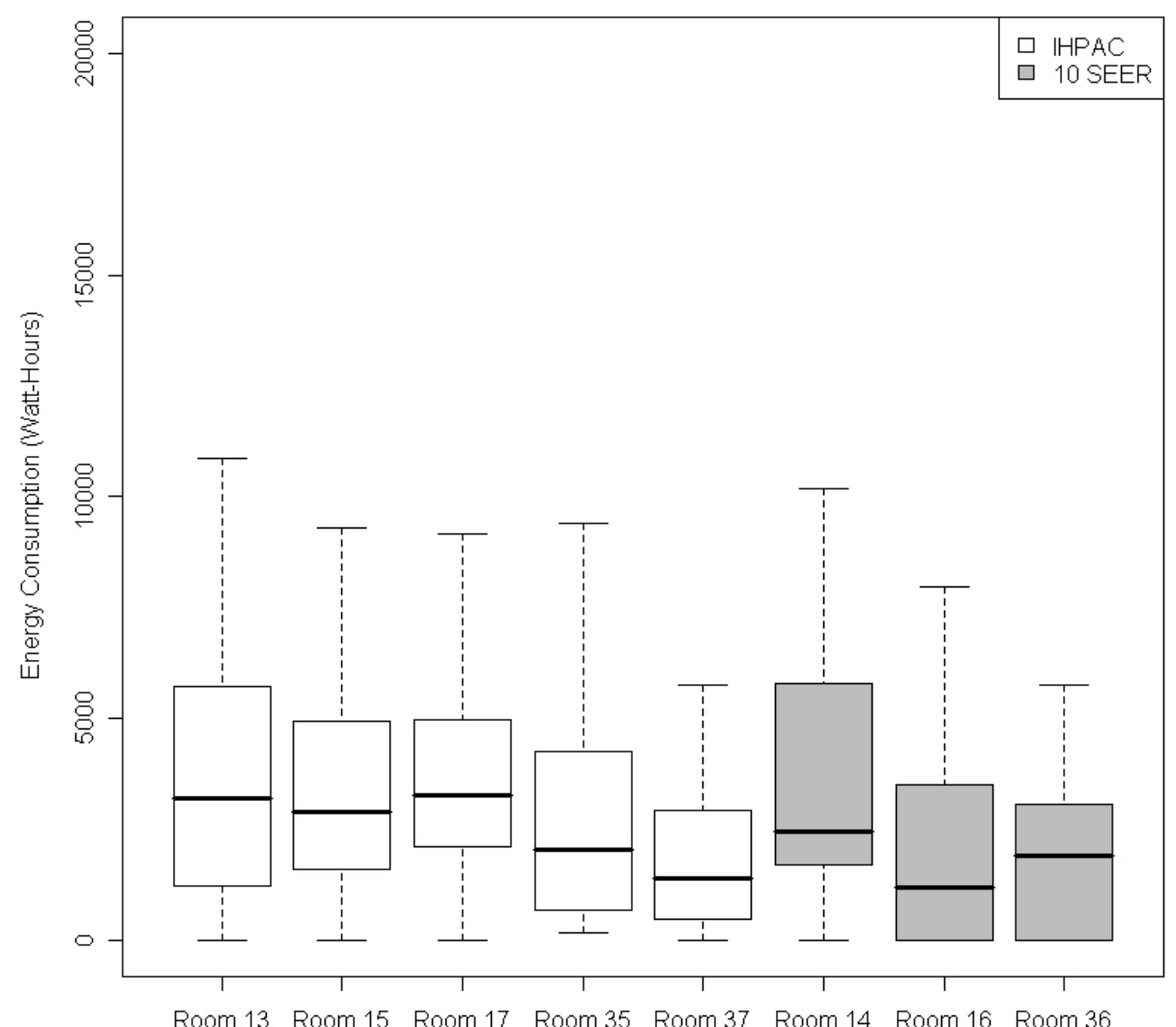

Figure 14. Box and whisker plots of measured daily energy consumption distributions for Northern and Southern California classroom in Fall 2005. The dark center line is the median value and the boxes bound the first and third quartiles. The whiskers mark the minimum and maximum measured values. 
Northern California Winter 2005 Energy Consumption

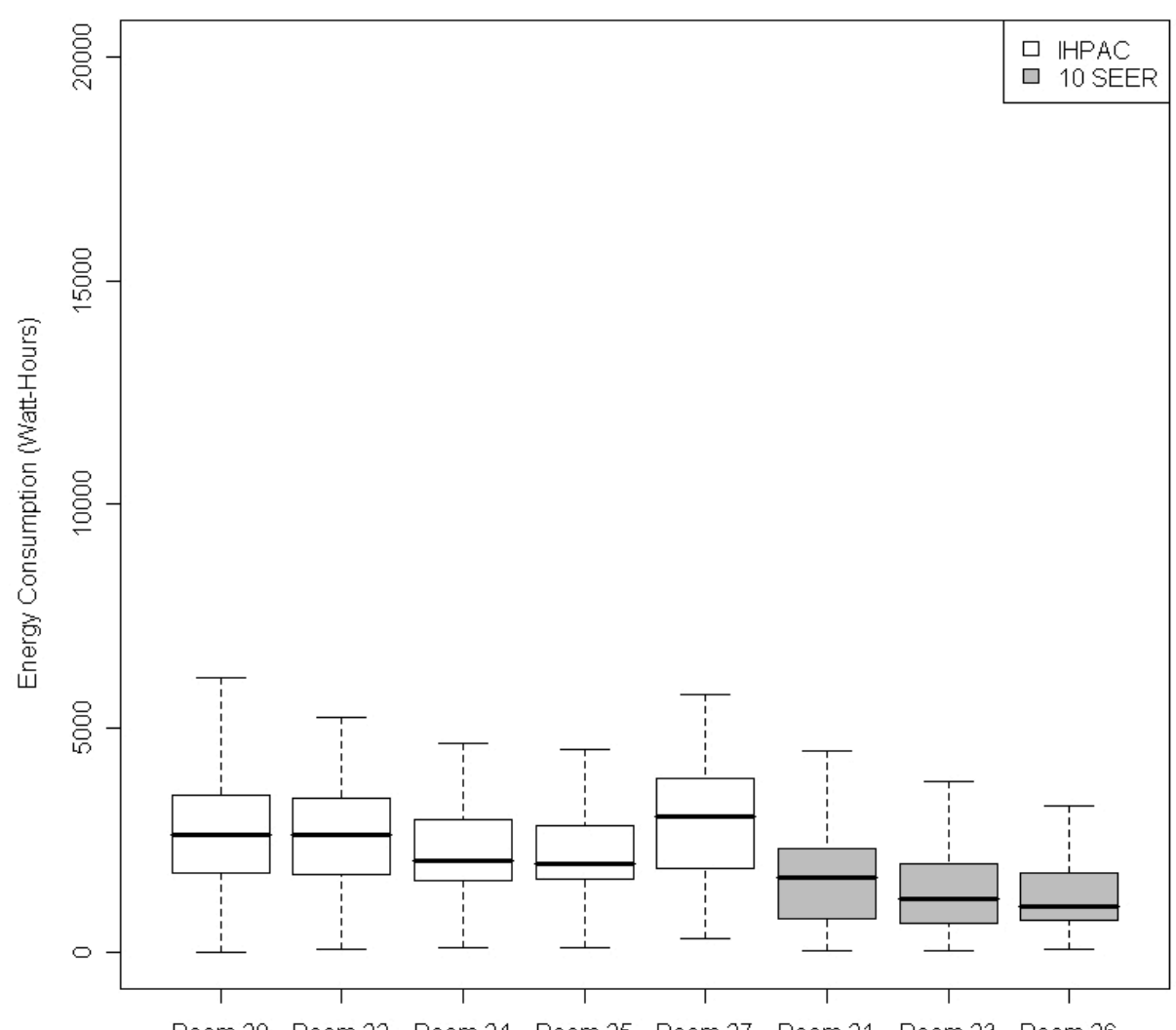

Southern California Winter 2005 Energy Consumption

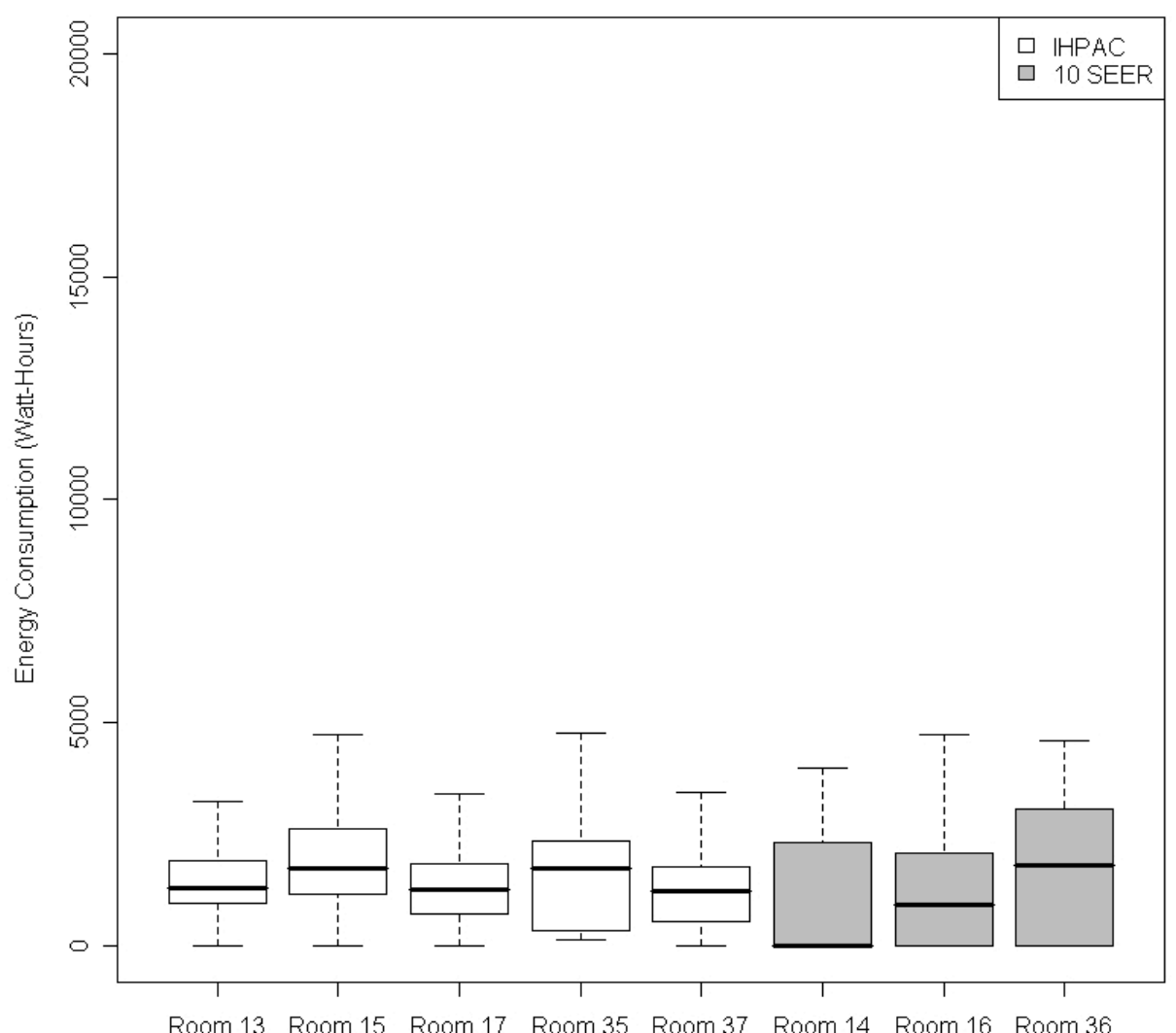

Figure 15. Box and whisker plots of measured daily energy consumption distributions for Northern and Southern California classroom in Winter 2005. The dark center line is the median value and the boxes bound the first and third quartiles. The whiskers mark the minimum and maximum measured values. 

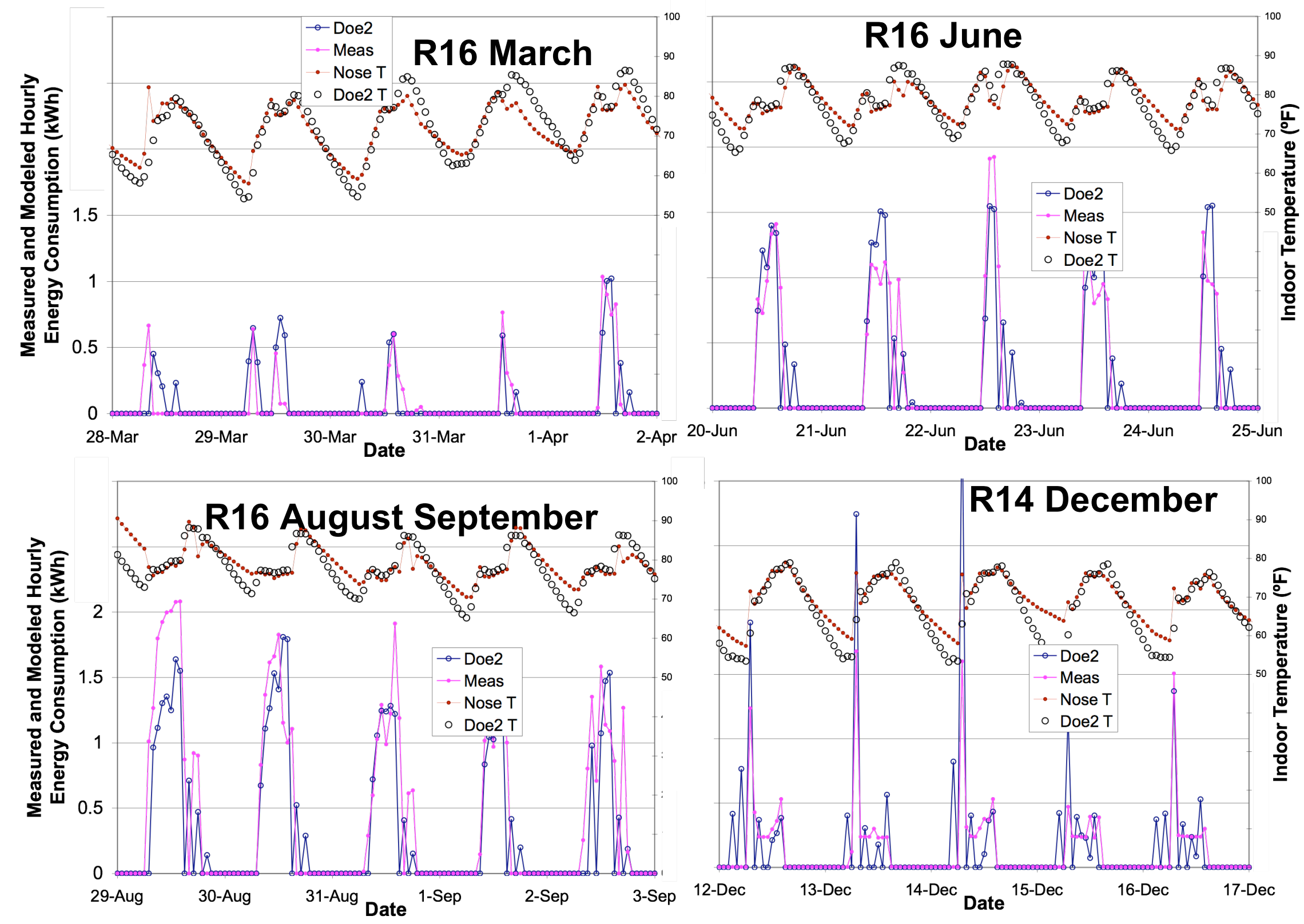

Figure 16. Measured and DOE-2 predictions of hourly energy consumption for the 10 SEER system operating in different northern and southern CA classrooms across four seasons 

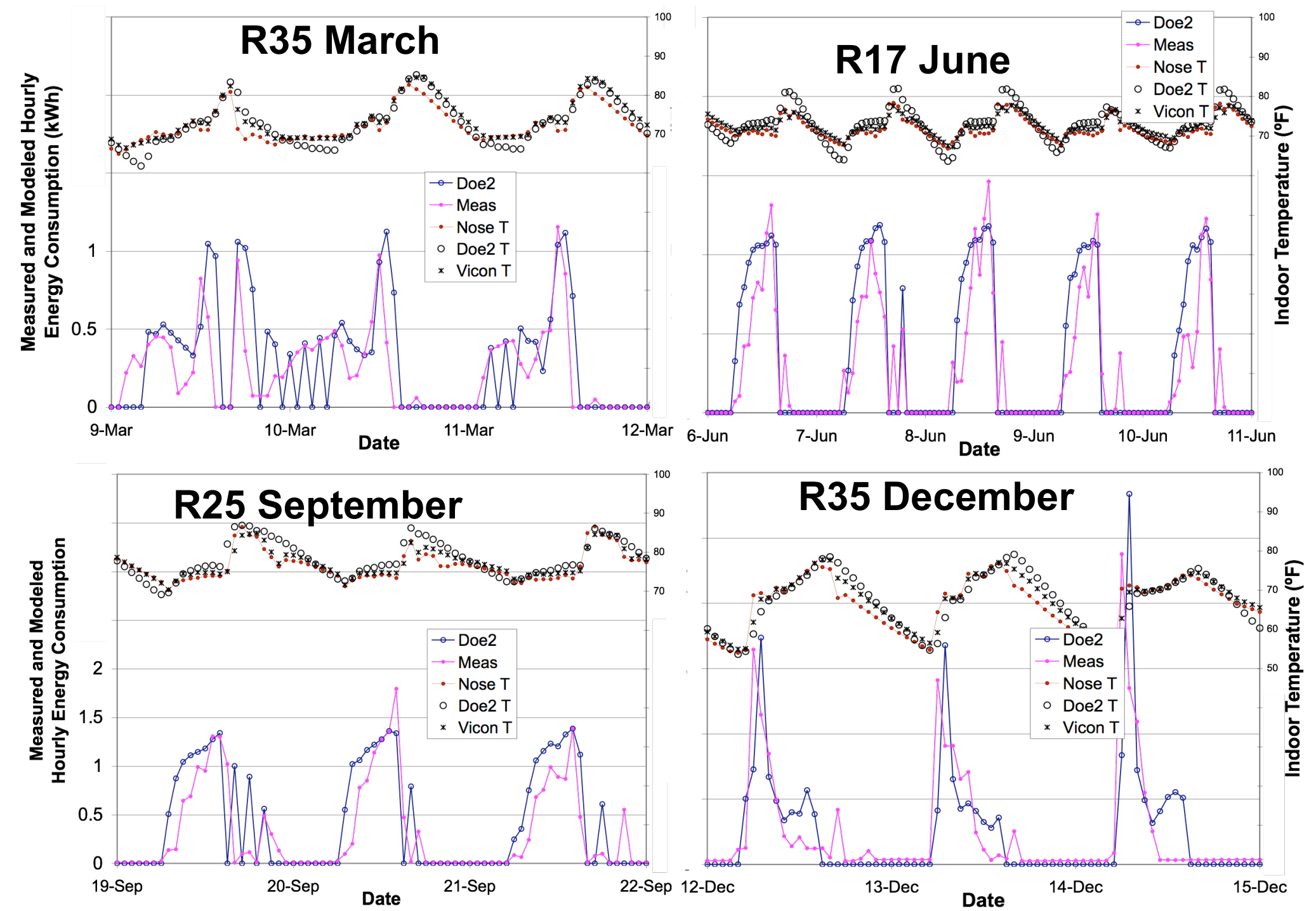

Figure 17. Measured and DOE-2 predictions of hourly energy consumption for the IHPAC system operating in different northern and southern CA classrooms across four seasons. 


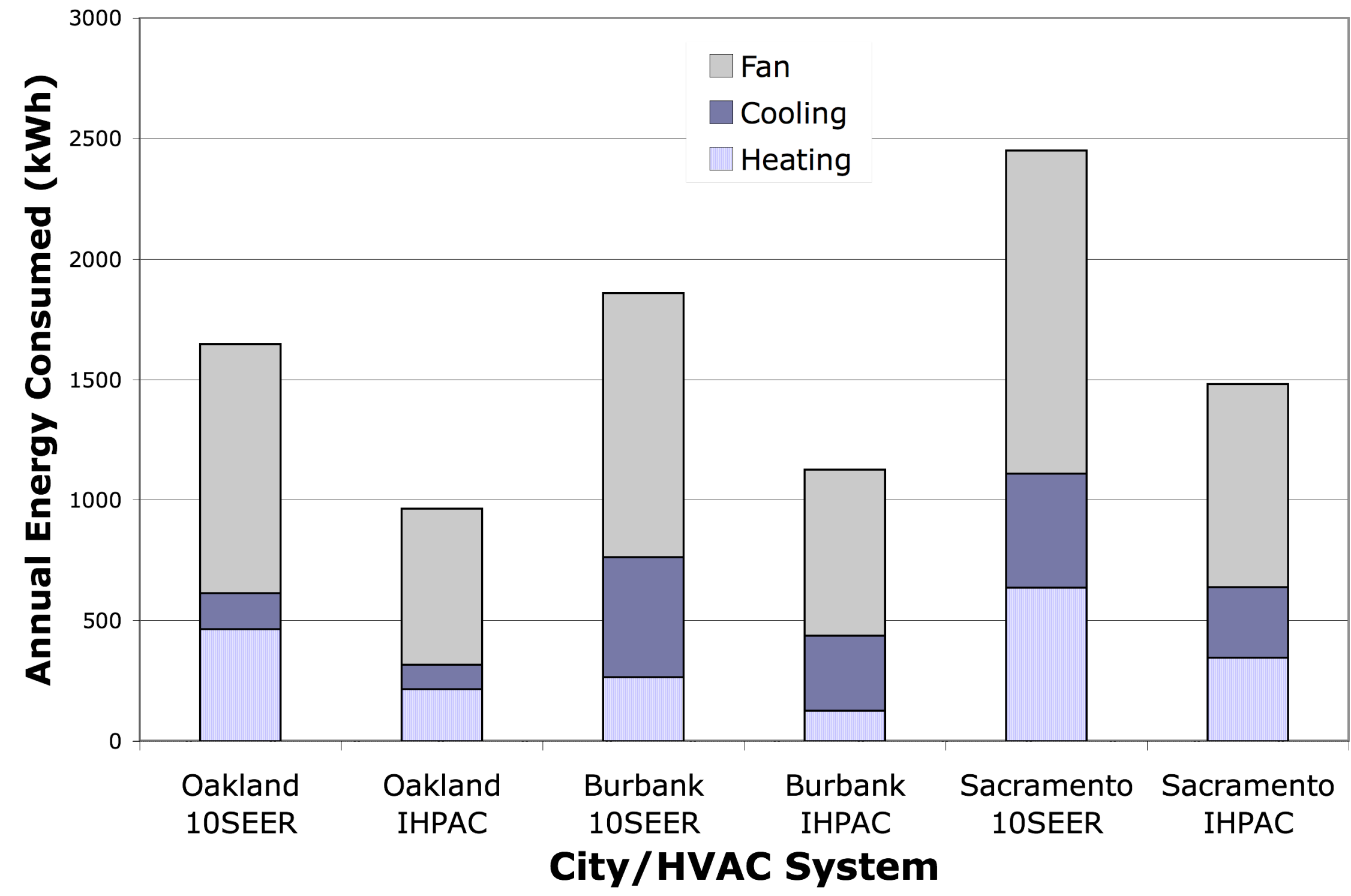

Figure 18 CA Cities. Annual energy consumption for 10 SEER and IHPAC systems in portable classrooms three CA Cities predicted using calibrated DOE-2 models. The energy consumption is broken down by fan, cooling, and heating energy use. Both HVAC systems were modeled using continuous ventilation during occupancy. 


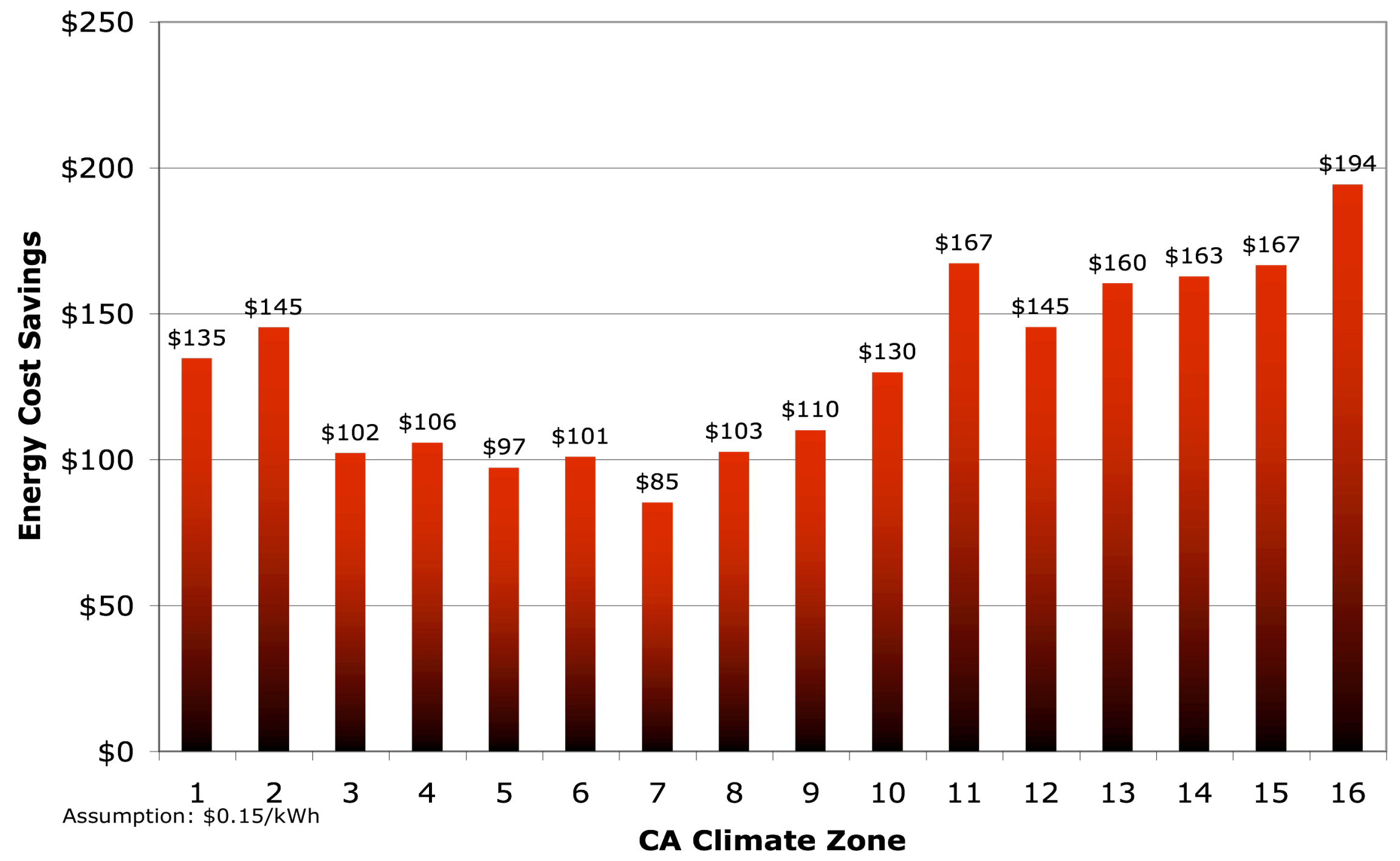

Figure 19. Energy savings in dollars assuming a $\$ 0.15$ cost per $\mathrm{kWh}$ across sixteen California climate zones from operating IHVAC classrooms relative to 10 SEER HVAC systems. 


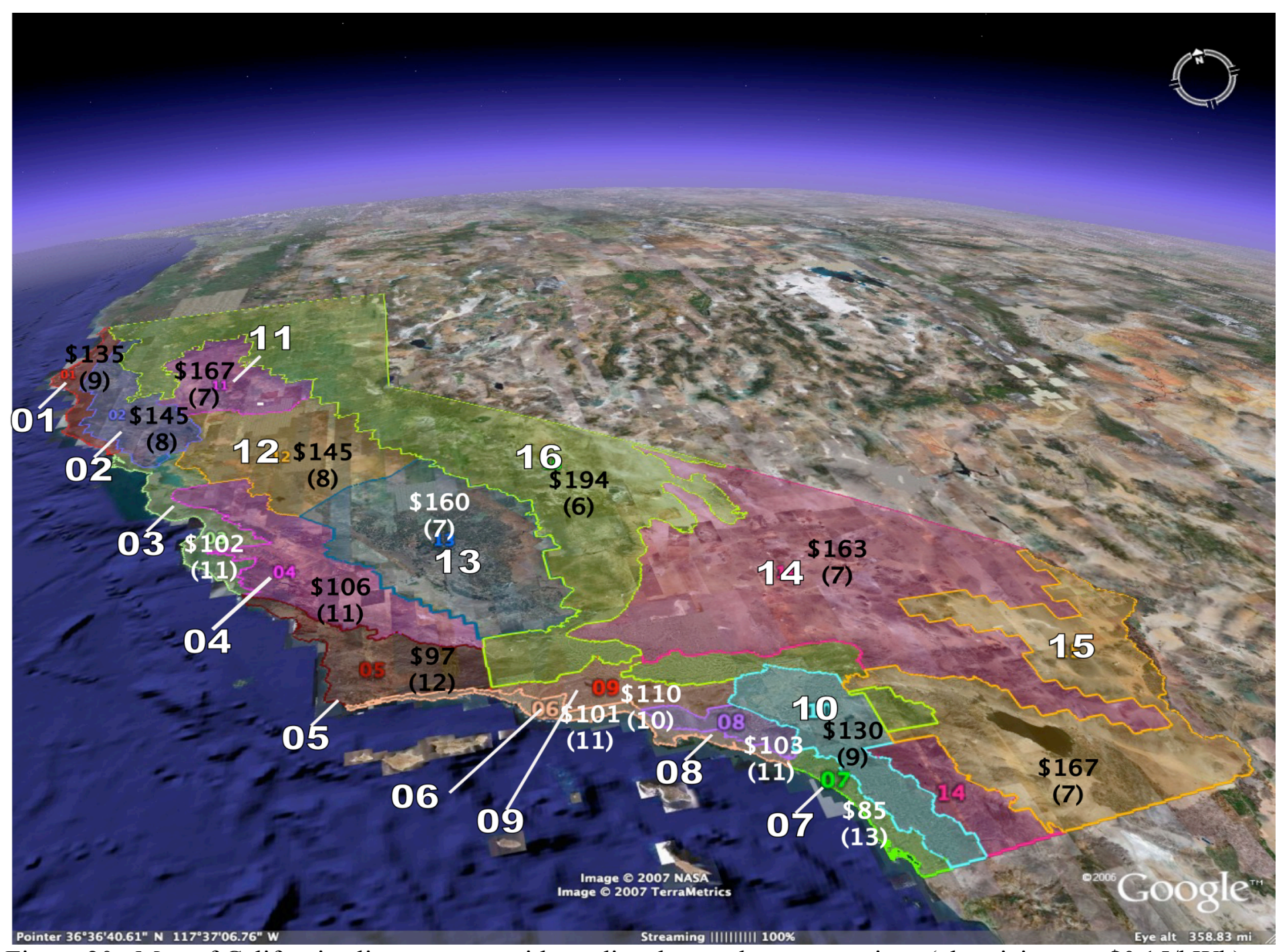

Figure 20. Map of California climate zones with predicted annual energy savings (electricity cost $\$ 0.15 / \mathrm{kWh}$ ) per classroom from using the IHPAC relative to the 10 SEER HVAC system. Climate Zones are highlighted in bold outlined white numerals. Simple payback in years is noted in parentheses based on a net cost premium of $\$ 1150$ per IHPAC unit. Underlying map from California Energy Commission an Google ${ }^{\mathrm{TM}}$. 

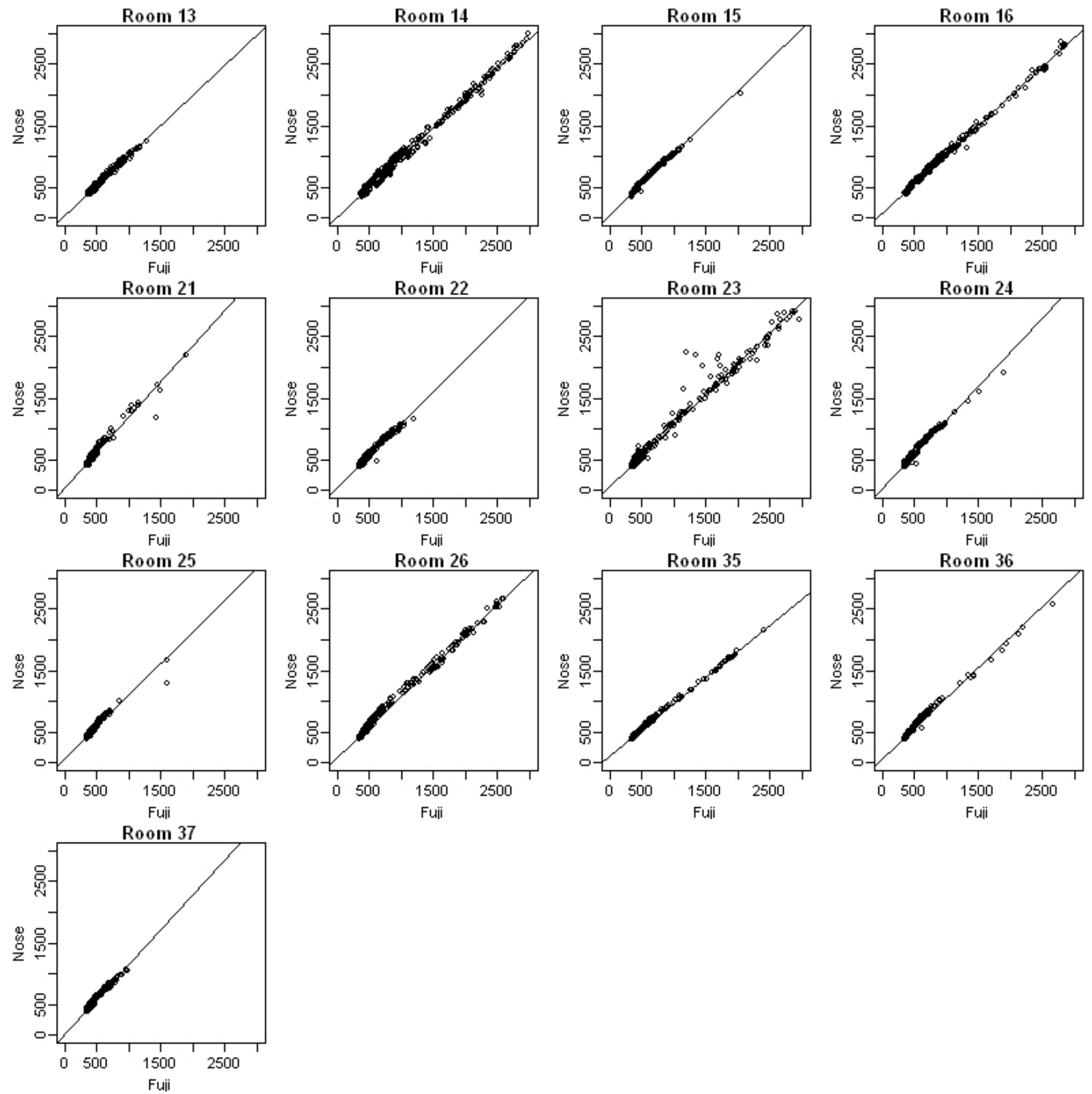

Figure 21. Nose and Fuji $\mathrm{CO}_{2}$ measurements collected from three one-week periods following Fuji calibrations conducted during spring, summer, and fall field visits. Lines in the plots are least square regression fits. See Table Nose and Fuji for regression statistics.. 